SERVIÇO DE PÓS-GRADUAÇÃO DO ICMC-USP

Data de Depósito: $\quad 22.04 .2003$

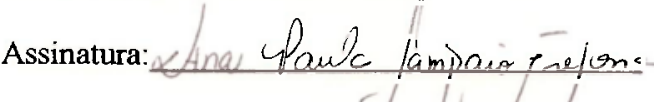

\title{
Investigação de regressão no processo de mineração de dados ${ }^{1}$
}

\author{
Daniel Gomes Dosualdo
}

Orientadora: Profa. Dra. Solange Oliveira Rezende

Dissertação apresentada ao Instituto de Ciências Matemáticas e de Computação - ICMC-USP, como parte dos requisitos para obtenção do título de Mestre em Ciências de Computação e

Matemática Computacional.

\section{USP - São Carlos}

Abril/2003

Trabalho realizado com auxilio financeiro da FAPESP e CAPES. 
A Comissão Julgadora:

Profa. Dra. Solange Oliveira Rezende Volchye Ohiveive Rejede

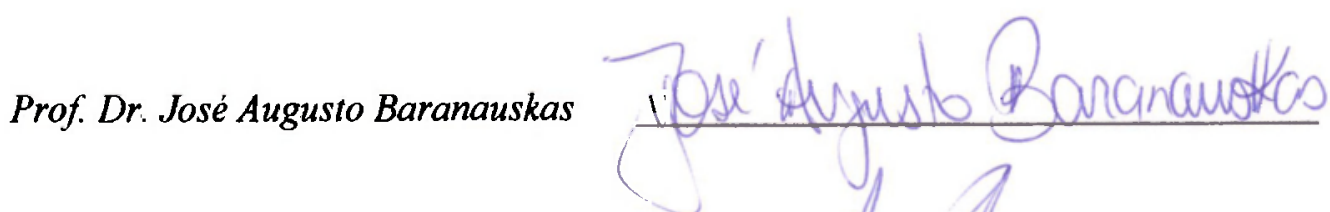

Prof. Dr. Juan Manuel Adan Coello

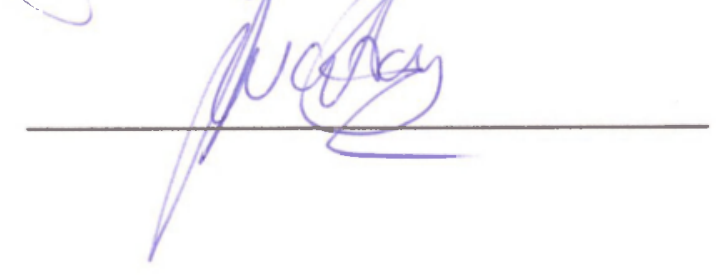


Este documento foi preparado utilizando-se o formatador de textos $\mathrm{HT}_{\mathrm{E}} \mathrm{X}$. Sua bibliografia é gerada automaticamente pelo $\mathrm{BIBT}_{\mathrm{E}} \mathrm{X}$, utilizando o estilo Chicago.

(c) Copyright 2003 - Daniel Gomes Dosualdo Todos os direitos Reservados 


\section{Dedicatória}

Aos meus pais,

Rubens e Maria do Carmo 


\section{Agradecimentos}

$\mathcal{A}$

ntes de mais nada, gostaria de agradecer aos meus pais, Rubens e Maria do Carmo, e minha irmã Debora, pelo amor, carinho, compreensão e apoio incondicional em todos os momentos. Vocês foram (e ainda são) os responsáveis por minha educação e caráter, ensinando-me sempre a agir com dignidade, respeito e honestidade. Agradeço a Deus por ter me privilegiado com uma familia tão maravilhosa e especial, que esteve em todos os momentos sempre pronta para me acolher. Gostaria também de agradecer ao meu cunhado Henrique e minha sobrinha Júlia, que mesmo sem saber. trouxe mais alegria para a minha vida. Nāo poderia deixar de citar aqui a importāncia da minha "irmãzinha" Janaina, que com seu carisma e bom-humor sempre esteve disposta a me ajudar no que eu precisasse.

Gostaria de agradecer à (professora) Solange. O parênteses no substantivo professora deve-se ao fato de eu considerá-la muito mais que isso. Desde que a conheci, no final do ano 2000 , descobri que entre um professor e seu orientado pode existir uma verdadeira amizade, muito mais do que a simples relação "professor-aluno". Com seu bom-humor e boa-vontade, suportou minhas brincadeiras, atrasos e "cnrolações", como ela mesmo dizia. Muito obrigado Solange pelo apoio, incentivo e paciência. Você contribuiu muito para meu crescimento cultural e pessoal.

Gostaria também de agradecer uma pessoa muito especial, que já conheço há algum tempo, mas que nos últimos meses tem feito parte do meu dia-adia. À minha namorada Élyda, que aos poucos, conquistou a mim e minha familia. Obrigado por todo seu carinho, amor e comprecnsão, principalmente nesses últimos meses em que fiquei tanto tempo trabalhando na elaboração desta Dissertação.

Também gostaria de ressaltar a importância de 4 pessoas do LABIC ao longo deste meu trabalho: Ronaldo, Jaqueline, Gustavo e Walter. O Ronaldo, que desde a êpoca de graduação o conheço como "Torrinha", sempre se mostrou disposto a ajudar, principalmente com minhas düvidas de LATEX e PERL. A Jaqueline, uma das grandes amigas que fi $z$ no LABIC, também me ajudou em diversas ocasiōes, inclusive na leitura e correçāo desta Dissertação. Ao 
Gustavo, pelos momentos de descontração, scmpre me deu dicas valiosas $c$ ajudou bastante neste trabalho fornecendo sua biblioteca de classes. E ao Walter, o "amigo da escola", sempre sorridente e bem disposto, que desde o primeiro momento que cheguei no LABIC, sempre me ajudou, principalmente nos meus projetos de graduaçāo. Gostaria de agradecer também aos demais amigos do LABIC: Valmir, Marcos Paula, Edson, Roberta, Marcos Aurélio, Marcelo, Claudinha, Patrícia, Zé Flávio, Claudia Regina, Katti, Rodrigo, entre outros. Essas pessoas, juntamente com as professoras Solange e Carolina, e o professor André, tornam o LABIC um ótimo ambiente, propício ao trabalho.

Não poderia deixar de agradecer aqui os amigos que tenho desde a época da graduação, com os quais passei a maior parte do tempo que morei em São Carlos e compartilhei bons momentos, em festas, churrascos, jogos de futebol, viagens e nas idas aos jogos do Sāo Paulo. Aos amigos da minha turma de graduação, conhecidos como "Malacos", em especial ao Capra, Shaq, Luisão, Pira, Juninho, Meleca, Boy, Maroldi e Stamato. E outros grandes amigos que fiz em São Carlos: Sílvio, Giovana, Izabel, Paulinho, Thiago, Locão, Fubá, João, Japonês, Gordo, entre outros.

Gostaria também de agradecer a todos os funcionários do ICMC pelo respcito, dedicação e educação: ao pessoal da biblioteca, ao pessoal da Seção de Graduação, em especial ao Zé Ângelo e ao pessoal da Pós, em especial à Beth. À FAPESP e CAPES pelo apoio financeiro.

Finalmente, agradcço à Deus, por estar sempre comigo iluminando meu caminho, mesmo nos momentos mais dificeis. Sem Ele, eu nāo teria forças para completar mais essa jornada em minha vida. 


\section{Resumo}

$\mathcal{M}$

ineração de dados refere-se ao processo responsável por identificar padrões em grandes conjuntos de dados com o objetivo de extrair um novo conhecimento. Depois de extraidos os padrões, a etapa de pós-processamento tem como objetivo avaliar alguns aspectos desses padrōes, como precisão. compreensibilidade e interessabilidade.

Um dos problemas da mineração de dados preditiva conhecido como regressão tenta predizer o valor de um atributo-meta contínuo baseado em um conjunto de atributos de entrada. No entanto, a regressão em mineração de dados preditivo é uma questão pouco explorada nas áreas de aprendizado de máquina e mineraçāo de dados, uma vez que a maioria das pesquisas são voltadas para os problemas de classificação.

Por outro lado, o Discover é um projeto que está sendo desenvolvido no Laboratório de Inteligência Computacional. Ele tem como objetivo fornecer um ambiente integrado para apoiar as etapas do processo de descoberta de conhecimento. oferecendo funcionalidades voltadas para aprendizado de máquina e mineração de dados e textos. O Discover tem motivado a realizaçāo de muitos trabalhos em diversas àreas, sendo este mais um projeto a ele integrado.

Para auxiliar na preparação dos dados para a construção de um modelo de regressão simbólico e na posterior avaliação desse modelo foi proposto e implementado neste trabalho o ambiente computacional DISCOVER POSTPROCESSING ENVIRONMENT OF REGRESSION - DiPER. Esse ambiente é composto por uma biblioteca de classes, implementada de acordo com as especificações do Discover, que oferece uma série de mètodos para serem utilizados na etapa de pós-processamento do processo de mineração de dados. 


\section{Abstract}

$\mathcal{D}$ ata mining refers to the process which are able to find patterns from big amounts of data in order to discover knowledge. After found the patterns, the post-processing stage of Data Mining evaluates some aspects of these patterns such as precision, compreensibility and interessability.

The activity of regression in Data Mining tries to predict the values of a continuous target variable based on a set of other variables. Beside the fact of many researches in Machine Learning and Data Mining are concerned to classification problems, there are many real world regression problems. This fact motivates the study of methods related to post-processing in symbolic regression.

Moreover, a group of researchers of Computational Intelligence Laboratory (LABIC) is developing a research project, called Discover. The aim of DisCOVER is to support the stages of knowledge discovery offering methods to Machine Learning, Data Mining and Text Mining. This work, that is related to regression problems, is one of the projects integrated into the Discover.

In this work we proposed and implemented a computational environment, the Discover Post-Processing Environment of Regression - DiPER which is a framework implemented according the specifications of DISCOVER project, that offers a collection of methods to be used in the post-processing stage of Data Mining. 


\section{Sumário}

1 Introdução 1

1.1 Regressão . . . . . . . . . . . . . . . . . . . 2

1.2 O Projeto Discover . . . . . . . . . . . . . . . . . 4

1.3 Objetivos e Contribuições desta Dissertação . . . . . . . . . . . 4

1.4 Organizaçāo desta Dissertaçāo . . . . . . . . . . . . . . . 6

2 Visão Geral do Processo de Mineração de Dados 7

2.1 Etapas do Processo de Mineraçāo de Dados . . . . . . . . . . . . 7

2.1.1 Pré-Processamento . . . . . . . . . . . . . . . 9

2.1.2 Extração dos Padrões . . . . . . . . . . . . . . 11

2.1.3 Pós-Processamento . . . . . . . . . . . . . . 14

2.2 A Regressão em Mineração de Dados . . . . . . . . . . . . . 15

2.3 Consideraçōes Finais . . . . . . . . . . . . . . . . . . . 16

3 Métodos de Regressão 17

3.1 Modelo Paramétrico Global . . . . . . . . . . . . . . . 18

3.2 Modelos Locais . . . . . . . . . . . . . . . . . . . . . . . 18

3.2.1 Método: Aprendizado Baseado em Exemplos . . . . . . . . 19

3.2.2 Método: Locally Weighted Regression . . . . . . . . . . . . . 21

3.3 Modelos Baseados em Aprendizado Simbólico . . . . . . . . . . 22

3.3.1 Método: Indução de Regras de Regressão . . . . . . . . . . . 22

3.3.2 Método: Indução Top-Down de Árvores de Regressāo . . . . 23

3.4 Modelo Baseado em Redes Neurais Artificiais . . . . . . . . . . . . 25

3.5 Modelos Aditivos . . . . . . . . . . . . . . . . . 26

3.5.1 Método: Project Pursuit Regression . . . . . . . . . . . . 27

3.5.2 Método: Adaptive Regression Splines . . . . . . . . . . . 27

3.6 Modelo Baseado em Support Vector Machines . . . . . . . . . . . 28

3.7 Considerações Finais . . . . . . . . . . . . . . . . . . . . 29

4 Regressão Simbólica no Processo de Mineração de Dados 31

4.1 O Projeto Discover . . . . . . . . . . . . . . . . . . . 31

4.2 O Ambiente Discover . . . . . . . . . . . . . 33

4.3 Trabalhos Realizados e em Desenvolvimento . . . . . . . . . . 34

4.4 Sistemas e Algoritmos de Regressão . . . . . . . . . . . . . . . . 35

4.4 .1 RT . . . . . . . . . . . . . . . 35

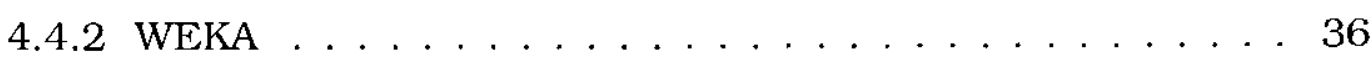

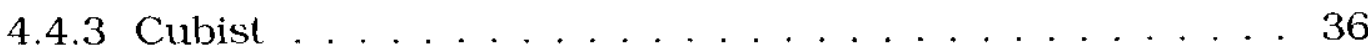

4.5 Regressāo Simbólica no Ambiente Discover . . . . . . . . . . 37

4.5.1 Preparação dos Dados para Extração dos Padrões . . . . . 37

4.5 .2 Método Cross-Validation . . . . . . . . . . . . . . 40

4.5 .3 Pós-Processamento . . . . . . . . . . . . . . 4 41

4.6 Considerações Finais . . . . . . . . . . . . . . . . . . . 42 
5 O Ambiente DIPER

5.1 Conversão dos Regressores . . . . . . . . . . . . . . . . . . 46

5.2 Tratamento Scmântico de Regras de Regressão . . . . . . . . . . . 47

5.2 .1 Atributos Numéricos . . . . . . . . . . . . . . . . . . 49

5.2 .2 Atributos Nominais . . . . . . . . . . . . 50

5.3 Cálculo de Medidas de Regressāo . . . . . . . . . . . . . . . . . . . 50

5.3.1 Medidas de Precisāo . . . . . . . . . . . . . . . . . . 51

5.3.2 Medidas de Compreensibilidade . . . . . . . . . . . . . 52

5.4 Tabela de Contingência para Regras de Regressāo . . . . . . . . . . 53

5.4.1 Tabela de Contingência c Medidas Derivadas . . . . . . . . 53

5.4 .2 Algoritmo P-Class . . . . . . . . . . . . . . . 56

5.4.3 Processo de Geração da Tabela de Contingência para

Regras de Regressāo . . . . . . . . . . . . . . . . . . . . . 58

5.4 .4 Interpretação das Medidas . . . . . . . . . . . . . . . . 60

5.5 Teste de Hipôteses . . . . . . . . . . . . . . . . . . . . . 66

5.6 Considerações Finais . . . . . . . . . . . . . . . . . . . 67

6 Validação do Ambiente DIPER

6.1 Experimentos com o Conjunto de Dados Abalone . . . . . . . . . . 71

6.1.1 Conversão dos Regressores e Tratamento Semântico . . . . 72

6.1.2 Precisāo dos Regressores no Conjunto de Dados Abalone . 76

6.1.3 Teste de Hipôteses com o Conjunto de Dados Abalone . . . 78

6.1.4 Compreensibilidade das Regras geradas a partir do Conjunto de Dados Abalone . . . . . . . . . . . . . 79

6.1.5 Tabela de Contingência para Regras de Regressão do Conjunto de Dados Abalone . . . . . . . . . . . . . . . . . . . 80

6.2 Expcrimentos com o Conjunto de Dados Housing . . . . . . . . . . 82

6.2.1 Conversão dos Regressores c Tratamento Semântico . . . . . 83

6.2.2 Precisāo dos Regressores no Conjunto de Dados Housing . 83

6.2.3 Teste de Hipôteses no Conjunto de Dados Housing . . . . . . 87

6.2.4 Compreensibilidade das Regras geradas a partir do Conjunto de Dados Housing . . . . . . . . . . . . . . . 88

6.2.5 Tabela de Contingência para Regras de Regressão do Conjunto de Dados Housing . . . . . . . . . . . . . . . . . 89

6.3 Avaliação Geral dos Resultados . . . . . . . . . . . . . . . . . . . . . . . . . . . . . .

6.4 Considerações Finais . . . . . . . . . . . . . . . . . . . . . . . . . 94

7 Conclusões e Trabalhos Futuros $\quad 95$

Referências $\quad 105$ 


\section{Lista de Figuras}

2.1 Etapas do processo de mineração de dados . . . . . . . . . . . 8

2.2 Pré-processamento no processo de mineração de dados . . . . . . 9

2.3 Atividades do processo de mineração de dados . . . . . . . . . . . 11

2.4 Conjunto de exemplos fornecido . . . . . . . . . . . 13

2.5 Possiveis hipóteses . . . . . . . . . . . . . . . . . . . . . 14

3.1 Exemplo de regressão linear global . . . . . . . . . . . . . . . 19

3.2 Exemplos mais similares do conjunto de treinamento . . . . . . . 19

3.3 Exemplo de uma Model Tree . . . . . . . . . . . . . . . . . . . . 24

3.4 Exemplo de uma rede neural artificial . . . . . . . . . . 26

4.1 Funcionalidades do projeto Discover . . . . . . . . . . . . 32

4.2 Preparação dos dados para a geração de um regressor . . . . . . . 41

5.1 Funcionalidades do ambiente DiPER . . . . . . . . . . . . 46

5.2 Gramática da sintaxe padrāo de regras de regressão . . . . . . . . 48

5.3 Conjunto de regras padronizadas . . . . . . . . . . . . . . . . 49

5.4 Regra de regressão com condiçōes desnecessárias sobre atributo numérico . . . . . . . . . . . . . . . . . . . . . 49

5.5 Regra de regressāo com tratamento semântico sobre atributo numérico . . . . . . . . . . . . . . . . . . . 50

5.6 Regra de regressão com condiçōes desnecessárias sobre atributo nominal . . . . . . . . . . . . . . . . . 50

5.7 Regra de regressão com tratamento semântico sobre atributo nominal . . . . . . . . . . . . . . . . 50

5.8 Desempenho de acordo com o número de pseudo-classes . . . . 57

5.9 Regras geradas pelo Cubist com o conjunto de treinamento mpg da Tabela $5.5 \ldots \ldots \ldots \ldots$. . . . . . . . . . . . . 61

6.1 Classes do ambiente DIPER . . . . . . . . . . . . . . . . 69

6.2 Primeira fase dos experimentos $\ldots \ldots \ldots \ldots \ldots \ldots \ldots$

6.3 Segunda fase dos experimentos . . . . . . . . . . . . . 71

6.4 Regras geradas pelo Cubist com o conjunto de dados abalone . . 73

6.5 Regras convertidas do formato do Cubist para o formato padrăo com o conjunto de dados abalone . . . . . . . . . . . . 74

6.6 Model Tree gerada pelo M5 com o conjunto de dados abalone . . 75

6.7 Algumas regras convertidas para o formato padrão a partir da Model Tree gerada pelo algoritmo M5 com o conjunto de dados abalone e semanticamente tratadas . . . ......... 76

6.8 Model Tree gerada pelo RETIS com o conjunto de dados abalone. 77

6.9 Conjunto de regras convertidas para o formato padrão a partir da Model Tree gerada pelo RETIS com o conjunto de dados abalone 77 6.10 Regression Tree gerada pelo M5 com o conjunto de dados housing 84 
6.11 Algumas regras convertidas a partir da Regression Tree gerada pelo M5 para o formato padrāo com o conjunto de dados housing 85

6.12 $\mathrm{N}$ gumas regras semanticamente tratadas a partir do conjunto de regras convertido do M5 com o conjunto de dados housing . . . . 86

6.13 Regression Tree gerada pelo CART com o conjunto de dados hou-

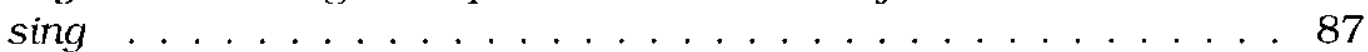

6.14 Conjunto de regras convertido a partir da Regression Tree gerada pelo CART com o conjunto de dados housing . . . . . . . . . 87 


\section{Lista de Tabelas}

2.1 Conjunto de exemplos no formato atributo-valor . . . . . . . . 10

2.2 Alguns métodos de regressāo . . . . . . . . . . . . . . . . . 12

4.1 Exemplo de arquivo contendo as declarações dos atributos para o RT . . . . . . . . . . . . . . . . . . . 37

4.2 Exemplo de arquivo contendo os dados para o RT . . . . . . . 38

4.3 Exemplo de arquivo ARFF para o WEKA . . . . . . . . . . . . . 39

4.4 Exemplo de arquivo . names da sintaxe DSX . . . . . . . . . . 40

4.5 Exemplo de arquivo .data da sintaxe DSX . . . . . . . . . . 40

5.1 Formas de representaçāo de hipótese dos algoritmos de regressão utilizados neste trabalho . . . . . . . . . . . . . . 47

5.2 Cálculo das medidas MAD e MSE sobre uma hipótese $h_{1} \ldots \ldots .52$

5.3 Cálculo das medidas MAD e MSE sobre uma hipótese $h_{2} \ldots \ldots .52$

5.4 Tabela de contingência para a regra $B \rightarrow H \ldots \ldots . \ldots . . .54$

5.5 Exemplos de treinamento do conjunto de dados mpg . . . . . . . 6 61

5.6 Pseudo-intervalos gerados com o conjunto de dados mpg . . . . . 62

5.7 Exemplos de teste do conjunto de dados mpg . . . . . . . . . . 62

5.8 Tabelas de contingência das regras R1, R2 e R3 . . . . . . . . 62

5.9 Valores das medidas calculadas para as regras R1, R2 e R3 . . 66

6.1 Descrição detalhada dos atributos do conjunto de dados abalone 72

$6.2 \mathrm{M} \Lambda \mathrm{D}$ calculada no conjunto de dados abalone . . . . . . . . 78

6.3 MSE calculada no conjunto de dados abalone . . . . . . . . . . . . 78

6.4 Resultado do teste de hipóteses realizado com o conjunto de dados abalone ...................... 79

6.5 Compreensibilidade calculada no conjunto de dados abalone . . 80

6.6 Pseudo-intervalos gerados com o conjunto de dados abalone . . . 81

6.7 Medidas calculadas sobre o regressor gerado pelo Cubist com o conjunto de dados abalone . . . . . . . . . . . . . . . . 81

6.8 Medidas calculadas sobre o regressor gerado pelo M5 Model com o conjunto de dados abalone . . . . . . . . . . . . . . . . . . . 82

6.9 Medidas calculadas sobre o regressor gerado pelo RETIS com o conjunto de dados abalone . . . . . . . . . . . . . . . 82

6.10 Medidas calculadas sobre o regressor gerado pelo CART com o conjunto de dados abalone . . . . . . . . . . . . . . . 82

6.11 Descrição detalhada do conjunto de dados housing . . . . . . . . 83

$6.12 \mathrm{MAD}$ calculada no conjunto de dados housing . . . . . . . . . . 84

6.13 MSE calculada no conjunto de dados housing . . . . . . . . . . . . 86

6.14 Resultado do teste de hipóteses realizado com o conjunto de dados housing . . . . . . . . . . . . . . . . 88

6.15Compreensibilidade calculada no conjunto de dados housing por meio dos algoritmos M5 Model, Cubist e RETIS . . . . . . . . . . . 89 
Lista de Tabelas

6.16Compreensibilidade calculadas no conjunto de dados housing por meio dos algoritmos M5 Regression, RT e CART . . . . . . . . 89

6.17 Pseudo-intervalos gerados com o conjunto de dados housing . . . 90

6. 18 Medidas calculadas sobre o regressor gerado pelo Cubist com o conjunto de dados housing . . . . . . . . . . . . . . . . . . . . 99

6. 19 Medidas calculadas sobre o regressor gerado pelo M5 Model com o conjunto de dados housing . . . . . . . . . . . . . . . . . 90

6.20 Medidas calculadas sobre o regressor gerado pelo RETIS com o conjunto de dados housing . . . . . . . . . . . . . . . . 91

6.2 l Medidas calculadas sobre o regressor gerado pelo CAR' com o conjunto de dados housing . . . . . . . . . . . . . . . . . . 91

6.22 Medidas calculadas sobre o regressor gerado pelo R'T com o conjunto de dados housing . . . . . . . . . . . . . . . . . . 91

6.23 Medidas calculadas sobre o regressor gerado pelo M5 Regression com o conjunto de dados housing . . . . . . . . . . . . . . . 92 


\section{Lista de Algoritmos}

1 Algoritmo P-Class . . . . . . . . . . . . . . . . . . . 57

2 Algoritmo de Construção da Tabela de Contingência para Regras de Regressāo . . . . . . . . . . . . . . . . . . . . . . . . 59 


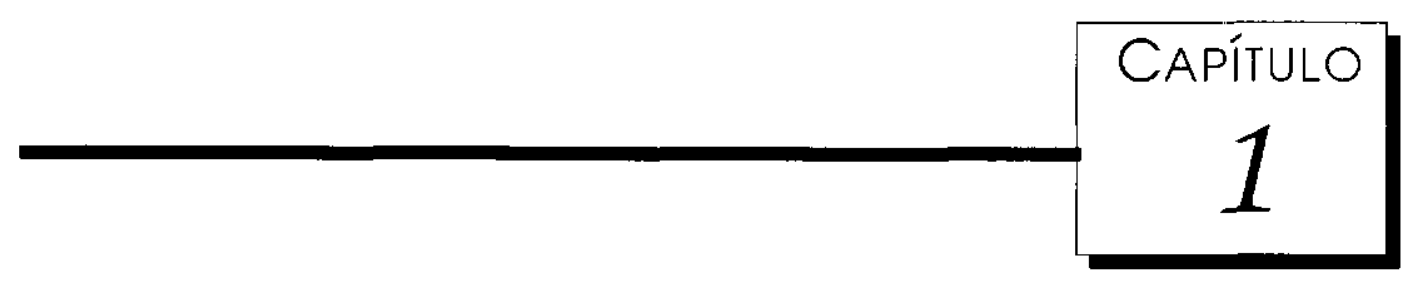

\section{Introdução}

$\mathcal{A}$

quantidade de informaçōes que pode ser armazenada pelas bases de dados vem aumentando a cada dia que passa. Até a metade do século $\mathrm{XX}$, poucas empresas possuiam mais do que dezenas de megabytes de dados armazenados. No final da década de 90 . grandes empresas já armazenavam terabytes de informaçōes em suas bases de dados. Além disso, o custo para armazenar essa enorme quantidade de dados é relativamente baixo nos dias de hoje. Porém, até alguns anos atrás, essa enorme quantidade de dados era coletada desorganizadamente e qualquer análise sobre esses dados era feita de maneira manual, o que dificultava bastante essa análise, principalmente devido ao grande volume de dados armazenado.

Por outro lado, nos últimos anos, com o advento da globalização, mudanças fundamentais têm influenciado o modo como as empresas conduzem seus negócios e tratam seus clientes. Tais mudanças têm resultado em um mercado cada vez mais competitivo. Alguns fatores, como a mudança de comportamento dos clientes, a saturação dos mercados e a ineficiência do marketing tradicional fizeram com que as empresas passassem a ter como foco principal o cliente, resultando nas estratégias de CRM (Custommer Relationship Management), ou marketing one-to-one (Peppers and Rogers Group do Brasil, 2000). Para conhecer melhor seus clientes, as empresas precisavam analisar o grande volume de dados armazenado a respeito dos seus clientes com o objetivo de encontrar padrões, tendéncias e informações úteis que lhes auxiliassem na acirrada competição pela conquista do mercado. Dessa maneira, a tomada de decisão tornou-se mais complexa, obrigando as empresas a utilizarem ferramentas e sistemas que permitissem analisar os dados armazenados, para posteriormente, tomar as decisões.

Essa grande quantidade de dados que pode ser armazenada a um custo relativamente baixo e a necessidade das empresas de extrair conhecimento a partir de suas bases de dados, somados a outros fatores - popularização da Internet, aparecimento de novas soluçōes tecnológicas, como a tecnologia 
de Data Warehouse (Inmon, 1997), avanços científicos em diversas áreas, por exemplo nas áreas de aprendizado de máquina e estatística - impulsionaram o processo de mineraçāo de dados, responsável por extrair padrões ou modelos embutidos em grandes conjuntos de dados (Fayyad et al., 1996).

Mineração de dados refere-se ao processo de análise e aplicaçāo de algoritmos que, mediante limitações de eficiência computacional aceitáveis, são capazes de produzir uma relação particular de padrões a partir de grandes massas de dados (Fayyad et al., 1996). Trata-se de um processo iterativo e interativo constituído de várias etapas, no qual são utilizadas técnicas c métodos que auxiliam na identificaçāo de padrōes a partir dos dados, com o objetivo de extrair novo conhecimento.

O processo de mineração de dados possui duas grandes atividades: a predição e a descrição. A atividade de predição, ou mineração de dados preditiva, utiliza-se de inferência indutiva para examinar exemplos que possuam algum rótulo $\mathrm{c}$ obtcr uma generalização que permita prever os rótulos de novos exemplos. A prediçāo apresenta dois tipos de problemas, de acordo com os valores que os rótulos assumem: se os rôtulos assumem valores nominais (discretos ou categóricos), o problema é denominado classificação, e se eles assumem valores contínuos, então o problema é chamado de regressão. Os modelos gerados no processo de mineraçāo de dados (tanto de classificação quanto de regressāo) são conhecidos como hipóteses.

Já na atividade de descrição, ou mineração de dados descritiva, os exemplos fornecidos não possuem nenhum rótulo associado. O objetivo é identificar algum tipo de comportamento que esteja embutido nos dados. Regras de associaçāo, agrupamentos e sumarização são exemplos de atividades descritivas (Weiss \& Indurkhya, 1998).

\subsection{Regressão}

Os métodos de regressão já são estudados pela comunidade estatística há bastante tempo. Porém, nas âreas de aprendizado de máquina e mineração de dados, a maioria das pesquisas são voltadas para os problemas de classificaçāo, que são mais comumente encontrados na vida real do que problemas de regressão (Weiss \& Indurkhya, 1995). Recentemente, as pesquisas têm se voltado também para problemas de regressão, já que muitos problemas sāo desse tipo, como problemas relacionados com habilidades esportivas e controle dinâmico de robôs (Uysal \& Güvenir, 1999). Portanto, a regressāo em mineraçāo de dados preditiva é uma questão pouco explorada dentro do processo de extração de conhecimento de bases de dados, sendo de grande relevância o estudo de métodos para a exploração de tarefas desse tipo. 
Os métodos de regressão geram modelos ${ }^{1}$ em diferentes formatos de representação. Como esses modelos expressam o conhecimento obtido durante o processo de mineração de dados, então cada método pode expressar o conhecimento de uma forma diferente. Dependendo dos objetivos a serem alcançados ao final do processo de mineraçāo de dados, a compreensibilidade dos modelos gerados è considerada muito importante, tanto para uma tarefa de regressão quanto para uma tarefa de classificação. A necessidade de modelos capazes de fornecerem soluçōes interpretáveis leva à utilização dos métodos de aprendizado simbólico. Regras e árvores são tipos de modelos gerados por esses métodos. Elas sāo bastante semelhantes, diferenciando-se, por exemplo, pelo fato de que as árvores sāo mutuamente exclusivas e as regras nem sempre. Pelo fato de fornccerem soluções compreensiveis, este trabalho tem como foco os modelos de regressão gerados pelos métodos de aprendizado simbólico.

Para induzir uma hipótese utiliza-se algum algoritmo de indução (ou indutor), que recebe como entrada um conjunto de dados e gera um modelo que representa o conhecimento extraído desses dados. Os algoritmos de regressāo utilizados no processo de mineraçāo de dados normalmente reccbem esses dados em diferentes formatos de representaçāo. Com isso, se um conjunto de dados precisa ser submetido a diferentes algoritmos de regressão, é necessário que esse conjunto passe por um processo de transformação para se adequar ao formato dos dados de entrada desse algoritmo. Por outro lado, os métodos de regressāo simbólicos, aqui estudados, induzem hipóteses no formato de regras e árvores de regressāo. As regras sāo diferentes das árvores, c mesmo as árvores geradas por diferentes algoritmos sāo distintas umas das outras. Desse modo, ao submeter um conjunto de dados a vários algoritmos de regressāo, difcrentes tipos de regressores são obtidos. Com isso, torna-se dificil avaliar o conhecimento extraído por diferentes algoritmos porque a avaliação precisa ser feita de maneira diferente para cada algoritmo, uma vez que cada modelo é representado de uma forma diferenciada. Essa avaliação dos modelos simbólicos extraídos faz parte de uma etapa do processo de mineração de dados conhecida como pós-processamento do conhecimento.

O primeiro ponto que deve ser avaliado na etapa de pós-processamento é o desempenho da prediçāo (ou precisāo) do modelo frente a novos exemplos. Porém, quando o problema é de regressāo, não é fácil medir o desempenho de prediçāo do modelo, pois como o rótulo a ser predito assume valores numéricos, não se pode afirmar se o valor predito está correto ou não. Além da precisão, existem ainda outros fatores que devem ser avaliados, como a compreensibilidade, que caracteriza o quão compreensivel esse modelo é ao usuário, e a interessabilidade, que consiste em verificar se o conhecimento

${ }^{1}$ Os modelos de regressão são também conhecidos como regressores. 
obtido por esse modelo é novo ou não. Além disso, no caso de se tratar de um novo conhecimento, deve-se verificar se ele é interessante e útil para os usuários do processo de mineraçāo de dados.

\subsection{O Projeto DISCOVER}

Em nosso laboratório de pesquisa - LABIC $^{2}$ (Laboratório de Inteligência Computacional) sempre foram implementados diversos tipos de programas por parte dos pesquisadores nas áreas de aprendizado de máquina e mineraçāo de dados e textos, de acordo com as necessidades de cada um. Porém, por causa de vários fatores, como a falta de documentação desses programas, essas implementaçōes não eram reaproveitadas, fazendo com que, muitas vezes, um mesmo programa fosse implementado diversas vezes por diferentes pessoas. Isso impulsionou a criação de um projeto que envolvesse os membros do laboratório, projeto esse que recebeu o nome de Discover.

O objetivo do DIScover é fornecer um ambiente intcgrado para apoiar as etapas do processo de descoberta do conhecimento, oferecendo funcionalidades voltadas para aprendizado de máquina, mineração de dados e de textos. Essas funcionalidades são baseadas em sintaxes padrōes utilizadas para representar os dados (Batista, 2001) e o conhecimento extraído dos dados. Algumas sintaxes padrões utilizadas para representação do conhecimento são a sintaxe padrāo para regras de decisão (Prati, Baranauskas, \& Monard, 2001b,a) e a sintaxe padrāo para regras de regressāo (Pugliesi, Dosualdo, \& Rezende, 2003), utilizada neste trabalho. No Discover, os programas são implementados como bibliotecas de classes e essas classes são empacotadas como componentes, com a composição deles sendo feita por meio de uma interface gráfica.

\subsection{Objetivos e Contribuições desta Dissertação}

Como citado, a maioria das pesquisas realizadas nas áreas de aprendizado de máquina e mineração de dados são voltadas para os problemas de classificaçāo. No projeto Dıscover, a situação não é muito diferente. A maioria dos trabalhos já implementados são voltados para problemas desse tipo. Nesse sentido, este trabalho objetiva auxiliar na construção e avaliação de um modelo de regressāo simbólico, fornecendo, para isso, métodos a serem utilizados na etapa de pós-processamento do processo de mineração de dados.

O objetivo principal deste trabalho é fornecer uma biblioteca de classes integrada ao Discover que oferece uma série de funcionalidades para auxiliar na preparação dos dados para a geração de um modelo de regressão simbólico, e principalmente, na avaliação desse modelo.

${ }^{2}$ http://labic.icmc.usp.br/ 
Cada algoritmo de regressāo utilizado no processo de mineraçāo de dados recebe dados de cntrada em um formato de representação diferente. Baseado na sintaxe padrāo de dados do Discover foram implementadas algumas classes que convertem um conjunto de dados no formato padrão do Discover para o formato dos dados de cntrada dos sistemas de regressão utilizados neste trabalho. Isso permite aos usuários do Discover facilmente realizarem essa conversão, c dessa maneira, submeter um conjunto de dados a qualquer um dos algoritmos de regressāo.

Com relaçāo aos diferentes formatos de modelos gerados pelos métodos de regressão, foi implementada neste trabalho uma classe que converte os diferentes regressores simbólicos para um formato único, sendo essa conversāo baseada na sintaxe padrāo de regras de regressāo do Discover. Isso auxilia bastante na avaliaçāo dos modelos, uma vez que qualquer tipo de avaliação que precise ser efetuada, como implementaçāo de medidas e cálculos, é implementada uma única vez e pode ser aplicada aos modelos gerados pelos diferentes algoritmos, já que eles estão padronizados em um mesmo formato. Alèm de facilitar a implementaçāo de medidas e cálculos a serem efetuados sobre os modelos, isso permite comparar os regressores gerados pelos diferentes algoritmos.

Para auxiliar na avaliação dos modelos de regressão simbólicos foi implementada neste trabalho uma biblioteca de classes que oferece várias funcionalidades:

- tratamento semântico de regras de regressão, que melhora a compreensibilidade das regras e aumenta o desempenho dos programas que utilizam essas regras como entrada;

- cálculo de medidas de precisāo baseadas na diferença entre o valor predito pelo algoritmo para um rótulo e o valor real desse rótulo;

- cálculo de medidas para avaliar a compreensibilidade de regras de regressāo;

- construção de uma tabela de contingência para regras de regressão baseada no algoritmo P-Class descrito em (Weiss \& Indurkhya, 1995). Uma tabela de contingência é comumente construida para regras de decisão, que sāo induzidas em problemas de classificaçāo. A partir dessa tabela sāo calculadas várias medidas. Neste trabalho foi implementado um mecanismo que permite construir tal tabela para regras de regressāo. e assim, calcular todas as medidas dela derivadas;

- teste de hipóteses, que implementa um mecanismo que permite comparar as hipóteses induzidas pelos diferentes algoritmos de regressão, 
afirmando se uma hipótese supera a outra, e se essa superaçāo é comprovada com um certo grau de confiança.

\subsection{Organização desta Dissertação}

Neste capítulo foi apresentado o contexto em que se insere este trabalho, bem como os objetivos e contribuiçōes do mesmo. O restante do trabalho está organizado da maneira descrita a seguir.

No Capitulo 2 é feita uma descrição geral do processo de mineraçāo de dados, detalhando as etapas do processo e apresentando as principais dificuldades encontradas ao longo do mesmo. Além do processo de mineração de dados, serāo descritos também os problemas de regressāo, apresentando alguns conceitos e descrevendo alguns exemplos.

Como existem vârios métodos para se realizar uma tarefa de regressão, que gcram modelos em diferentes tipos de representação. no Capitulo 3 são descritos alguns dos principais métodos, apresentando as caracteristicas, vantagens e desvantagens de cada um deles.

No Capítulo 4 è apresentado como este trabalho está integrado ao DiscoVER. Para isso, são melhor detalhados o projeto e o ambiente Discover e relatados trabalhos realizados c outros que estão em desenvolvimento. São também apresentados alguns sistemas e algoritmos de regressão utilizados neste trabalho.

O Capitulo 5 tem como objetivo apresentar o ambiente computacional DisCover Post-Processing Environment of Regression - DiPER implementado e integrado ao Discover neste trabalho. São descritas todas as classes que compõem esse ambiente, bem como as funcionalidades de cada uma. Nesse capitulo será detalhado ainda o processo de construção da tabela de contingência para regras de regressāo utilizando o algoritmo P-Class.

No Capítulo 6 são descritos alguns experimentos realizados para avaliar o ambiente DIPER implementado. Para isso, sāo descritos os conjuntos de dados utilizados e a maneira como os experimentos foram realizados, apresentando a saida obtida em cada parte dos experimentos. Além disso, è feita uma avaliaçāo dos resultados obtidos nesses experimentos para cada conjunto de dados utilizado.

Por fim, no Capitulo 7, são apresentadas as conclusões deste trabalho e propostas para trabalhos futuros. 


\section{- \\ Visão Geral do Processo de Mineração de Dados}

$\mathcal{M}$

ineração de dados refere-se ao processo de análise e aplicação de algoritmos que, mediante limitações de eficiência compulacional aceitáveis, são capazes de produzir uma relação particular de padrões a partir de grandes massas de dados (Fayyad et al., 1996). Trata-se de um processo iterativo e interativo constituído de várias etapas. Nesse processo, são utilizadas técnicas e métodos que auxiliam na identificação de padrões a partir dos dados, com o objetivo de extrair um novo conhecimento.

As etapas que constituem o processo de mineração de dados são detalhadas na Seçāo 2.1, na qual é apresentada a função de cada uma dessas etapas dentro do processo como um todo. Na Seçāo 2.2 é apresentada a regressão, que corresponde a um tipo de atividade do processo de mineração de dados. Por fim, na Seção 2.3 são feitas as consideraçōes finais deste capitulo.

\subsection{Etapas do Processo de Mineração de Dados}

Primeiramente, antes de descrever as etapas que constituem o processo de mineraçāo de dados, é importante entender como os dados coletados do mundo real sāo transformados em conhecimento por meio desse processo. Os dados são coletados e armazenados em diversos tipos de fontes, como bases de dados (operacionais ou um Data Warehouse), planilhas c arquivos-texto. Uma parte desses dados ć selecionada e passa entāo por uma etapa de preparaçāo, na qual esses dados são colocados em algum formato especifico (geralmente no formato atributo-valor), além de passarem por transformaçōes, se necessário. Em seguida, esses dados são submetidos a um algum algoritmo para gerar um modelo que represente os padrões extraídos. Os padrōes extraídos são então avaliados para verificar se o conhecimento extraido é novo, ou trata-se de um conhecimento já existente.

Os padrões extraidos podem ser representados de diferentes formas. Cada 
método possui uma forma de representação, denominada linguagem de representação de hipóteses. Alguns exemplos de linguagens de representação de hipóteses são: regras, árvores, funções matemáticas e cláusulas de Horn.

O número de etapas que constituem o processo de mineraçāo de dados varia bastante, visto que existem diferentes visões de como o processo é dirigido. Neste trabalho foi adotada a divisāo do processo proposta em (Fayyad. Piatetsky-Shapiro, \& Smyth, 1996) e adotada em (Rezende et al., 2003), que considera três grandes etapas: pré-processamento, extração de padrões e pósprocessamento. Essa divisão de etapas do processo de mineraçāo de dados pode ser observada na Figura 2.1.

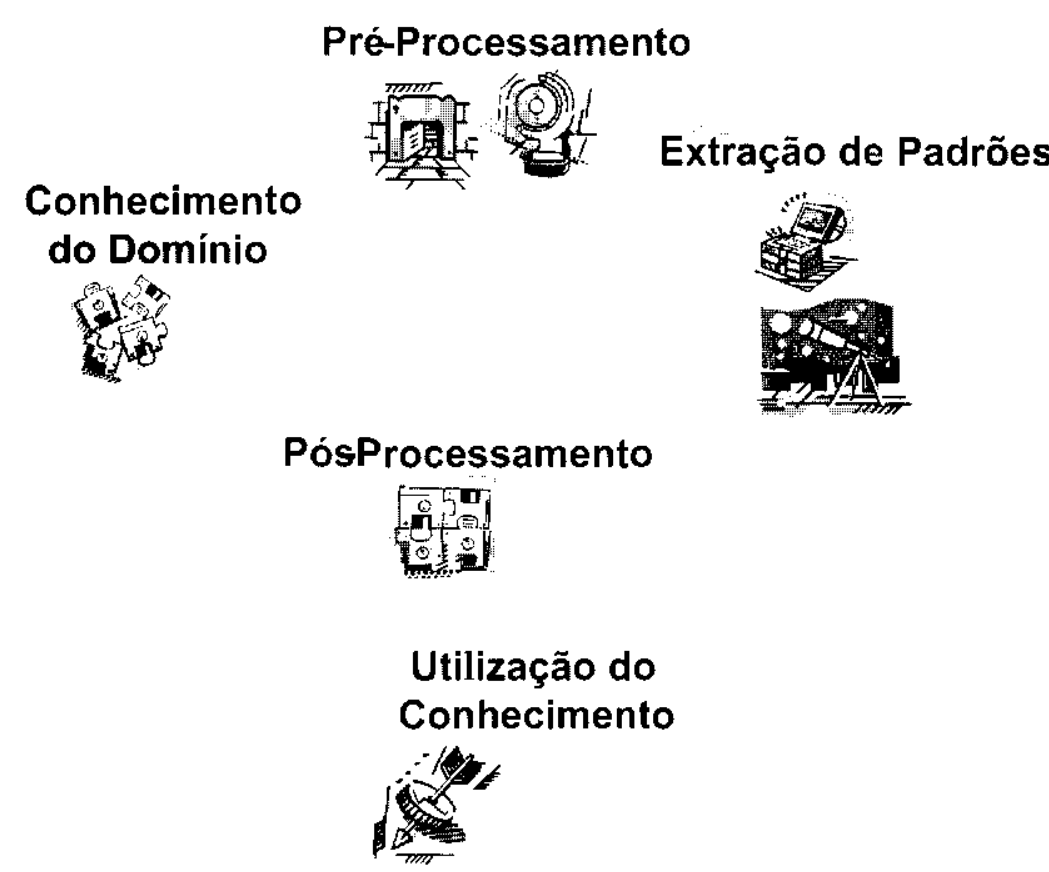

Figura 2.1: Etapas do processo de mineração de dados (Rezende et al., 2003)

Na etapa de pré-processamento, os dados sāo preparados para a etapa de extração dos padrões, passando por diversas fases, como extraçāo, unificaçāo, limpeza e redução do volume de dados. Na etapa de extraçāo dos padrōes, são escolhidos a atividade, o método e o algoritmo a serem utilizados. Em seguida, os dados são entāo submetidos ao algoritmo escolhido com o objetivo de extrair os padrōes. Para representar os padrōes extraidos è gerado então um modelo, que contém o conhecimento obtido. Esse modelo é então avaliado na etapa de pós-processamento. Nessa avaliaçāo sāo levados em consideraçāo vários fatores, como a precisāo, a compreensibilidade e a interessabilidade do modelo.

Antes da etapa de pré-processamento devem ser definidos quais os objetivos a serem alcançados e que tipo de informação se deseja extrair dos dados. Isso é muito importante, pois se os objetivos nāo forem identificados com cla- 
reza, o processo todo pode estar condenado. Além disso, é importante contar com a participação de um especialista, que possua amplo conhecimento do domínio da aplicação e forneça apoio para a execução do processo. Se realizada de maneira adequada, a definição dos objetivos pode fornecer um subsidio para as etapas do processo de mineraçāo de dados.

\subsubsection{Pré-Processamento}

Na grande maioria das vezes, os dados utilizados no processo de mineraçāo de dados apresentam uma série de imperfeições, precisando passar por um processo de limpeza. Esses dados também precisam passar por algumas transformaçōes, pois geralmente não estão em um formato adequado para a execuçāo do processo. Além disso, devido a limitaçōes computacionais ou de tempo, muitas vezes a quantidade de dados precisa ser reduzida. A etapa de pré-processamento geralmente consome a maior parte do esforço gasto no processo todo, em torno de $60 \%$ do total (Cabena et al., 1997). Essa etapa pode ser dividida em várias fases, como mostra a Figura 2.2 .

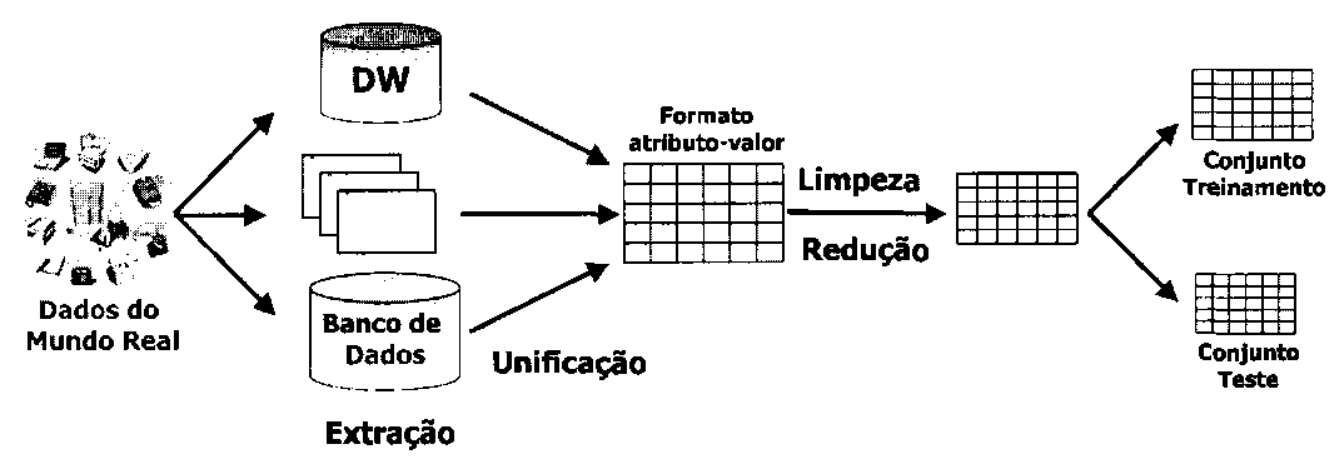

Figura 2.2: Pré-processamento no processo de mineração de dados

\section{Extração e Unificaçāo}

Essa fase tem como objetivo identificar as fontes de dados disponiveis e cxtrair os dados que serão preparados para a etapa de extração dos padrōes. Os dados podem ser provenientes de diversas fontes, como arquivos-texto, arquivos de planilhas, bases de dados operacionais e Data Warehouse. Dessa maneira, é necessário extrair os dados e unificá-los em um único formato. Uma forma bastante comum de representar os exemplos que compōem o conjunto de dados e também aceita por muitos algoritmos é o formato atributo-valor, mostrado na Tabela 2.1.

O conjunto de exemplos no formato atributo-valor é composto de $n$ exemplos $\mathrm{e} d$ atributos, sendo que a linha $i$ refere-se ao $i$-ésimo exemplo $(i-$ $1,2, \ldots, n)$ e a entrada $x_{i, j}$ refere-se ao valor do $j$-ésimo $(j=1,2, \ldots, d)$ atributo $X_{j}$ do exemplo $i$. A última coluna da tabela corresponde aos valores do atributometa ( $y_{i}$ é o valor do atributo-meta do exemplo $i$ ). Portanto, cada exemplo 


\begin{tabular}{|c|c|c|c|c|c|}
\hline Exemplo & $X_{1}$ & $X_{2}$ & $\ldots$ & $X_{d}$ & $Y$ \\
\hline 1 & $x_{11}$ & $x_{12}$ & $\ldots$ & $x_{1 d}$ & $y_{1}$ \\
\hline 2 & $x_{21}$ & $x_{22}$ & $\ldots$ & $x_{2 d}$ & $y_{2}$ \\
\hline 3 & $x_{31}$ & $x_{32}$ & $\ldots$ & $x_{3 d}$ & $y_{3}$ \\
\hline$\vdots$ & $\vdots$ & $\vdots$ & $\ddots$ & $\vdots$ & $\vdots$ \\
\hline$n$ & $x_{n 1}$ & $x_{n 2}$ & $\ldots$ & $x_{n d}$ & $y_{n}$ \\
\hline
\end{tabular}

Tabela 2.1: Conjunto de exemplos no formato atributo-valor

corresponde a uma tupla $\left(x_{i 1}, x_{i 2}, \ldots, x_{i d}, y_{i}\right)$, em que $y_{i}=h\left(x_{i}\right)$ é a função que calcula o valor do atributo-meta em funçāo dos demais atributos.

Transformação

Depois de extraidos e unificados em um mesmo formato, os exemplos devem ser adequados para serem utilizados por algum algoritmo, podendo ser necessário realizar algum tipo de transformação. Alguns tipos de transformaçōes possiveis sāo: normalizaçāo de dados, discretizaçāo de valores e conversão de tipos.

\section{Limpeza}

Essa fase objetiva tratar, principalmente, dois problemas:

1. dados com ruído: são dados que possuem valores inconsistentes para um determinado atributo. Por exemplo: o atributo em questão é a idade de uma pessoa, e um certo exemplo possui o valor 950 para esse atributo;

2. dados com valores ausentes: muitas vezes, alguns exemplos são incompletos, nāo possuindo o valor de um ou mais atributos.

\section{Redução do Volume}

Quando o volume de dados é muito grande, deve-se reduzir a quantidade de dados, pois essa quantidade pode ser muito grande para ser aplicada a algum algoritmo, ou ainda, o tempo esperado para induzir uma soluçāo pode ser muito grande (Weiss \& Indurkhya, 1998). A reduçāo da dimensão dos dados pode ser feita diminuindo o número de exemplos (selecionando uma certa quantidade deles), diminuindo o número de atributos (nesse caso, alguns atributos podem ser selecionados, ou podem ser compostos novos atributos a partir da combinação de outros (Hall \& Smith, 1998)), ou ainda, reduzindo o número de valores de um atributo.

É muito importante selecionar cuidadosamente os atributos e os exemplos a serem utilizados, pois o desempenho dos algoritmos depende bastante da qualidade dos dados fornecidos. 


\subsection{Etapas do Processo de Mineração de Dados}

\section{Geração de Sub-Conjuntos Disjuntos}

Essa fase do processo de mineraçāo de dados é opcional, sendo omitida por muitos autores. O conjunto de exemplos extraido, unificado, transformado, limpo e reduzido pode ser dividido em dois subconjuntos disjuntos: o conjunto de treinamento, utilizado para o aprendizado do conceito, e o conjunto de teste, utilizado para medir o grau de efetividade do conceito aprendido (Mitchell, 1997).

\subsubsection{Extração dos Padrōes}

Esta etapa é direcionada a cumprir os objetivos definidos na etapa de identificação do problema. Ela compreende a escolha da atividade, do método, do algoritmo a scr utilizado para extrair os padrōes e a extração dos padrōes propriamente dita.

\section{Escolha da Atividade}

De acordo com a especificação dos objetivos, deve-se escolher uma das atividades do processo de mineraçāo de dados: a predição ou a descrição, como mostrado na Figura 2.3 .

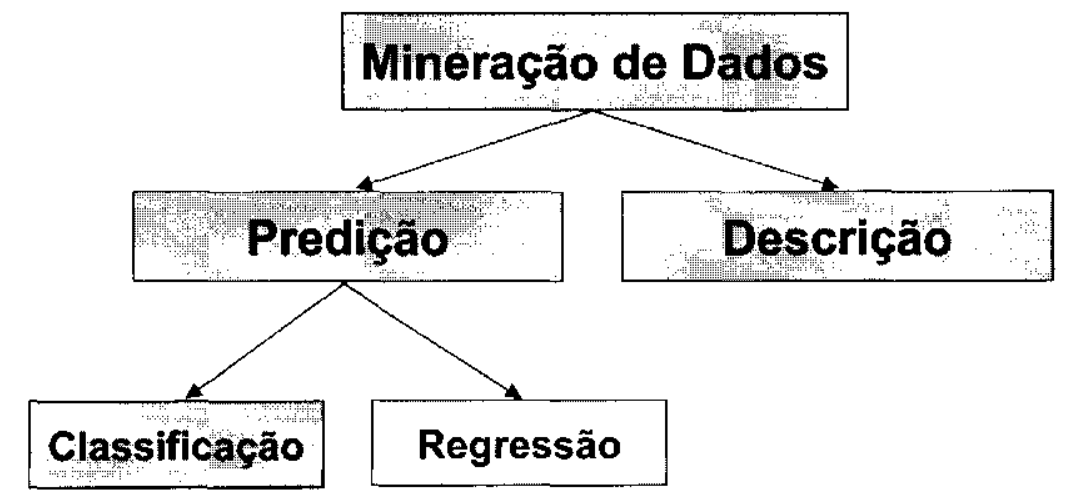

Figura 2.3: Atividades do processo de mineração de dados

Fornecido um conjunto de exemplos que possua rótulos associados, a atividade de predição (ou mineração de dados preditiva) utiliza de inferência indutiva para construir um modelo que generalize esses exemplos, e que permita determinar corretamente o rótulo de novos exemplos não rotulados (Mitchell, 1997). Como citado, de acordo com os valores que os rótulos assumcm, a prediçāo apresenta dois tipos de problemas: se os rótulos assumem valores nominais (ou discretos), o problema é denominado classificaçāo, e se eles as sumem valores contínuos, então o problcma é chamado de regressão. A re gressão é o foco principal deste trabalho e será detalhada na Seção 2.2 deste capítulo e nos próximos capítulos.

Já na atividade de descrição, ou mineração de dados descritiva, os exemplos fornecidos não possuem nenhum rótulo associado. O objetivo é identifi- 
car algum tipo de comportamento que esteja embutido nos dados. Regras de associaçāo, agrupamentos e sumarização são exemplos de atividades descritivas (Weiss \& Indurkhya, 1998).

\section{Escolha do Método}

Baseado no tipo de atividade escolhida, deve-se escolher um método que permita construir um modelo que represente os padrōes extraídos. Como descrito anteriormente, cada mètodo possui uma linguagem de representação de hipóteses, que corresponde à forma como os padrões sāo apresentados. Como o foco deste trabalho é a regressão, na Tabela 2.2 sāo apresentados alguns métodos de regressāo e a forma como esses métodos representam os padrões extraídos. Alguns métodos de regressão são descritos no próximo capítulo.

\begin{tabular}{|c|c|}
\hline Mêtodo & Forma de Representação \\
\hline \hline Regressão Linear dos Mínimos Quadrados & Função de Regressão \\
\hline Regressão de Primeira Ordem & Cláusulas de Horn \\
\hline Redes Ncurais Artificiais & Rede com Pesos Associados \\
\hline Indução de Regras de Regressão & Conjunto de Regras de Regressão \\
\hline Indução Top-Down de Árvores de Regressão & Árvore de Regressāo \\
\hline Support Vector Machines & Vetor de Pesos \\
\hline
\end{tabular}

Tabela 2.2: Alguns métodos de regressāo

\section{Escolha do Algoritmo}

Definido o método a ser utilizado, deve-se escolher um algoritmo que receba como cntrada um conjunto de exemplos em um determinado formato, e a partir desses exemplos, gere um modelo na sua linguagem de representação de hipóteses.

Cada algoritmo possui associado uma linguagem de representaçāo de exemplos, que corresponde ao formato de rcpresentação que os exemplos devem possuir para que o algoritmo possa ser executado.

Para a escolha do algoritmo, existem também outras características importantes, como (Cabena et al., 1997):

- capacidade de manipular certos tipos de dados;

- formato de representação dos dados de entrada;

- comprecnsibilidade do modelo (da saida);

- nível de familiaridade do usuário;

- escalabilidade;

- requisitos de software e hardware; 
Alguns algoritmos utilizados para regressāo são descritos no Capítulo 4 .

\section{Extração dos Padrōes}

A extração dos padrōes propriamente dita consiste na aplicação do algoritmo escolhido ao conjunto de exemplos para obter um modelo que represente os padrōes extraídos.

Fornecido um conjunto de exemplos, o algoritmo tenta induzir uma função $h$ que se aproxima da função f (funçāo realmente existente nos dados) geralmente desconhecida. A função $h$ é chamada de hipótese sobre a função objetivo $f$, ou seja, $h\left(x_{i}\right) \approx f\left(x_{i}\right)$ (Mitchell, 1997). Essa hipótese $h$ tem como objetivo predizer o valor do atributo-meta de um novo exemplo fornecido. Existem muitas escolhas possiveis para a função $h$, uma vez que a verdadeira função $f$ é desconhecida. Por exemplo, fornecidos os exemplos como na Figura 2.4, como escolher a função (ou hipótese) que melhor se adapta aos dados?

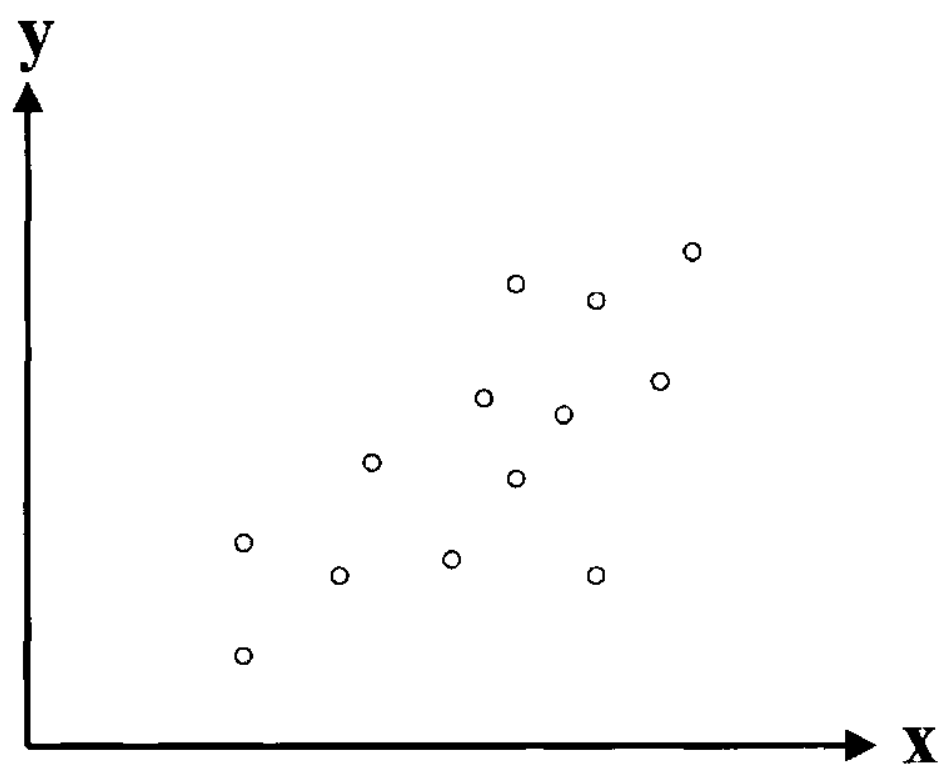

Figura 2.4: Conjunto de exemplos fornecido

As diferentes hipóteses formam o espaço de hipóteses, que consiste de todos os modelos possiveis dentro de uma linguagem de descrição selecionada (Torgo, 1999). Na Figura 2.5 sāo apresentadas algumas possîveis hipóteses baseado no conjunto de exemplos da Figura 2.4. Para escolher a melhor hipótese entre as existentes, os indutores possuem algum bias de aprendizado, que corresponde a qualquer preferencia de uma hipótese sobre outra, além da consistência com os dados (Russell \& Norvig, 1995). Para cada situaçāo, deve ser escolhido o bias mais adequado, pois não existe o melhor indutor para todos os dominios. O bias de aprendizado pode ser guiado por algum critério, como precisão ou compreensibilidade do modelo. Um critério de preferência é o Princípio da Navalha de Occam, que afirma: "A hipótese 
mais provável é a mais simples que seja consistente com todas as observaçōes" (Russell \& Norvig, 1995).

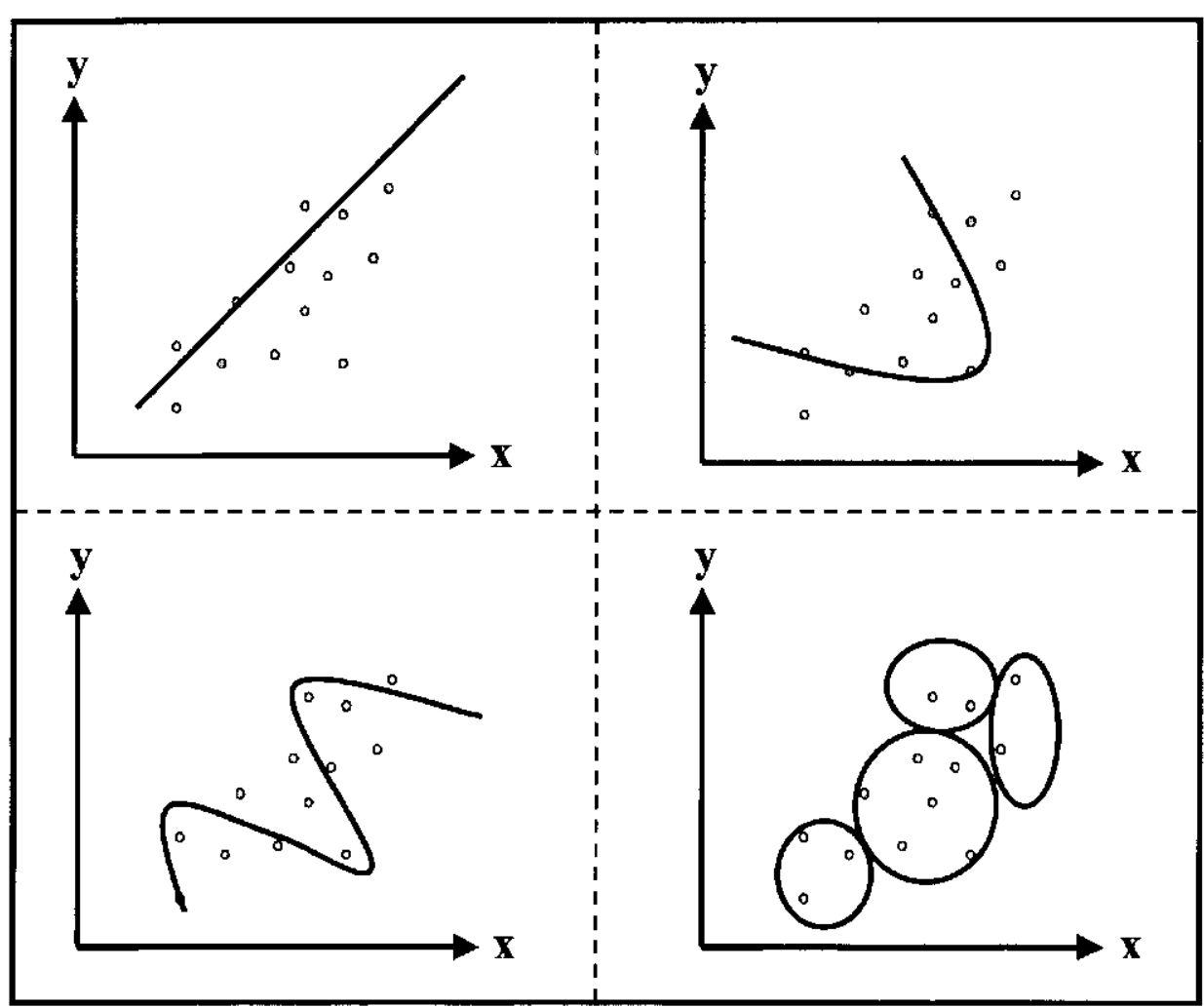

Figura 2.5: Possiveis hipóteses

\subsubsection{Pós-Processamento}

Os padrōes obtidos no processo de mineraçāo de dados formam um modelo que representa o conhecimento obtido. Esse modelo deve ser avaliado segundo alguns fatores. como precisão, compreensibilidade e interessabilidade.

No caso da atividade de prediçāo, tanto classificação quanto regressão, é necessário estimar o desempenho de predição desse modelo. Quando a tarefa é de classificação, o desempenho de predição do modelo é medida verificando se ele classificou os exemplos nāo rotulados dentro da classe correta ou nāo. Uma medida comumente utilizada para avaliaçāo de um classificador ${ }^{1}$ é a precisão. Uma descrição detalhada desta e de outras medidas utilizadas em problemas de classificaçāo pode ser encontrada em (Horst, 1999). Guando o problema é de regressão, torna-se um pouco mais dificil medir o desempenho de predição do modelo. Como o atributo-meta é continuo, nāo se pode afirmar se o valor predito está correto ou nāo. Algumas medidas utilizadas em problemas de regressão são: MAD (Mean Absolute Deviation), MSE (Mean Squared Error) e NMSE (Normalized Mean Squared Error).

Para obter uma estimativa confiável do desempenho de predição de um

${ }^{1}$ Um classificador corresponde à uma hipótese gerada por algum algoritmo de classificação. 
modelo ć neccssário que ele seja avaliado com os exemplos de teste, que não foram utilizados na sua geração. Quando as medidas de desempenho são efetuadas sobre o conjunto de treinamento elas sāo chamadas de aparentes e quando são efetuadas sobre o conjunto de teste são chamadas de medidas reais (Baranauskas, 2001).

Portanto, quando a hipótese é construida e seu desempenho testado no mcsmo conjunto de exemplos obtém-se uma estimativa altamente otimista da precisão e o bom desempenho no conjunto de treinamento não se estende a conjuntos de testes independentes. Porém, existem várias técnicas que geram conjuntos de treinamento e teste que permitem obter medidas reais, como: holdout, $k$-fold cross-validation, leave-one-out e bootstrap.

Além da precisão, existem outros critérios a serem avaliados, como a comprecnsibilidade e a interessabilidade dos modelos extraídos. A compreensibilidade de um modelo está relacionada com a facilidade de interpretação desse modelo por parte do usuário. Ela pode ser estimada de acordo com o tamanho do modelo. Em (Pazzani, Mani, \& Shankle, 1997; Pazzani, 2000) é discutido que outros fatores, além do tamanho, são importantes na determinação da compreensibilidade de um modelo. Já a interessabilidade avalia o quanto do conhecimento extraído é interessante (ou inesperado) (Piatetsky-Shapiro \& Matheus, 1994; Freitas, 1998). As medidas de interessabilidade baseiam-se em vários aspectos, principalmente na utilidade que o modelo obtido representa para o usuário final do processo de mineração de dados (Dong \& Li, 1998; Rezende et al., 2003).

Após a análise do conhecimento realizada na etapa de pós-processamento. caso o conhecimento não seja interessante ou não cumpra com os objetivos especificados, o processo de mineraçāo de dados pode ser repetido ajustando os parâmetros ou melhorando o processo de escolha dos dados. No entanto, se o conhecimento for interessante, ele pode ser utilizado para auxiliar os usuários finais em um processo de tomada de decisão. Vale ressaltar que o usuário final pode ser um especialista do domínio ou um usuário sem conhecimento profundo do domínio da aplicação.

\subsection{A Regressão em Mineração de Dados}

A tarefa de regressão consiste em obter um modelo baseado em um conjunto de exemplos que descrevem uma função não-conhecida. Esse modelo é então utilizado para predizer o valor do atributo-meta de novos exemplos.

O objetivo da regressão é encontrar uma relaçāo entre um conjunto de atributos de entrada (variáveis de entrada ou variáveis preditoras) e um atributometa contínuo. Sejam $X=\left\{x_{1}, \ldots, x_{d}\right\}$ os atributos de entrada e $y$ o atributometa, o objetivo é encontrar uma mapeamento da seguinte forma (Aptc \& 
Weiss, 1997):

$$
y=f\left(x_{1}, x_{2}, \ldots, x_{d}\right)
$$

A regressāo é também conhecida por predição funcional, predição de valor real, funçāo de aproximaçāo, ou ainda, aprendizado de classes continuas (Uysal \& Güvenir, 1999).

Por exemplo, suponha que se deseja predizer a porcentagem de gordura que uma pessoa possui no corpo. Fornecidos exemplos contendo algumas características de pessoas como: sexo, idade, peso e altura, mais a taxa de gordura (atributo-meta), o objetivo da regressão é predizer a porcentagem de gordura do corpo de outras pessoas baseado nesses exemplos.

Outro caso seria tentar predizer quantos carros passam em um determinado pedágio. Fornecidos alguns exemplos contendo informações como: rodovia em que o pedágio está localizado, cidades mais próximas, preço do pedágio. dia da semana e período do dia, mais a quantidade de carros (atributo-meta), o objetivo da regressão ê predizer quantos automóveis passam naquele pedágio.

A grande maioria dos problemas de regressão faz a predição de um único atributo-meta. Porém, a regressão também pode ser realizada predizendo mais que um atributo-meta. Por exemplo, as redes neurais artificiais, descritas no próximo capitulo, permitem realizar uma tarefa de regressão com vários atributos-meta.

\subsection{Considerações Finais}

Neste capitulo foi apresentada uma visão geral do processo de mineração de dados e uma descrição de cada uma de suas etapas. O processo de mineração de dados apresenta dois tipos de atividades principais: a prediçāo e a descrição. Na predição, os exemplos fornecidos possuem um rótulo associado, c o objetivo ć predizer o valor do rótulo de novos exemplos nāo rotulados. Dependendo dos valores que esses rótulos assumem, o problema é denominado de classificação ou regressão.

A regressão, foco principal deste trabalho, tem como objetivo encontrar uma relação entre um conjunto de atributos de entrada e um atributo-mcta contínuo. Existem vários métodos para se realizar uma tarefa de regressão. que geram modelos em diferentes formatos. Esses métodos, bem como os tipos de modelos gerados, são descritos no próximo capitulo. 


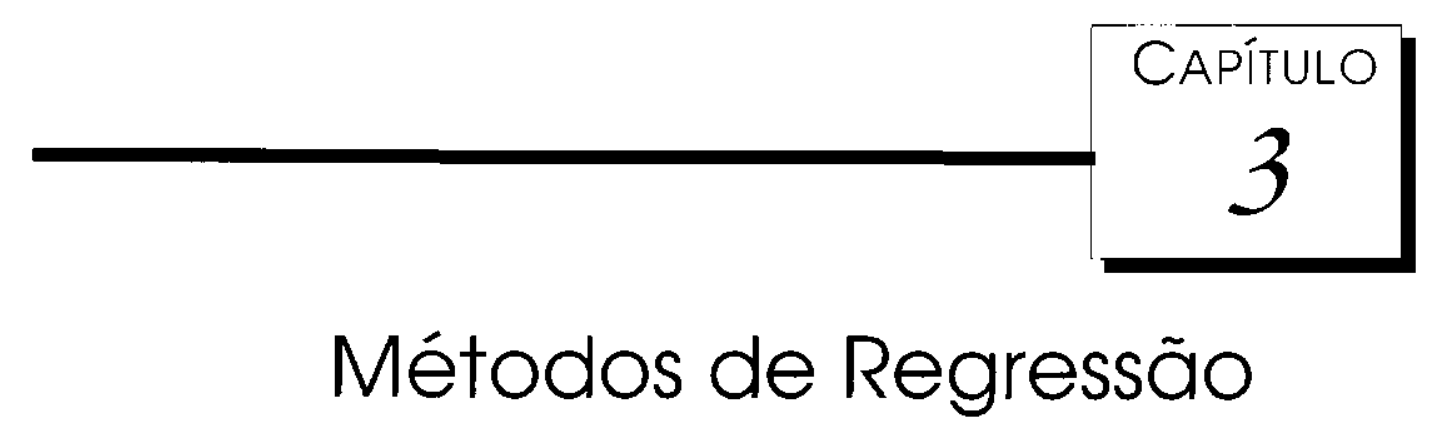

$O$

s diferentes métodos de regressāo podem ser divididos de muitas maneiras. Os critérios utilizados na divisão dos métodos são baseados no tipo de modelo gerado. Alguns desses critérios levam em consideração se os modelos obtidos:

- são paramétricos ou não-paramétricos;

- realizam um particionamento dos dados ou não;

- são gerados global ou localmente;

- são baseados em regressão linear ou não;

- são aditivos ou não;

- sāo estatísticos ou não.

Os métodos de regressão já sāo estudados pela comunidade estatística há bastante tempo. Porém, nas áreas de aprendizado de máquina e mineraçāo de dados, a maioria das pesquisas trata de problemas de classificaçāo, que são mais comumente encontrados na vida real do que problemas de regressão (Weiss \& Indurkhya, 1995). Reccntemente, o foco das pesquisas nessas áreas tem se voltado para problemas de regressão, já que muitos problemas são desse tipo, por exemplo, problemas relacionados com habilidades esportivas e controlc dinâmico de robôs.

O capitulo encontra-se organizado da seguinte maneira: na Seçāo 3.1 é descrito o modelo paramétrico global, um dos métodos de regressāo mais utilizados pela comunidade estatistica. Na Seção 3.2 são descritos os métodos de modelagem local, que utilizam os exemplos mais similares do conjunto de treinamento para fazerem suas predições. Na Seção 3.3 são descritos os modelos baseados em aprendizado simbólico, com destaque para as regras e árvores. Na Seção 3.4 sāo apresentadas as redes neurais artificiais, modelos 
computacionais inspirados no cérebro humano. Na Seção 3.5 são descritos os modelos aditivos, que decompōem uma função de regressāo complexa em várias funçōes mais simples. Na Seção 3.6 são apresentadas as support vector machines, que tentam encontrar um hiperplano para tornar linear um problema complexo. Por fim, na Seção 3.7 sāo feitas as consideraçōes finais do capitulo.

\subsection{Modelo Paramétrico Global}

A abordagem paramétrica global ê um dos método mais utilizados pela comunidade estatística para resolver problemas de regressão. Uma abordagem desse tipo tenta adaptar todos os dados de treinamento fornecidos a uma única funçāo paramétrica global (Uysal \& Güvenir, 1999).

Utilizar uma abordagem desse tipo implica em fazer uma forte suposição a respeito da forma da função de regressāo não conhecida, podendo levar a uma baixa precisāo dependendo do caso. Apesar disso, a abordagem paramétrica global tem sido amplamente utilizada e tem fornecido bons resultados de predição quando a função real existente nos dados pode ser representada corretamente por uma função paramétrica global. Além disso, esses modelos sāo facilmente interpretados e possuem soluçōes computacionais rápidas (Torgo. 1999).

Um exemplo clássico desse tipo de abordagem e tambêm um dos mais utilizados é o modelo paramétrico global utilizando o critério de erro dos mínimos quadrados. Esse critério tenta encontrar um vetor de parâmetros $\beta$ que minimize a soma dos erros quadrados, como mostrado na Equaçāo 3.1.

$$
\sum_{i=1}^{n}\left(y_{i}-\left(\beta_{0}+\beta_{1} x_{1}+\ldots+\beta_{d} x_{d}\right)\right)^{2}
$$

Esse modelo de regressão linear utilizando o critério dos mínimos quadrados tem se mostrado eficiente para muitas aplicações do mundo real (Weiss \& Indurkhya, 1995). Na Figura 3.1 é mostrado um exemplo em que os dados se adaptam muito bem ao modelo de regressāo linear gerado. Esse exemplo utiliza um atributo de entrada $x$ para predizer o valor do atributo-meta $y$.

\subsection{Modelos Locais}

A modelagem local caracteriza-se por fazer prediçōes baseadas nos exemplos do conjunto de treinamento mais semelhantes a um determinado exemplo fornecido. Os métodos de modelagem local utilizam alguma medida de similaridade para identificar os exemplos mais similares do conjunto de treinamento. como apresentado na Figura 3.2, e entāo utilizam esses exemplos para predizer o valor do atributo-meta. 


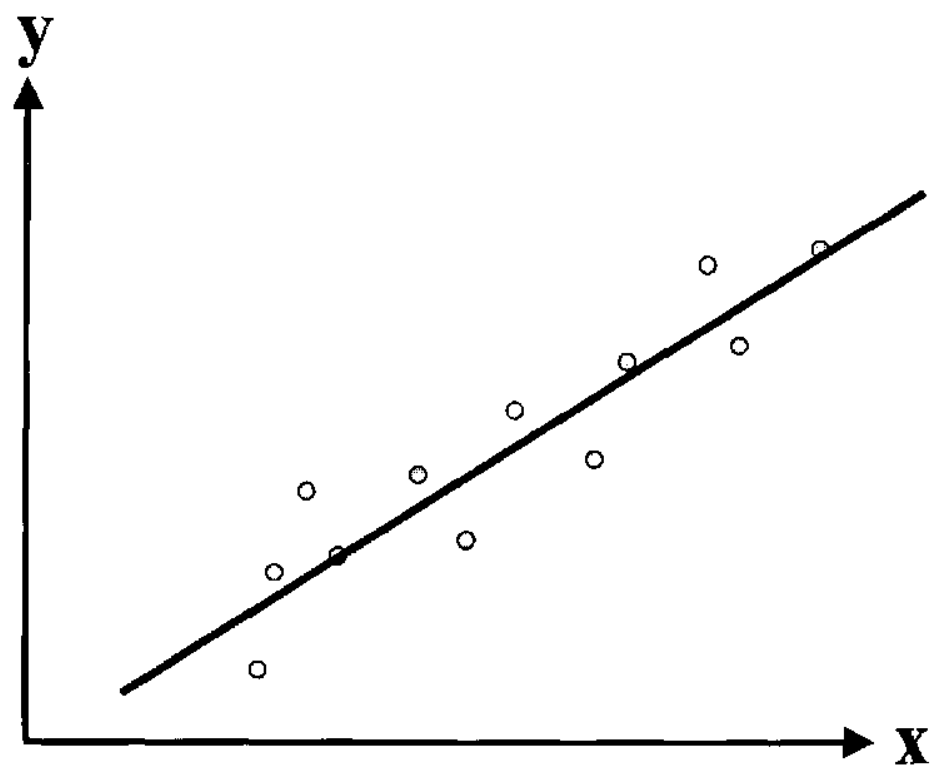

Figura 3.1: Exemplo de regressāo linear global

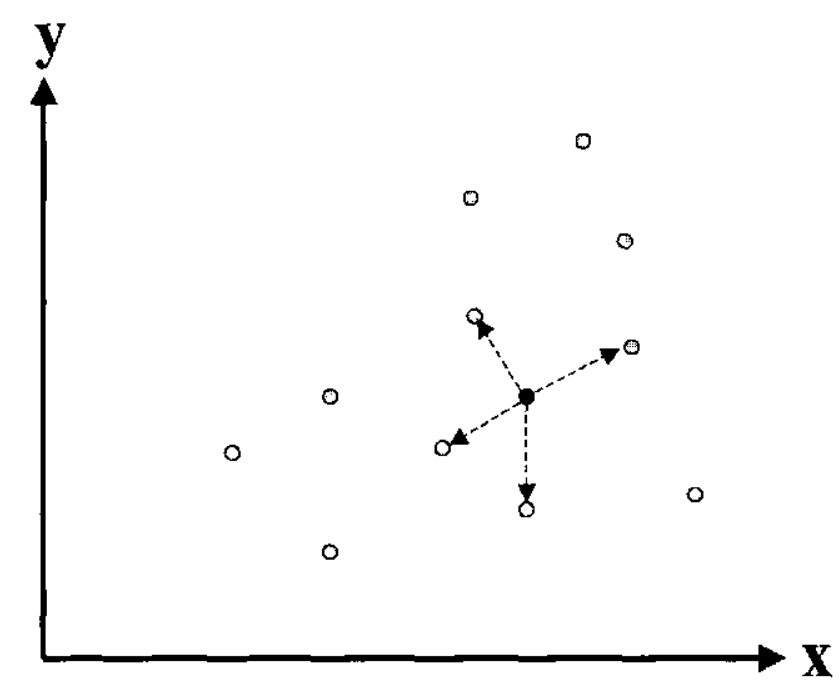

Figura 3.2: Exemplos mais similares do conjunto de treinamento

Esses métodos possuem um custo computacional de treinamento minimo. pois apenas armazenam os dados na memória. Porèm, a fase de prediçāo apresenta um custo maior porque para cada novo exemplo fornecido é necessário encontrar os exemplos de treinamento mais similares.

\subsubsection{Método: Aprendizado Baseado em Exemplos}

Os métodos de aprendizado baseado em exemplos (IBL - Instance BasedLearning) foram desenvolvidos pela comunidade de aprendizado de máquina e sāo também conhecidos como abordagens baseadas na memória, ou ainda, métodos de aprendizado lazy. 
De uma maneira geral, o aprendizado baseado $\mathrm{cm}$ exemplos é composto de três componentes básicos (Nagai, 2000):

1. um conjunto de exemplos de treinamento armazenados na memória;

2. determinação de uma métrica para realizar comparações entre um exemplo fornecido e os mais próximos a ele; e

3. determinaçāo de um número $k$ de exemplos mais próximos ou similares que serão utilizados para predizer o valor do atributo-meta de um novo exemplo.

O aprendizado baseado em exemplos simplesmente armazena todos os excmplos de treinamento na memória (por isso é também chamado de abordagem baseada na memória) sem fazer qualquer tipo de generalização dos dados fornecidos. Portanto, não existe uma fase de treinamento, sendo que todo o trabalho do algoritmo é feito durante a predição. Depois de armazenar os exemplos na memória, utiliza-se alguma métrica para encontrar os exemplos mais similares.

Pelo fato desses algoritmos fazerem suas prediçōes baseadas apenas nos exemplos armazenados na memória, a qualidade da predição pode ser comprometida devido a ruídos nos dados. Para melhorar o desempenho de predição desses algoritmos, o conjunto de dados deve ser selecionado e preparado adequadamente, podendo ser removidos exemplos ou até mesmo atributos do conjunto de treinamento, desde que isso não afete o desempenho preditivo do algoritmo.

A grande desvantagem do aprendizado baseado em exemplos é que ele não produz abstraçōes ou modelos que permitam a interpretaçāo do conhecimento contido no conjunto de dados.

O algoritmo do vizinho mais próximo (Nearest Neighbor - NN) é um dos mais simples e mais utilizados algoritmos de aprendizado baseado em exemplos. Encontrados os exemplos mais semelhantes, esse algoritmo prediz o valor do atributo-meta de um novo caso calculando a média dos valores dos atributos-meta dos exemplos do conjunto de treinamento mais similares. O NN compara um novo exemplo $x_{1}$ com um outro $x_{2}$ previamente armazenado na memória baseado na distância euclidiana. A distância euclidiana, descrita na Equação 3.2, é limitada pelo fato de classificar somente atributos numéricos.

$$
\triangle\left(x_{1}, x_{2}\right)=\sqrt{\left(x_{1,1}-x_{2,1}\right)^{2}+\left(x_{1,2}-x_{2,2}\right)^{2}+\ldots+\left(x_{1, d}-x_{2, d}\right)^{2}}
$$

em que $x_{i, j}$ é o valor do $j$-ésimo atributo do $i$-ésimo exemplo e $d$ é o número de atributos. 
O algoritmo do vizinho mais próximo puro classifica um caso baseado em um único exemplo similar, o que pode acarretar em erros prematuros. O $k$ Nearest Neighbor é uma versão mais elaborada do NN que classifica um novo exemplo calculando a média entre os $k$ exemplos mais próximos a ele.

$\mathrm{O}$ algoritmo $\mathrm{NN}$ assume que todos os exemplos mais similares encontrados são equivalentemente relevantes. Por esse motivo, a precisão da predição do modelo pode ser deteriorada. Uma solução para esse problema, descrita na próxima sub-seçāo, é fazer com que, entre os exemplos mais similares encontrados, os que estiverem mais próximos do novo exemplo possuam pesos maiores no modelo (Uysal \& Güvenir, 1999).

\subsubsection{Método: Locally Weighted Regression}

O método Locally Weighted Regression (LWR), que também faz parte dos métodos de aprendizado lazy, é bastante similar à abordagem Nearest Neighbor descrita anteriormente, principalmente em três aspectos (Uysal \& Güvenir, 1999):

1. a fase de treinamento desses algoritmos consiste apenas em armazenar os exemplos de treinamento na memória, sendo todo o trabalho realizado durante a predição de novos exemplos;

2. os novos exemplos preditos são fortemente influenciados pelos exemplos mais similares previamente armazenados; $\mathrm{e}$

3. os exemplos são representados como pontos reais em um espaço p-dimensional.

A principal diferença entre os dois métodos está no modo como eles predizem o valor de um novo exemplo lornecido. Enquanto o NN prediz o valor de novos exemplos apenas fazendo a média dos exemplos mais próximos do conjunto de treinamento. o LWR constrói modelos locais adaptando um plano aos exemplos mais próximos do conjunto de treinamento (Atkeson, Moore, \& Schaal, 1997). Para construir esses modelos, que geralmente sāo funçōes paramétricas lineares ou não-lineares, o LWR utiliza uma abordagem denominada distance weighted regression, em que os exemplos mais próximos possuem um peso maior no modelo, enquanto que os mais distantes possuem um peso menor. O LWR depende bastante da função de distância utilizada para calcular os exemplos mais próximos.

Como os modelos construídos sảo locais, depois que um exemplo tem seu valor predito, o modelo utilizado é apagado, c para cada exemplo apresentado, um novo modelo é construido (Uysal \& Güvenir, 1999). 


\subsection{Modelos Baseados em Aprendizado Simbólico}

A compreensibilidade dos modelos gerados é considerada muito importante quando se realiza uma tarefa de regressāo ou classificaçāo. A necessidade de modelos capazes de fornecerem soluçōes interpretáveis levou a comunidade de aprendizado de máquina a desenvolver os métodos de aprendizado simbólico. Esses métodos variam de acordo com a linguagem escolhida para representar as hipóteses. A lógica proposicional é uma linguagem de representaçāo de hipóteses bastante utilizada pelos métodos de aprendizado simbólico.

Os métodos de aprendizado simbólico proposicionais são aqueles que utilizam a lógica proposicional para representar suas hipóteses. A lógica proposicional permite determinar a validade de proposições compostas por meio de conectivos a partir da validade de fatos simples e da interpretação desses conectivos. Esse tipo de lógica aceita como resposta somente os valores verdadeiro e falso. Os conectivos utilizados para compor as proposiçōes podem ser do tipo AND, OR, NOT, etc. Se o conectivo utilizado é o operador OR, a notação proposicional é denominada Forma Normal Disjuntiva (FND) e se o conectivo é o $\Lambda$ ND, entāo a notaçāo é chamada de Forma Normal Conjuntiva (FNC). Dentre os modelos que fornecem soluçōes na FNC, destacam-sc as regras e ârvores de decisão, no caso da classificação, e as regras e árvores de regressão, no caso da regressão.

As regras e as árvores são bastante scmelhantes, diferenciando-se, entre outros, pelo fato de que as árvores sāo mutuamente exclusivas, e as regras nem sempre. Portanto, para cada exemplo, uma ou mais regras podem ser satisfeitas, ao contrário das árvores. As regras e as árvores. dependendo da aplicação, oferecem vantagens e desvantagens, que serāo descritas nas próximas sub-seções.

Pelo fato de fornecerem soluções compreensiveis, este trabalho tem como foco principal os modelos de regressão baseados em aprendizado simbólico.

\subsubsection{Método: Indução de Regras de Regressão}

Uma regra na Forma Normal Conjuntiva possui a scguinte forma:

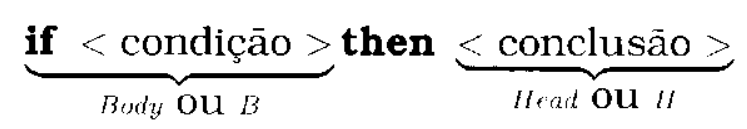

ou, na forma simbólica:

$$
B \rightarrow H
$$

Portanto, uma regra na FNC é composta de duas partes:

- a condiçāo, cauda ou corpo da regra - $B$, que consiste de uma conjunçāo de pares no formato atributo-valor, que assumem a forma $x_{i}$ op value, 
sendo que, $x_{i}$ é um atributo, op $\epsilon\{=, \neq,<, \leq,>, \geq\}$ e value é um valor constantc válido para o atributo em questão.

- a conclusão ou cabeça da regra - $I I$, responsável pela predição do valor do atributo-meta.

A diferença entre uma regra de decisão e uma de regressão está na conclusāo da regra. Em uma regra de decisão, $H$ é a classe associada, pois o atributo-meta a ser predito é nominal. Já em uma regra de regressāo, $1 /$ é uma função, pois nesse caso, o atributo-meta é contínuo.

Guando se trata de uma regra de regressāo, a prediçāo pode ser feita por meio da média dos valores do atributo-meta, de uma equaçāo linear, da utilização do método K-Nearest Neighbor, entre outros.

Como exemplo de um algoritmo de induçāo de regras de regressāo destacase o Cubist, descrito no próximo capitulo.

\subsubsection{Método: Indução Top-Down de Árvores de Regressão}

As árvores são compostas por dois tipos de nós:

- os nós internos da árvore: cada um desses nós corresponde a um teste feito em um dos atributos de entrada do conjunto de exemplos, e

- os nós-folha, nos quais sāo feitas as prediçōes do atributo-meta.

As árvores de regressão diferem das árvores de decisāo quanto ao conteúdo dos nós-folha. Os nós-folha de uma árvore de regressāo possuem uma função matemática (que no caso mais simples pode ser a simples média dos valores que caem em cada nó-folha) para predizer o atributo-meta, enquanto que os nôs-folha de uma árvore de decisão possuem valores nominais.

As árvores que predizem o valor de um atributo-meta continuo sāo conhecidas como Regression Tree ou Model Tree, dependendo de como os nós-folha calculam o valor desse atributo-meta. Quando os nós-folha da árvore apenas calculam a média de todos os exemplos de treinamento que caem naquele nó, entāo a árvore é conhecida como Regression Tree. Por outro lado, se os nós-folha possuem algum modelo de regressāo linear para predizer o valor do atributo-meta, então a árvore é conhecida como Model Tree. Um exemplo de uma Model Tree é mostrado na Figura 3.3. Essa árvore foi construida utilizando dois atributos de entrada $\left(x_{1}\right.$ e $\left.x_{2}\right)$ do conjunto de dados.

Um dos pontos mais importantes a serem levados em consideração quando uma árvore de regressão (ou de classificação) está sendo construida é a seleção do atributo que será utilizado para fazer o particionamento dos dados em cada nỏ da árvore. Além de selecionar o atributo, é muito importante escolher um 


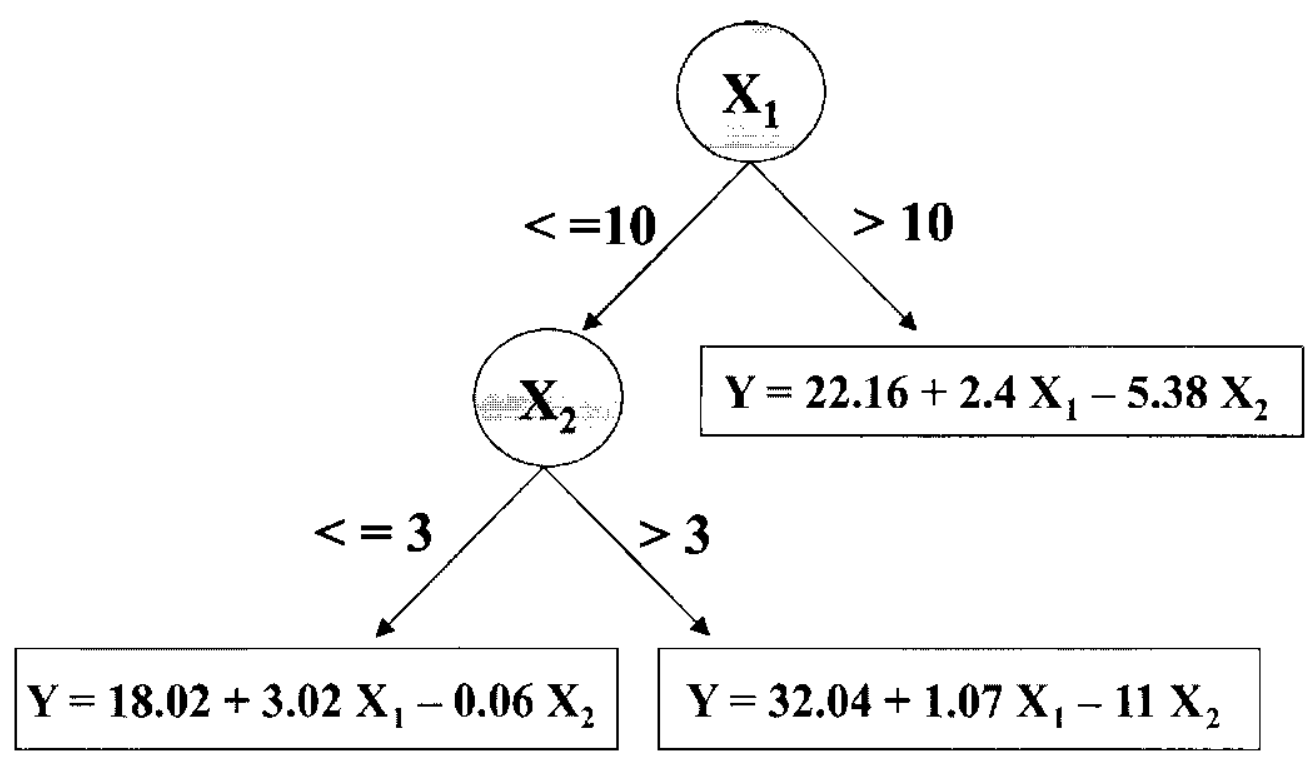

Figura 3.3: Exemplo de uma Model Tree

valor adequado para esse atributo de modo a particionar os dados da melhor maneira possivel.

As principais vantagens apresentadas pelos modelos de árvores de regressāo são: (i) seleção dinâmica de atributos: os métodos de indução de árvores são extremamente efetivos em encontrar os atributos-chave (os mais importantes) em aplicações de alta dimensão, e (ii) sua capacidade exploratória, porém. à medida que a árvore cresce de tamanho, sua interpretabilidade diminui. Guanto ao desempenho, as árvores de regressāo se equiparam aos demais métodos de regressāo (Weiss \& Indurkhya, 1995).

Os algoritmos de indução de árvores constroem modelos fazendo um particionamento recursivo do conjunto de treinamento da seguinte maneira: o nó-raiz da árvore contém um atributo que divide o conjunto de treinamento em sub-regiōes distintas (geralmente duas sub-regiōes). Os filhos do nó-raiz podem ser nós-folhas, ou entāo, sāo selecionados novos atributos com seus respectivos valores, dividindo assim, o conjunto de treinamento em novas subdivisõcs. O número de nós de uma árvore e a profundidade da mesma variam de acordo com o tamanho do conceito representado nos dados e com o mecanismo de inferência utilizado pelo algoritmo responsâvel pela construção da árvore. Um árvore muito grande provavelmente causa um "overfitting" dos dados, enquanto que uma árvore muito pequena geralmente nāo oferece bons resultados (Hastie, Tibshirani, \& Friedman, 2001).

Em geral, os algoritmos de indução de árvores apresentam as seguintes caracteristicas em comum: (i) particionam o conjunto de treinamento em regiōes disjuntas recursivamente, na qual a partiçāo final è determinada pelos nósfolha da árvore, e (ii) utilizam estratégias de poda para evitar o overfitting (Torgo, 1999). 
Os diversos algoritmos de indução de árvores de regressão diferenciam-se pelas estratégias de poda utilizadas, pela maneira como selecionam os atributos que particionarão os dados, e principalmente, pelo tipo de funçāo que utilizam para predizer o valor do atributo-meta (Torgo, 1997). Alguns exemplos de algoritmos desse tipo sāo o RETIS (Regression Tree Induction System), o M5 e o CART (Classification And Regression Trees), descritos no próximo capítulo.

\subsection{Modelo Baseado em Redes Neurais Artificiais}

Redes Ncurais Artificiais (RNAs) sāo modelos computacionais inspirados no cérebro humano. Elas são compostas por várias unidades de processamento (neurônios), interligadas por um grande número de conexōes (sinapses).

Graficamente, uma RNA pode ser vista como um conjunto de nós (unidades de processamento) e arcos, representando respectivamente, os neurônios e as conexōes entre os mesmos (Braga, Carvalho, \& Ludermir, 2000). Uma estrutura genérica de rede neural artificial é composta por uma camada de entrada, uma ou mais camadas intermediárias (escondidas) e uma camada de saída. Cada uma dessas camadas é composta por um número variado de neurônios, dependendo da aplicação. Os nós da camada de entrada estão relacionados com os atributos de entrada e contêm os valores dos exemplos fornecidos à RNA. Os nós das camadas intermediárias recebem um conjunto de entradas provenientes de outros nôs, computam uma funçāo (conhecida como função de ativação) sobre essas entradas e então enviam o resultado para outro conjunto de nós. Cada arco que conecta dois nós possui um peso associado. A camada de saida da RNA representa os valores de saida da rede, que sāo calculados por intermédio dos atributos de entrada e dos pesos associados às conexões.

Um exemplo genérico de uma rede neural artificial é mostrado na Figura 3.4

$O$ aprendizado em uma rede neural artificial consiste em encontrar os valores dos pesos de modo a fornecer a saida correta. A Rede começa com um vetor de pesos randômico, e então, à medida que lhe sāo fornecidos excmplos de treinamento, os pesos vão sendo modificados até que as predições se tornem satisfatórias.

Guando se trata de um problema de regressão, a rede neural artificial é utilizada para predizer o valor dos atributos contínuos (as saidas fornecidas pela RNA são valores continuos). Alguns exemplos em que as RNAs tem sido utilizadas para fazer regressāo sāo: previsão de séries temporais, aproximação de funções e fusão de sensores (Braga, Carvalho, \& Ludermir, 2000, 2003).

A grande vantagem das RNAs sobre os outros métodos é que elas nāo sāo restritas à um único atributo de saída, como acontece na maioria dos casos. 


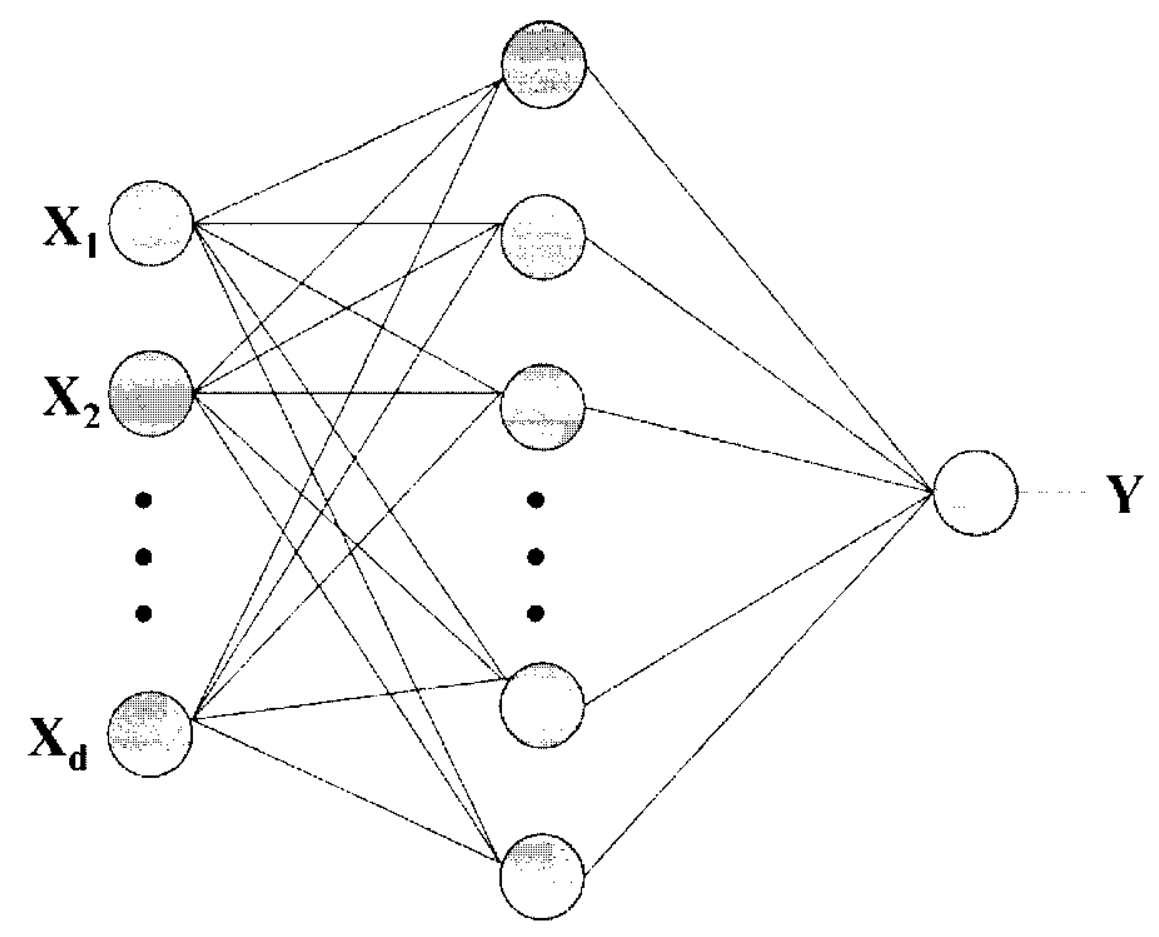

Figura 3.4: Exemplo de uma rede neural artificial

Portanto, podem ser realizadas várias regressões em uma RNA. Além disso, as RNAs são conhecidas pela alta precisão na prediçāo dos valores e são robustas diante de dados com ruido.

Porém, as RNAs também apresentam algumas desvantagens. A primeira é que, dependendo do modelo de rede e do algoritmo de aprendizado. as redes neurais podem apresentar lenta convergência para uma soluçāo. Isso porque a rede pode precisar ser treinada até que os pesos estejam corretos de modo a fornecer a saída esperada. Outra desvantagem é que as soluçōes por ela fornecidas nāo sāo facilmente interpretadas pelos usuários, pois o conhecimento está embutido nos pesos e conexōes da rede.

Para o treinamento de uma rede neural artificial pode ser utilizado o simulador SNNS (Stuttgart Neural Network Simulator) (SNNS Simulator. 1995). O SNNS é um software de uso compartilhado criado na Universidade de Stuttgart utilizado para manutenção e treinamento de RNAs, possibilitando a visualização de seus desempenhos na aprendizagem, validaçāo e teste.

\subsection{Modelos Aditivos}

Um método aditivo é aquele que se aproveita do fato de que uma função de regressão complexa pode ser decomposta em partes, sendo que cada uma dessas partes representa uma função simples. Portanto, um modelo com uma alta dimensão (com muitos atributos) pode ser visto como a soma de outras funções de dimensōes menores (Torgo, 1999). Project Pursuit Regression e Adaptive Regression Splines sāo exemplos de métodos aditivos. 


\subsubsection{Método: Project Pursuit Regression}

Project Pursuit Regression (PPR) constitui um modelo refletindo o conjunto de treinamento em projeçōes de dimensōes menores, como uma soluçāo quando o conjunto de dados fornecido possui uma alta dimensão. PPR funciona da seguinte maneira: em cada passo da construçāo do modelo, a melhor aproximação dos dados cncontrada ê selecionada, adicionada ao modelo que está sendo gerado c essa parte é removida do conjunto de exemplos. A busca pela melhor aproximação continua com os dados restantes do conjunto de treinamento até que todos façam parte do modelo final. Esse processo é também conhecido como Refinamento Sucessivo, porque a cada passo a complexidade do modelo aumenta (Uysal \& Güvenir, 1999).

A desvantagem apresentada por esse método é a complexidade computacional. Quando se possui um conjunto grande de funções candidatas, è necessário escolher entre elas e refinar os parâmetros da função selecionada de modo que ela se adapte da melhor maneira aos dados.

\subsubsection{Método: Adaptive Regression Splines}

Adaptive Regression Splines pode ser visto como uma generalização das árvores de regressão, apresentadas anteriormente, e foram desenvolvidos para superar algumas de suas limitaçōes. Algumas dessas limitaçōes são: (i) a lacuna de continuidade apresentada pclas árvores de regressão, que afeta a capacidade preditiva do modelo, e (ii) a incapacidade das árvores de regressão de fornecerem boas aproximaçōes para algumas funçōes (Uysal \& Güvenir, 1999). A lacuna de continuidade corresponde ao fato de que os valores de um nô-folha nāo sāo continuos em relação aos valores dos outros nós-folha.

Uma adaptação paramétrica piecewise aproxima uma função por meio de várias funçōes paramétricas simples (geralmente polinômios de ordens menores), cada uma delinida sobre diferentes sub-regiōes do conjunto de treinamento. Esses polinómios precisam ser contínuos em cada ponto, isto é, cada funçāo definida sobre uma sub-região do conjunto de treinamento deve ser contínua com relação à função definida sobre a próxima sub-região deste conjunto.

O mais popular cntre os procedimentos de adaptação paramétrica piecewise são aqueles baseados em splines, em que as funçōes paramétricas globais sāo polinômios de grau $q$. O procedimento é implementado por intermédio da construçāo de um conjunto de funçōcs-base delinidas globalmente.

O algoritmo MARS (Multivariate Adaptive Regression Splines), desenvolvido no inicio dos anos 90 por Jerry Friedman, é um algoritmo de particionamento recursivo que possui algumas modificações para resolver os problemas discutidos nesta seção, principalmente no que diz respeito à descontinuidade. 
A metodologia MARS è detalhada em (Friedman, 1991; Hastie, Tibshirani, \& Friedman, 2001).

Para executar o algoritmo MARS pode-se fazer uso do software R. Esse software é utilizado para manipulaçāo de dados, cálculos e visualização gráfica (Vcnables \& Smith, 2002). As funcionalidades do R são divididas em pacotcs, que assim como o software, encontra-se disponivel em (The $\mathrm{R}$ Development Core, 2002). O pacote mda do R possibilita gerar e testar um modelo MARS.

\subsection{Modelo Baseado em Support Vector Machines}

A teoria Support Vector Machines (SVMs), ou Máquinas de Suporte Vetoriais, foi proposta no final da década de 60 por V. Vapnik e A. Chervonenkis. Uma descriçāo detalhada desse método pode ser encontrada em (Vapnik, 1998).

O princípio das SVMs consiste em encontrar um hiperplano ótimo que separe membros e não-membros de uma classe em um espaço abstrato, denominado feature space. Nesse espaço, as classes presentes no conjunto de treinamento se tornam linearmentc separávcis, c o hipcrplano ótimo é definido como aquele para o qual a margem de separação entre as mesmas é maximizada.

Uma propriedade importante das SVMs está na utilizaçāo de kernels. Os kernels são produtos internos das coordenadas de dois vetores, e são utilizados para construção do hiperplano ótimo no feature space sem a necessidade de considerar a forma explícita desse, geralmente bastante complexa (Haykin. 1999). Alguns exemplos de kernel utilizados sāo: o polinomial, o radial e o sigmoidal.

Algumas vantagens apresentadas pelas SVMs sāo:

- trabalham bem quando o conjunto de dados possui uma alta dimensão;

- costumam apresentar uma alta precisão na prediçāo de valores;

- não existe o risco de encontrarem mínimos locais, um problema que ocorre bastante quando se trabalha com redes neurais artificiais.

Uma desvantagem apresentada pelas SVMs é que os modelos fornecidos nāo sāo facilmente compreensiveis ao ser humano.

As SVMs tem despertado grande interesse devido a obtençāo de resultados que superam os obtidos por outras abordagens de aprendizado de máquina na solução de alguns problemas, como por exemplo, na categorizaçāo de textos c na detecção de faces.

Um sistema que pode ser utilizado para realizar experimentos com as SVMs é o mySMV. uma implementaçāo das support vector machines baseada no algoritmo apresentado em (Joachims, 1999). Ele suporta a realização de regressão 
e reconhecimento de padrões, entre outras funcionalidades. Uma das grandes vantagens do mySVM é que ele aceita múltiplos formatos de entrada para os dados, eliminando a necessidade de conversão dos exemplos para um formato especifico (Rüping, 2000).

\subsection{Considerações Finais}

Os diversos métodos existentes para se realizar uma tarefa de regressāo geram modelos em diferentes formatos de represcntação.

Os modelos paramétricos globais são bastante utilizados pela comunidade estatistica. Eles são facilmente interpretados e apresentam soluçōes computacionais rápidas.

Os modelos locais utilizam apcnas os excmplos de treinamento mais similares para fazerem suas predições. Esses modelos apresentam um custo de treinamento mínimo, possuindo um custo mais elevado na fase de prediçāo. Dentre os algoritmos desse tipo, destaca-se o Nearest Neighbor.

Os modelos baseados em aprendizado simbólico possuem como principal característica a compreensibilidade, isto é, fornecem soluções mais facilmente interpretáveis ao ser humano. As regras e árvores sāo modelos desse tipo e sāo as abordagens mais utilizadas pela comunidade de aprendizado de máquina.

Os modelos baseados em redes neurais artificiais permitem a predição de vários atributos-meta e apresentam uma alta precisāo em suas prediçōcs. Já os modelos aditivos decompōem uma função de regressão complexa em várias funçōes simples.

Por fim, os modelos baseados em support vector machines apresentam como principal vantagem o fato de trabalharem bem quando o conjunto de dados possui uma alta dimensāo. 


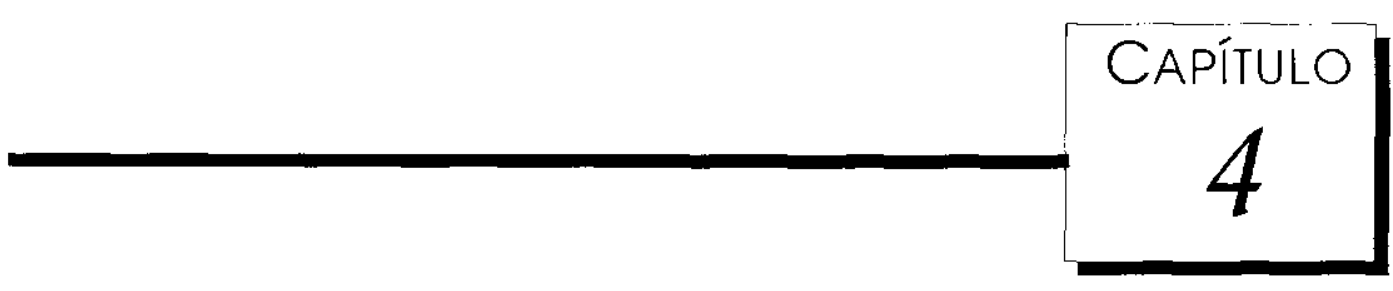

\section{Regressão Simbólica no Processo de Mineração de Dados}

$\mathcal{D}$ os métodos de regressão descritos no capitulo anterior, destacamse aqui aqueles que induzcm regras $e$ árvores de regressão. Esses métodos, conhecidos como métodos de aprendizado simbólico, constituem o foco principal deste trabalho, e caracterizam-se por gerarem modelos compreensiveis.

Este capitulo tem como objetivo apresentar ao leitor o contexto em que se insere este trabalho. Ele faz parte de um projeto maior denominado Discover, que está sendo desenvolvido em nosso laboratório de pesquisa, cujo objetivo é fornecer um ambiente integrado para apoiar as etapas do processo de descoberta do conhecimento. Para isso, nas Seções 4.1 e 4.2 são apresentados, respectivamente, o projeto e o ambiente Discover. Na Seção 4.3 são relatados os trabalhos já realizados e outros que estão em desenvolvimento, para compor o Discover. Na Seçāo 4.4 são apresentados os sistemas e algoritmos de regressão utilizados neste trabalho. Na Seçāo 4.5 é apresentado como este trabalho está integrado ao ambiente Discover. Por fim, na Seçāo 4.6, sāo feitas as consideraçōes finais deste capítulo.

\section{1 O Projeto DISCOVER}

O processo de mineração de dados, descrito no Capitulo 2, considera três grandes etapas, que são: pré-processamento, extração de padrōes e pósprocessamento. Durante a etapa de pré-processamento, várias tarefas se fazem necessárias, como extração, unificação, limpeza (como tratamento de valores ausentes), redução do volume de dados, entre outras.

Na etapa de extração dos padrões, alèm da extração propriamente dita, existem outras tarefas embutidas nessa etapa, como a escolha da atividade e do algoritmo a ser utilizado para extrair os padrōes. Com relação aos algoritmos, a falta de un formato único para os conjuntos de exemplos causa um 
grande transtorno às comunidades de mineração de dados e aprendizado de máquina. Cada algoritmo utilizado para induzir uma hipotese (tanto de regressāo quanto de classificação) possui um formato diferente para seus dados de entrada. Dessa maneira, cada vez que é preciso executar algum desses algoritmos, é necessário converter o conjunto de dados para o formato de entrada desse algoritmo.

Já na fase de pós-processamento, ocorre que as hipóteses induzidas pelos algoritmos (regras e árvores, no caso dos métodos de aprendizado simbólico) possuem formatos diferentes. Em conseqüência, qualquer operaçāo que necessite ser feita sobre a hipótese induzida (como cálculo de medidas, construçāo de tabela de contingência) precisa ser implementada diversas vezes, uma para cada formato de hipótese.

Em nosso laboratório de pesquisa - LABIC - sempre foram realizadas implementações desses tipos por parte de professores e alunos, conforme as necessidades de cada um. Porém, devido a alguns fatores, como a falta de documentaçāo dos programas já implementados, ou porque seus autores se desligavam do laboratôrio, normalmente essas implementações não eram reaproveitadas. Dessa maneira, muitas vezes, um mesmo programa era implementado diversas vezes por diferentes pessoas.

Esses fatores impulsionaram entāo alguns pesquisadores do LABIC a criar um projeto que envolvesse vários membros do laboratório. Esse projeto, que recebeu o nome de DISCOVER, devcria fornecer um ambiente para apoiar as ctapas do processo de descoberta do conhecimento, oferecendo funcionalidades voltadas para aprendizado de máquina, mineraçāo de dados e de tcxtos, como apresentado na Figura 4.1.

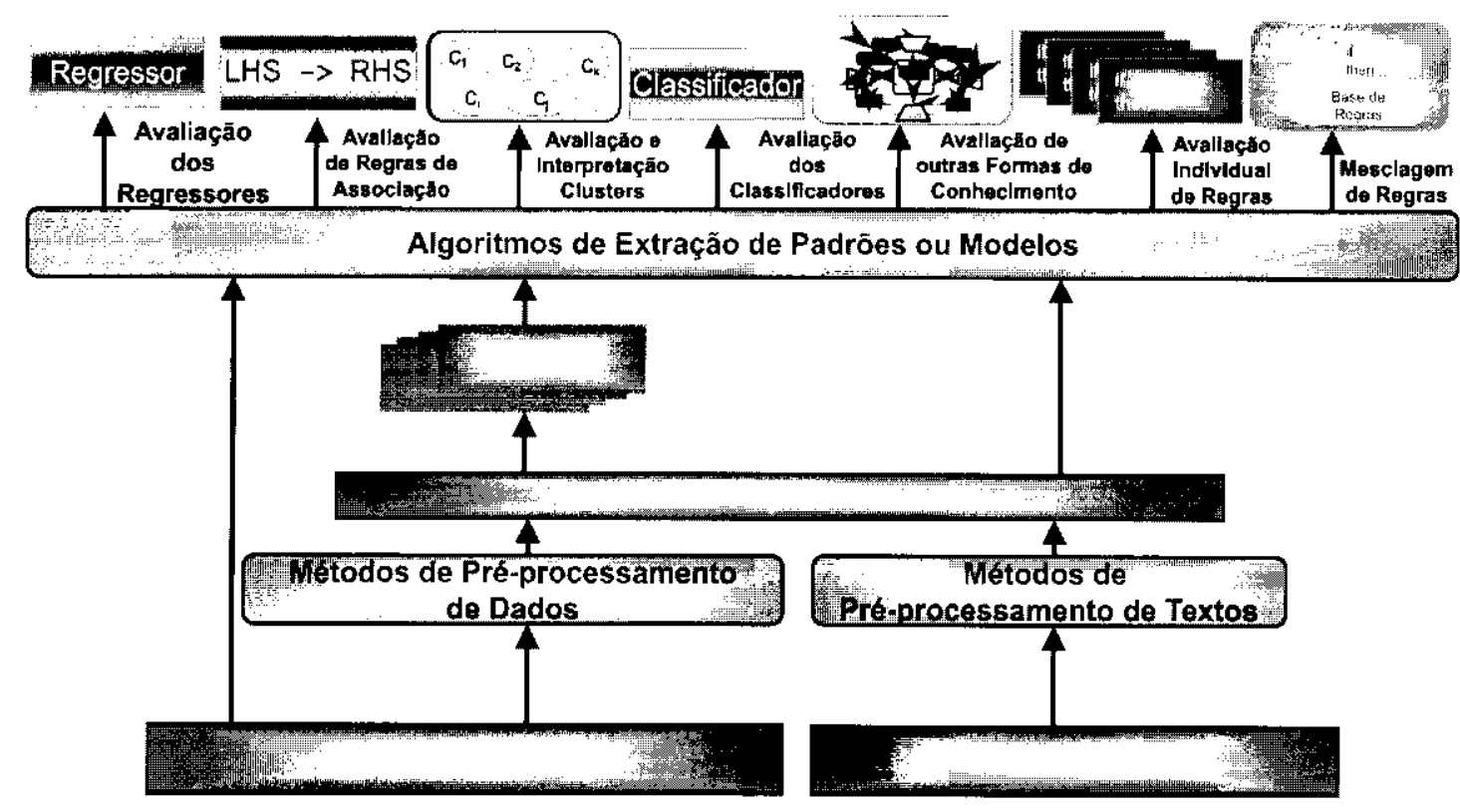

Figura 4.1: Funcionalidades do projeto Discover 


\subsection{O Ambiente DISCOVER}

Em princípio, o projeto Discover consistiria apenas de um repositório de scripts $^{1}$, que seriam implementados na linguagem PERL (Till, 1996) - Practical Extraction and Report Language - e posteriormente reutilizados de modo a facilitar a execuçāo de experimentos. Algumas vantagens dessa linguagem sāo:

- permite desenvolver códigos de maneira bastante rápida;

- fornece um poderoso mecanismo para trabalhar com expressōes regulares, muito utilizadas nessas implementaçōes;

- permite manipular grande quantidade de dados de maneira eficiente e é bastante flexivel com relaçāo aos tipos de dados;

- facilita a escrita de protótipos e scripts, bem como funções genéricas e pacotes:

- alem dessas vantagens, o $\mathrm{CPAN}^{2}$ fornece um excelente repositório de código reusável dessa linguagem.

Portanto, a priori, o projeto Discover consistiria de um conjunto de ferramentas independentes que poderiam ser compostas conforme as necessidades dos usuários, e reunidas em um repositório compartilhado entre esses usuários. Assim, os usuários poderiam combinar essas ferramentas para executar experimentos mais complexos.

Posteriormente, surgiu a proposta de se criar um ambiente integrado, $\mathrm{cm}$ que os scripts seriam substituídos por bibliotecas de classes e essas classes empacotadas como componentes, com a composição deles sendo feita por meio de uma interface gráfica. Dessa maneira, os programas desenvolvidos pelos pesquisadores são os componentes e o DISCOVEr possibilita a construçāo de experimentos por meio da composição desses componentes.

Essa nova abordagem facilitou a utilizaçāo e permitiu obter um melhor desempenho do ambiente. Isso porque nāo é possível compartilhar memória com a utilização de scripts, causando uma sobrecarga com operaçōes de leitura e escrita. No entanto, para tornar o Discover um ambiente integrado, sua implementaçāo tornou-se bem mais complexa. Surgiu a necessidade de uma maior comunicação entre os participantes e de interação entre os diferentes componentes. Com relação à arquitetura do ambiente, em (Prati. 2003) é proposto um framework para a integração dos componentes do ambiente

Scripts são pequenos programas que realizam tarefas atomicas.

${ }^{2}$ hltp://www.cpan.org/ 
Discover baseado em software patterns, no qual os componentes são integrados por meio de uma linguagem baseada em XML. Além disso, a interface gráfica responsável pela composiçāo dos componentes deveria ser implementada de acordo com a arquitetura proposta para o ambiente. Essa interface é apresentada em (Geromini, 2002).

De um modo geral, o Drscover pode ser entendido como um conjunto de métodos aplicados sobre os dados ou sobre o conhecimento extraído a partir dos dados. Dessa maneira, é muito importante que o Discover ofereça uma base sólida para manipular dados e conhecimento. Essa base é composta por sintaxes padrōes utilizadas para representar dados e conhecimento, e por bibliotecas que oferecem um conjunto de funcionalidades básicas de manipulação de dados e conhecimento. A sintaxe padrāo para representaçāo de dados é denominada DSX (Discover Dataset Sintax) e è apresentada em (Batista, 2003). Com relação às sintaxes padrões para representação de conhecimento, destacam-se a sintaxe padrão para regras de decisão (Prati, Baranauskas, \& Monard, 2001b), regras de regressāo (Pugliesi, 2001), regras de associação (Melanda, 2002) e agrupamentos (Martins, 2001).

\subsection{Trabalhos Realizados e em Desenvolvimento}

Como citado, o Discover tem como objetivo integrar os trabalhos desenvolvidos por pesquisadores do LABIC. Existem ferramentas e sistemas que fazem parte do Discover e que já estão implementados, entre os quais destacam-se:

- uma biblioteca que transforma os classificadores simbólicos para o formato padrāo de regras de decisāo do Discover (Prati, Baranauskas, \& Monard, 2001b). É importante destacar que uma biblioteca com a mesma finalidade foi implementada neste trabalho, porém, para as regras de regressão. Essa biblioteca serã detalhada no Capítulo 5;

- um conjunto de ferramentas para processamento de dados, como cálculo de estatísticas descritivas básicas, remoçāo, troca de posição c criação de novos atributos a partir de expressões, embaralhamento, amostragem aleatória e complementar, entre outros (Batista, 2003: Batista \& Monard, 2003);

- o sistema XRULER (Baranauskas, 2001; Baranauskas \& Monard, 2003), no qual um conjunto de exemplos é dividido em amostras de treinamento e teste. As amostras de treinamento são submetidas a diferentes indutores e os classificadores obtidos são convertidos para o formato padrão de regras de decisāo. Entāo, a partir de um subconjunto dessas rcgras que cobrcm os exemplos obtém-se um classificador simbólico final. 
Apesar dos trabalhos já implementados descritos aqui, a grande maioria das ferramentas e sistemas que vão compor o Discover estão sendo desenvolvidos pelos pesquisadores do nosso laboratório, com funcionalidades para processamento de dados (Batista, 2003) e textos (Imamura, 2001; Martins, 2001; Gonçalves, 2002), aprendizado de máquina (Pila, 2001; Bernardini, 2002; Gomes, 2002) e processamento de padrōes (Lee, 2000; Baranauskas, 2001; Pugliesi, 2001; Melanda, 2002; Paula, 2003; Milaré, 2003).

\subsection{Sistemas e Algoritmos de Regressão}

Nesta seção é apresentada uma descrição dos sistemas e algoritmos de regressão utilizados neste trabalho. Os sistemas RT e WEKA são freeware, enquanto que o LABIC possui uma versão do Cubist.

\subsubsection{RT}

O RT (Regression Trees) foi desenvolvido por Luis Fernando Rainho Alves Torgo, do Departamento de Ciências de Computadores da Faculdade de Cièncias da Universidade do Porto (Torgo, 2001). Esse algoritmo permite obter modelos de regressão em diferentes tipos de representação baseados em um conjunto de exemplos fornecido. Alguns tipos de modelos que podem ser obtidos são:

- modelo baseado em árvores de regressão, em que os nós-folhas são rotulados com a média dos valores neles mapeados;

- modelo paramétrico global;

- modelo local, por intermédio do algoritmo K-Nearest Neighbor.

O RT permite ainda, emular os algoritmos de regressão RETIS e CAR'T, descritos a seguir.

RETIS O RETIS (Regression Tree Induction System) é um sistema utilizado para induzir árvores de regressão desenvolvido por Aram Karalic. As árvores de regressāo sāo utilizadas para modelar uma relaçāo linear piecewise entre atributos nominais ou continuos e um atributo-meta continuo (Karalic, 1995). Portanto, esse algoritmo gera uma Model Tree.

CART O algoritmo CART (Classification And Regression Trees) foi desenvolvido por Breiman, Friedman, Olshen e Stone (Breiman et al., 1984).

O algoritmo CART permite a construçāo de árvores de decisāo e árvores de regressão (Regression Trees) realizando um particionando recursivo binário do conjunto de dados e associando a cada nó-folha da árvore uma classe, no caso das árvores de decisāo, ou um valor continuo, no caso das árvores de regressāo. 


\subsubsection{WEKA}

O ambiente WEKA (Waikato Environment for Knowledge Analysis) disponibiliza vários algoritmos de aprendizado de máquina implementados na linguagem Java, desenvolvido na Universidade de Waikato na Nova Zelândia ${ }^{3}$.

No WEKA, cada implementação de um algoritmo de aprendizado é representada por uma classe. A linguagem Java permite que as classes sejam organizadas em pacotes, que sāo simplesmente diretórios contendo uma coleçāo de classes relacionadas. Isso é bastante útil porque certos algoritmos compartilham muitas funcionalidades, e dessa maneira, várias classes em um pacote podem ser utilizadas por mais de um algoritmo (Witten \& Frank, 1999).

O pacote weka.classifiers contém implementaçōes dos algoritmos de classificaçāo c prediçāo numérica do WEKA. A classe weka.classifiers.m5 é a classe que implementa o M5, um algoritmo que trabalha com atributos e classes contínuas descrito em (Quinlan, 1992). O algoritmo M5 possui uma fase de particionamento, que divide o conjunto de dados; uma fase de poda, para reduzir o número de nós da árvore obtida; e uma fase adicional denominada smoothing, que tem como objetivo reduzir a grande diferença dos valores preditos entre os nós-folhas (Wang \& Witten, 1997). O M5 permite obter como modelos de saida tanto uma Model Tree quanto uma Regression Tree. Neste trabalho será utilizado o termo M5 Model quando o algoritmo gera uma Model Tree e M5 Regression quando ele gera uma Regression Tree.

\subsubsection{Cubist}

O Cubist é uma ferramenta utilizada para a geração de modelos preditivos numéricos bascados em regras a partir de um conjunto de dados fornecido. Ele constrói um modelo contendo uma ou mais regras, na qual cada regra é uma conjunçāo de condiçōes associadas com uma expressão linear. Portanto, os modelos gerados pelo Cubist sāo modelos lineares piecewise. Porém, o Cubist permite também construir outros tipos de modelos, como os compostos. que permitem melhorar a precisão da prcdição de um modelo baseado em regras combinando-o com um modelo baseado em exemplos (Nearest Neighbor) (Rulequest-Research, 2001).

Além dos diferentes tipos de modelos que podem ser gerados, o Cubist disponibiliza ainda várias outras funcionalidades, como a utilização de um parâmetro de extrapolaçāo (que controla quais prediçōes feitas pelos modelos lincares do Cubist podem estar fora do intervalo de valores do conjunto de treinamento) e da técnica de cross-validation.

\footnotetext{
"http://www.waikato.ac.nz/
} 


\subsection{Regressão Simbólica no Ambiente DISCOVER}

Como citado, a maioria das pesquisas realizadas nas áreas de aprendizado de máquina e mineração de dados são voltadas para os problemas de classificação. No projeto Discover, a situação não é muito diferente. A maioria dos trabalhos jâ implementados são voltados para problemas desse tipo, como (Prati, Baranauskas, \& Monard, 2001b) e (Baranauskas, 2001). Nesse sentido. este trabalho tem como objetivo auxiliar na preparação dos dados para a construçāo de um modelo de regressão simbólico e sua posterior avaliaçāo dentro do ambiente Discover, oferecendo para isso, métodos a screm utilizados nas etapas de extração dos padrōes, e principalmente, pósprocessamento.

\subsubsection{Preparação dos Dados para Extração dos Padrões}

Como apresentado anteriormente, cada sistema ou algoritmo utilizado para extrair padrōes durante o processo de mineração de dados, independentemente da atividade ou método escolhidos, recebe dados de entrada em um dilerente formato de representação. Os sistemas descritos na seção anterior utilizados para gerar um modelo de regressão (RT, WEKム e Cubist) possuem diferentes formatos para scus dados de entrada, que serão brevemente descritos a seguir. Em seguida, è apresentada a sintaxe padrāo de dados DSX do DIScover, utilizada, entre outros, para converter os dados para os formatos de entrada dos sistemas RT, WEKA e Cubist.

$R T$

O sistema RT utiliza dois arquivos de entrada no formato texto. O primeiro arquivo, que possui a extensāo domain, contém as declarações (nomes e tipos) dos atributos. Um exemplo de arquivo contendo a declaração dos atributos para o R'l é apresentado na Tabela 4.1 .

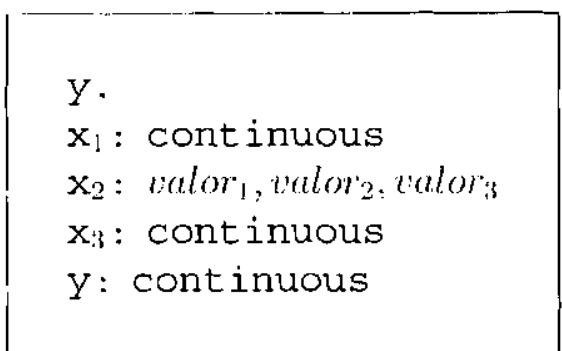

Tabela 4.1: Exemplo de arquivo contendo as declaraçōes dos atributos para o $\mathrm{RT}$

Nesse arquivo, que contém a declaração dos atributos para o R' $\Gamma$, deve ser adicionada uma linha antes de qualquer declaração de atributo, contendo o nome do atributo-meta. Na Tabela $4.1, y$ corresponde ao atributo-meta, e o 
RT tenta obter um modelo de regressão para predizer o valor de $y$ em funçāo dos demais atributos.

O segundo arquivo utilizado como entrada pelo RT é o arquivo .data, que contém o conjunto de dados utilizado para obter o modelo de regressão. Essse arquivo contém tantas linhas quanto for o número de exemplos no conjunto de dados. Cada linha possui uma lista com valores dos atributos, que correspondem aos atributos declarados no arquivo .domain, sendo que a ordem dos valores deve ser a mesma $\mathrm{cm}$ que os atributos foram declarados. Na Tabela 4.2 é apresentado um arquivo de dados contendo cinco exemplos (assumindo que os atributos foram declarados como na Tabela 4.1). Nesse caso, a última coluna corresponde aos valores do atributo-meta.

17.2 , valor $, 4,3.74$

45.8 , valor $, 6,1.26$

54, valor ${ }_{2}, 5,2.79$

22.7, valor $, 4,2.13$

39.5 , valor $_{3}, 5,1.75$

Tabela 4.2: Exemplo de arquivo contendo os dados para o RT

\section{WEKA}

Para utilizar os algoritmos de aprendizado do WEKA, o usuário deve fornecer um arquivo no formato ARFF (Atribute Relation Format File). Esse arquivo contém informações sobre os atributos do conjunto de dados e os valores desses atributos para cada exemplo.

$\mathrm{O}$ arquivo $\Lambda \mathrm{RFF}$ é composto por três partes:

1. o nome do conjunto de dados, introduzido pela tag @relation;

2. os nomes, tipos e valores (no caso de atributos nominais) de cada atributo, definidos pela tag @attribute;

3. os valores dos atributos para cada exemplo do conjunto de dados, que começam após a inserção da tag @data.

Um arquivo no formato ARFF, contendo as mesmas declarações de atributos e dados descritos para o RT, é apresentado na Tabela 4.3. O WEKA assume que o atributo-meta corresponde ao último atributo declarado no arquivo ARFF.

\section{Cubist}

O Cubist, assim como o RT, também utiliza como entrada dois arquivos no formato texto. Porém, existem ainda outros arquivos opcionais, cada um 


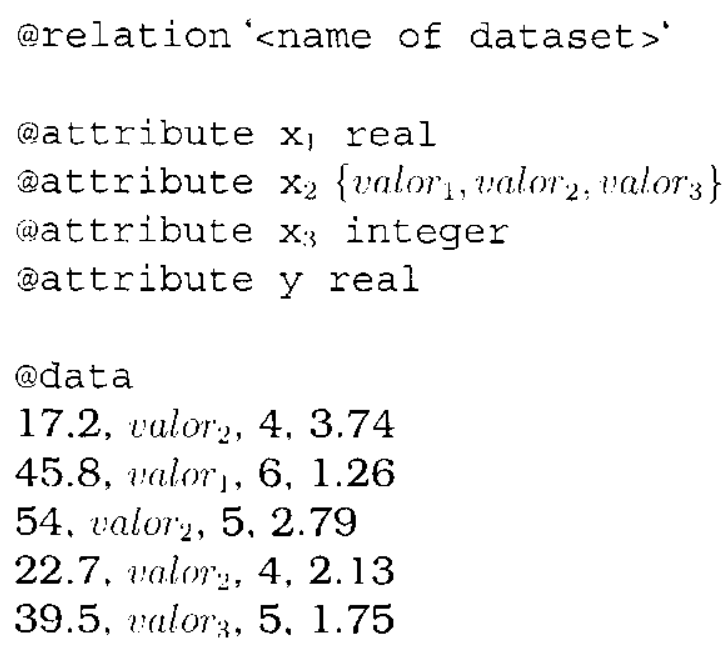

Tabela 4.3: Exemplo de arquivo ARFF para o WEKA

deles identificado por uma extensão diferente (Rulequest-Research, 2001). O primeiro ê o arquivo . names, que define os atributos utilizados para descrever cada exemplo. Existem dois subgrupos importantes de atributos: quando o valor de um atributo é definido explicitamente, sendo fornecido diretamente pelos dados, podendo ser nominais (discrete), numéricos (continuous). tipo data (date), tipo hora (time), tipo hora-data (timestamp), ou ainda do tipo rótulo (label) que serve apenas para identificar um exemplo $\mathrm{cm}$ particular; c quando o valor de um atributo é definido implicitamene, por meio de uma fórmula. O arquivo names é idêntico ao arquivo .domain descrito para o RT, diferenciando-se apenas pela extensão. O segundo arquivo utilizado pelo $\mathrm{Cu}$ bist é o arquivo . data, que fornece os valores do conjunto de dados que o $\mathrm{Cu}$ bist utiliza na construção do modelo. A entrada para cada exemplo consiste de uma linha que fornece os valores dos atributos definidos explicitamente. Esse arquivo é idèntico ao arquivo .data descrito para o RT.

\section{DSX}

A sintaxe padrão DSX, descrita em (Batista, 2001), utiliza arquivos no formato texto para declarar os atributos e seus respectivos tipos, além dos valores que esses atributos assumem em um conjunto de dados. Os atributos são declarados em um arquivo com a extensão . names, e os valores que esses atributos assumem em um conjunto de dados são declarados em um outro arquivo com a extensão data. Os dois arquivos devem possuir o mesmo nome, diferenciando-se apenas pela extensão. Opcionalmente, pode existir também um arquivo de dados com a extensão . test com casos rotulados de teste para calcular medidas de erro e . cases com casos não rotulados para serem rotulados por um regressor ou classificador. 
Essa sintaxe suporta, além dos tipos de dados mais comuns, como os tipos numérico (real e integer) e nominal (nominal), alguns tipos de dados mais sofisticados, como o tipo enumerated, (semelhante ao tipo de dado nominal, com a diferença de que com o tipo enumerated é possivel definir uma ordem entre os valores que o atributo pode assumir) e o tipo string (utilizado no processo de mineração de textos). Uma descrição completa da sintaxe DSX ć feita em (Batista, 2003).

Nas Tabelas 4.4 e 4.5 sāo apresentados, respectivamente, um exemplo de um arquivo . names e de um arquivo . data, baseado nas mesmas declarações de atributos e dados feitas para os sistemas RT e WEKA.

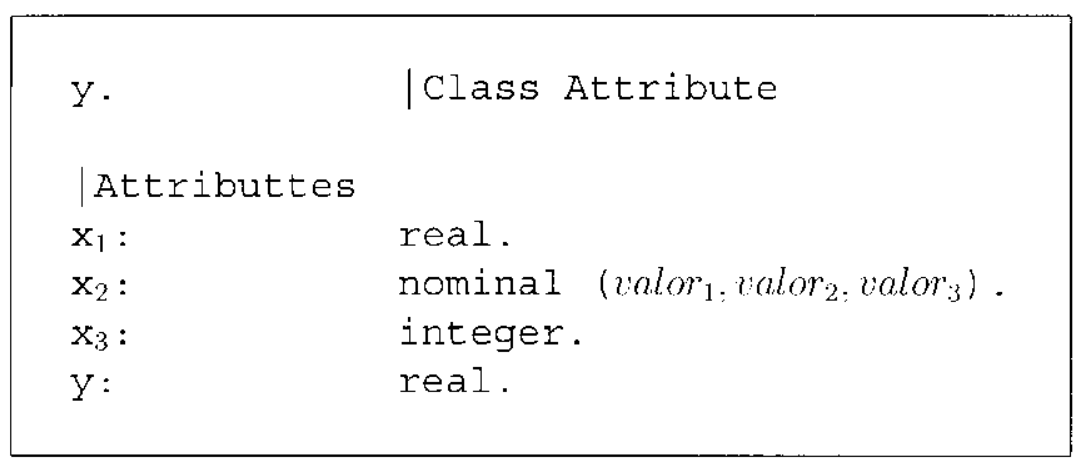

Tabela 4.4: Exemplo de arquivo . names da sintaxe DSX

17.2, walor $2,4,3.74$

45.8, valor $, 6,1.26$

54 valor $_{2}, 5,2.79$

22.7, valor $, 4,2.13$

39.5 , valor $_{3}, 5,1.75$

Tabela 4.5: Exemplo de arquivo .data da sintaxe DSX

Baseado nessa sintaxe padrão de exemplos, foram definidas então algumas classes que convertem um arquivo de dados no formato da DSX para o formato dos dados de entrada dos sistemas de regressão RT, WEKA e Cubist. Dessa maneira, uma vez que o usuârio do ambiente Discover possui uma base de dados no formato padrão de exemplos DSX, ele pode converter esses dados para o formato de entrada do RT, WEKA ou Cubist. e assim, executar qualquer um dos algoritmos de regressão suportados por esses sistemas, como apresentado na Figura 4.2.

\subsubsection{Método Cross-Validation}

Como descrito anteriormente, é importante avaliar a precisão de um modelo com exemplos que não foram utilizadas em seu treinamento, como na técnica de cross-validation. A técnica do $k$-fold cross-validation consiste em 


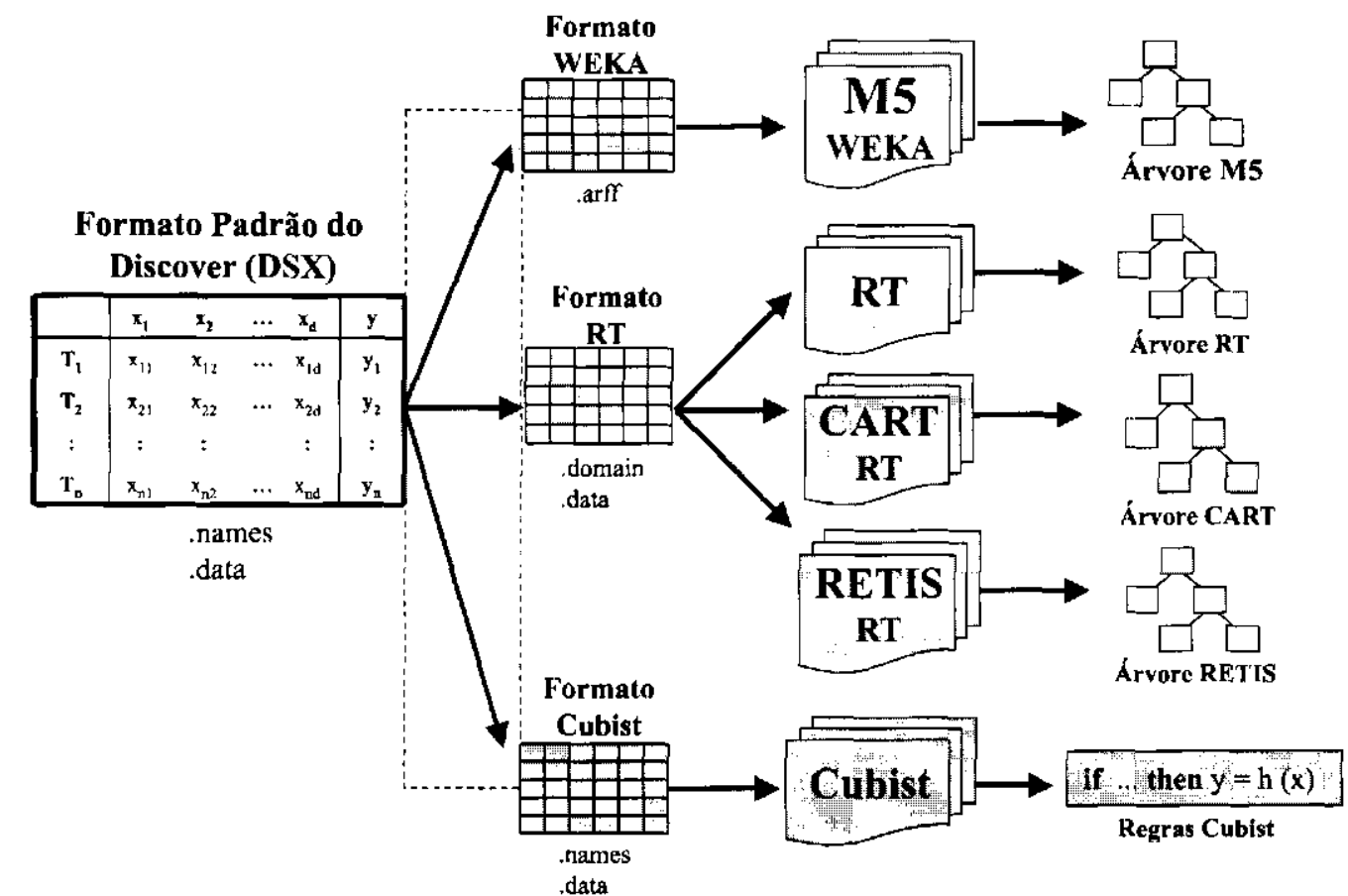

Figura 4.2: Preparação dos dados para a geração de um regressor

dividir aleatoriamente o conjunto de exemplos em $k$ : partiçōes mutuamente exclusivas de tamanhos aproximadamente iguais. O processo é realizado um número $k$ de vezes, sendo que em cada vez $(k-1)$ partições são utilizadas para treinamento, e a partição restante é utilizada para testar a hipótese induzida. $O$ erro no método cross-validation consiste na média dos erros calculados para cada um dos $k$-folds.

Para testar um regressor em um conjunto de dados diferente daquele utilizado em sua geração foi construída neste trabalho uma classe denominada RegCV, que implementa o método cross-validation. Para a utilização dessa classe, o conjunto de dados deve estar no formato padrāo DSX de exemplos do DISCOVER.

\subsubsection{Pós-Processamento}

A obtenção de um modelo ao final da etapa de extraçāo de padrōes do processo de mineração de dados não é o passo final do processo. Depois de obtido um modelo (por exemplo, uma árvore ou um conjunto de regras) é preciso avaliar esse modelo para testar se ele é eficiente na prediçāo do valor do atributo-meta de novos exemplos, verificar o seu grau de compreensibilidade e constatar se o conhecimento obtido por esse modelo é novo ou não.

Para avaliar esses fatores (precisão, compreensibilidade e interessabilidade) é comum efetuar o cálculo de algumas medidas que permitem expressar tais fatores em números, e dessa maneira, avaliá-los de uma maneira mais sistemática. Além de avaliar esses fatores, existem ainda outros pon- 
tos importantes que devem ser levados em consideração na etapa de pósprocessamento. Um desses pontos diz respeito ao tratamento realizado com a hipótese induzida, nesse caso, uma árvore ou um conjunto de regras de regressāo. Uma padronizaçāo das diferentes representaçōes dessas hipóteses em um formato único de regras apresenta-se de extrema importância, uma ve $z$ que facilita qualquer tipo de implementaçāo que precise ser realizada sobre essas regras, além de permitir comparar as hipóteses induzidas pelos diferentes algoritmos de regressão. Ainda com relação ao conjunto de regras padronizadas, a aplicação de um filtro que reduza o número de regras, ou que reduza o número de condições dessas regras também pode ser bastante ütil.

No caso da regressāo, como existem poucas medidas utilizadas para avaliar os modelos gerados no processo de mineração de dados, é importante investigar novas maneiras de se avaliar o conhecimento embutido nesses modelos.

Neste trabalho foram implementadas uma série de métodos que auxiliam na avaliaçāo de um modelo de regressāo simbólico na etapa de pós-processamento do processo de mineração de dados. Cada método implementado corresponde a uma classe, compondo assim, uma biblioteca de classes, descrita no próximo capitulo.

\subsection{Considerações Finais}

O Discover é um projeto que está sendo desenvolvido em nosso laboratório de pesquisa com o objetivo de fornecer um ambiente para apoiar as etapas do processo de descoberta do conhecimento. Trata-se de um ambiente integrado em que os programas desenvolvidos pelos pesquisadores são componentes, possibilitando então a construção de experimentos complexos por meio da composição desses componentes. Este trabalho, mais um dos projctos integrado ao ambiente Discover, tem como objetivo permitir a construção de um modelo de regressāo simbólico e sua posterior avaliação.

Neste trabalho foram utilizados os sistemas de regressão RT, WEKA e Cubist. O primeiro gera como saida uma Regression Tree, c pcrmite ainda emular os algoritmos de regressāo RETIS e CART. O WEKA disponibiliza vários algoritmos na linguagem Java, sendo um desses algoritmos o M5, que permite obter como saida uma Model Tree ou uma Regression Tree. Já o Cubist gera um conjunto de regras com uma expressão linear associada a cada uma dessas regras.

Cada um desses sistemas (RT, WEKA e Cubist) possui um formato diferente para seus dados de entrada, que foram brevemente descritos neste capitulo. Baseada na sintaxe padrāo de dados DSX definida para o DISCover foram definidas algumas classes que convertem um arquivo de dados no formato da DSX para os formatos de entrada dos sistemas de regressão RT, WEKA e 
Cubist. Dessa maneira, os usuários do DISCOVER podem facilmente converter uma base de dados no formato DSX para qualquer um desses sistemas, e assim, executar os algoritmos de regressão por eles suportados.

Com os dados padronizados na sintaxe padrāo de dados DSX, pode-se utilizar a classe RegCV que implementa o método cross-validation, para testar os regressores com um conjunto de exemplos diferente daquele utilizado em sua geração.

Depois de extraídos os padrōes no processo de mineração de dados, a próxima etapa do processo é a de pós-processamento, em que os modelos de regressāo gerados precisam ser avaliados com relação a alguns fatores, como precisão, compreensibilidade e interessabilidade. Neste trabalho foram implementados métodos que realizam essas avaliaçōes, além de outras funcionalidades que auxiliam na etapa de pós-processamento, ou avaliaçāo do conhecimento. Esses métodos serāo detalhados no próximo capítulo por constituirem o foco principal deste trabalho. 


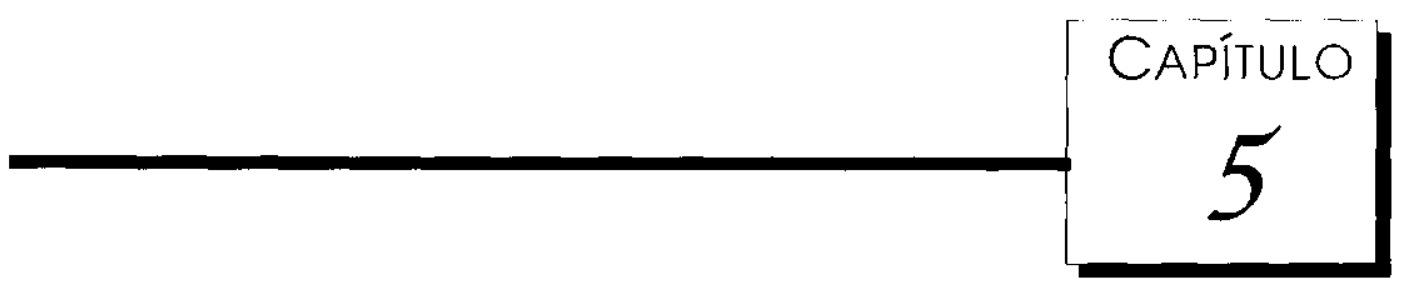

O Ambiente DIPER

$\mathcal{A}$

etapa de pós-processamento do processo de mineração de dados tem como objetivo avaliar o modelo resultante da extração de padrōes.

Neste trabalho, os modelos obtidos são regras e árvores de regressão. Dessa mancira, è muito importante avaliar esses modelos com relação a alguns fatores, como precisāo, compreensibilidade e interessabilidade. A precisão diz respeito à eficiência com que o modelo prediz o valor do atributo-meta de novos exemplos. A compreensibilidade não é fácil de ser medida, e envolve alguns fatores, como a capacidade de abstração do usuário. Já a interessabilidade é responsável por verificar se o conhecimento obtido por esse modelo é novo ou não, e no caso de se tratar de um novo conhecimento, constatar se ele é interessante e útil para os usuários do processo de mineração de dados. Alèm disso, existem outras operaçōes que sāo realizadas depois da extração de um modelo. por exemplo, comparar modelos resultantes da indução de diferentes algoritmos.

Neste capítulo é apresentado o ambiente DiPER (Discover Post-PRocesSING ENVIRONMENT OF REGRESSION) implementado e integrado ao Discover neste trabalho. Na Seção 5.1 é descrito o processo de conversão dos regressores baseado na sintaxe padrão de regras de regressão do Discover, uma ve $z$ que os algoritmos de regressão simbólicos executados geram diferentes hipóteses. Com os regressores padronizadas em um formato único, torna-se possivel comparả-los, além de facilitar implementaçōes futuras necessárias. Na Seção 5.2 é descrito o tratamento semântico aplicado ao conjunto de regras de regressão, com o objetivo de melhorar a compreensibilidade das regras e aumentar o desempenho dos programas que utilizam esse conjunto de regras como entrada. Na Seção 5.3 são apresentadas as medidas utilizadas para calcular a precisāo dos algoritmos de regressāo baseadas na diferença entre o valor real e o valor predito do atributo-meta, além de algumas medidas de compreensibilidade. Porém, como existem poucas medidas que podem ser aplicadas aos problemas de regressāo neste trabalho foi definida uma es- 
tratégia para calcular a tabela de contingência para uma regra de regressão. Todo o processo utilizado para construir essa tabela, o modo como são calculadas as medidas dela derivadas e a interpretação dessas medidas para os problemas de regressão são descritos na Seção 5.4. Essas funcionalidades descritas podem ser visualizadas na Figura 5.1. Ainda com relação ao pósprocessamento de regressão simbólica, não é fácil decidir se um algoritmo é melhor que outro levando-se em consideração apenas medidas de erro obtidas sobre os regressores extraidos desses algoritmos. Para decidir qual algoritmo de regressão é melhor que outro com um grau de confiança de $95 \%$ foi realizado neste trabalho um teste de hipóteses, apresentado na Seçāo 5.5. Por fim. na Seçāo 5.6 são feitas as consideraçōes finais deste capítulo.

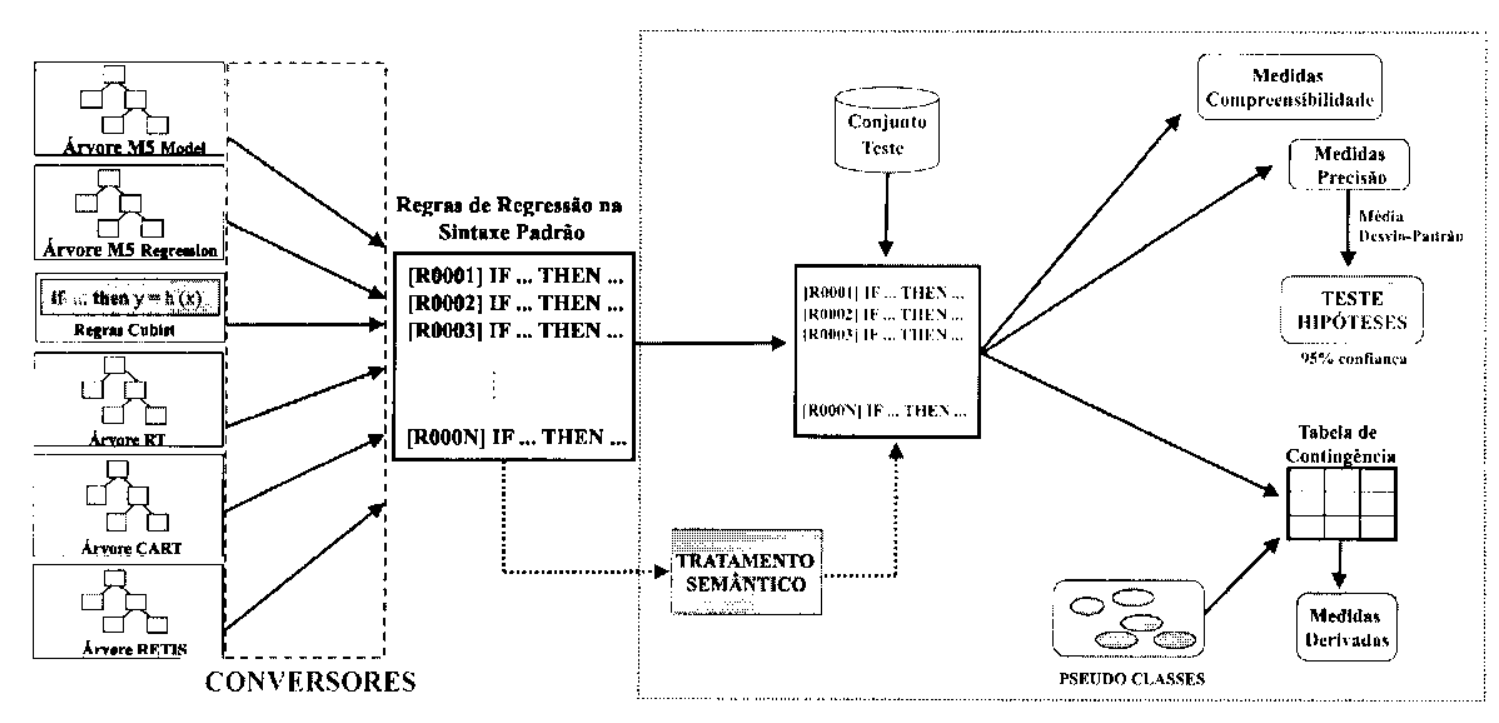

Figura 5.1: Funcionalidades do ambiente DIPER

\subsection{Conversão dos Regressores}

Os métodos de regressão simbólicos geram como saída hipóteses no formato de regras e árvores. Como apresentado anteriormente, as regras sāo diferente das árvores. E mesmo as árvores geradas por diferentes algoritmos são distintas umas das outras: elas diferem no modo como ė particionado o conjunto de dados, na escolha dos atributos e valores utilizados nos nós internos da árvore, no modo como predizem o valor do atributo-meta em seus nós-folha, nos mecanismos de poda e no formato em que a árvore pode ser visualizada.

Os algoritmos de regressão simbólicos utilizados neste trabalho, juntamente com a forma como representam suas hipótcses, são apresentados na Tabela 5.1

Devido aos diferentes formatos de representação das hipóteses geradas por esses algoritmos, qualquer medida ou estatística que precisasse ser calculada 


\begin{tabular}{|c|c|}
\hline Algoritmo & Forma de Representação \\
\hline \hline Cubist & Conjunto de regras de regressão \\
\hline M5 WEKA & Model Tree ou Regression Tree \\
\hline RT & Regression Tree com desvios-padrōes \\
\hline RETIS RT & Model Tree \\
\hline CART RT & Regression Tree com desvios-padrōes \\
\hline
\end{tabular}

Tabela 5.1: Formas de representação de hipótesc dos algoritmos de regressão utilizados neste trabalho

sobre as hipoteses teria de ser implementada várias vezes, uma para cada formato de hipótese. Dessa maneira, foi definida então uma sintaxe padrão de regras de regressão para o ambiente Discover. A gramática dessa sintaxe, apresentada na Figura 5.2, è descrita detalhadamente em (Pugliesi, Dosualdo, \& Rezende, 2003). Baseado nessa sintaxc, padroniza-sc os regressores convertendo-os para um formato único. Além de facilitar a implementaçāo de medidas e cálculos a serem efetuados sobre as hipóteses, isso permite comparar os regressores gerados pelos diferentes algoritmos.

O processo de conversāo dos regressores funciona da seguinte maneira: primeiramente, o conjunto de dados é submetido a algum dos possiveis algoritmos de regressāo, e a saida por eles gerada è salva com a extensão .out. Em seguida, utiliza-se a classe RegConvert construída neste trabalho, quc contém os métodos que convertem a saída de cada algoritmo para o formato padrāo de regras de regressāo, para gerar entāo um arquivo com a extensão .rules, que contém o regressor no formato padrāo definido para o ambicnte Discover.

Independentemente do algoritmo de regressão utilizado para induzir a hipótese, o conjunto de regras padronizado obtido a partir dessa hipótese, apresenta o formato apresentado na Figura 5.3.

\subsection{Tratamento Semântico de Regras de Regressão}

Muitas vezes, depois que os regressores sāo convertidos para o formato padrāo de regras de regressão, as regras que constituem esse regressor podem possuir condiçōes desnecessárias, principalmente quando o conjunto de regras é derivado de uma árvore. Isso acontece porque em muitos casos um mesmo atributo é utilizado para particionar o conjunto de dados em diferentes niveis de uma ärvore assumindo diferentes valores, o que faz com que uma condição sobreponha a outra, tanto no caso de atributos numéricos quanto nominais. Nesse sentido, aplica-se entāo um tratamento semântico ao arquivo .rules, que contém as regras no formato padrão com o objetivo de excluir as condiçōes desnecessárias de cada regra. Esse tratamento apresenta duas vantagens: 


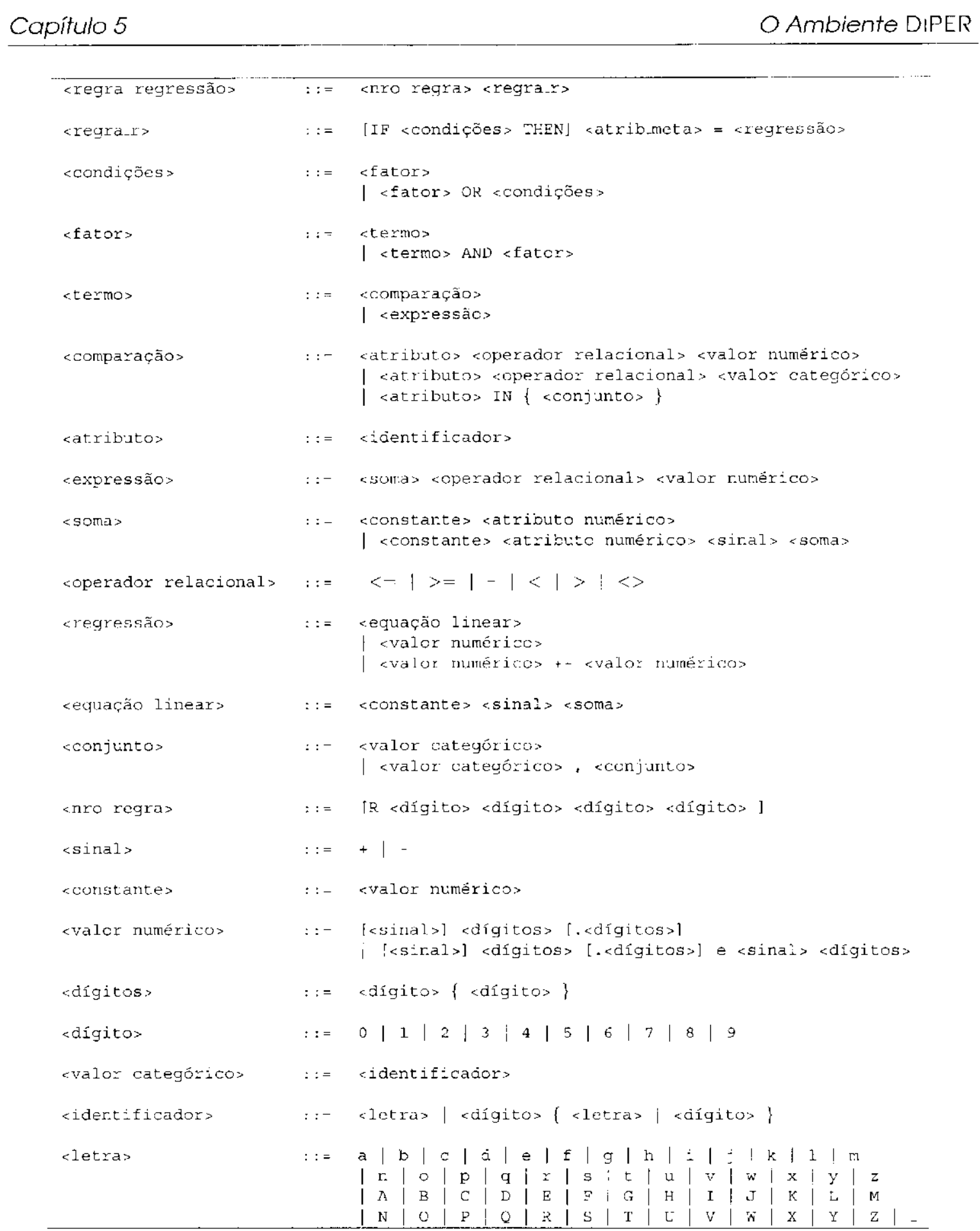

Figura 5.2: Gramática da sintaxe padrão de regras de regressão

1. melhora a compreensibilidade da regra, visto que quanto maior o número de condiçōes, mais dificil o entendimento da regra;

2. aumenta o desempenho dos programas que utilizam essas regras como entrada, já que muitos testes desnecessários são evitados. Isso se apresenta extremamente importante quando o arquivo de regras é extenso e o número de exemplos de teste é grande.

Para realizar o tratamento semântico, utiliza-se a classe RegSemantic implementada neste trabalho para gerar um arquivo com a extensão .Srules, 


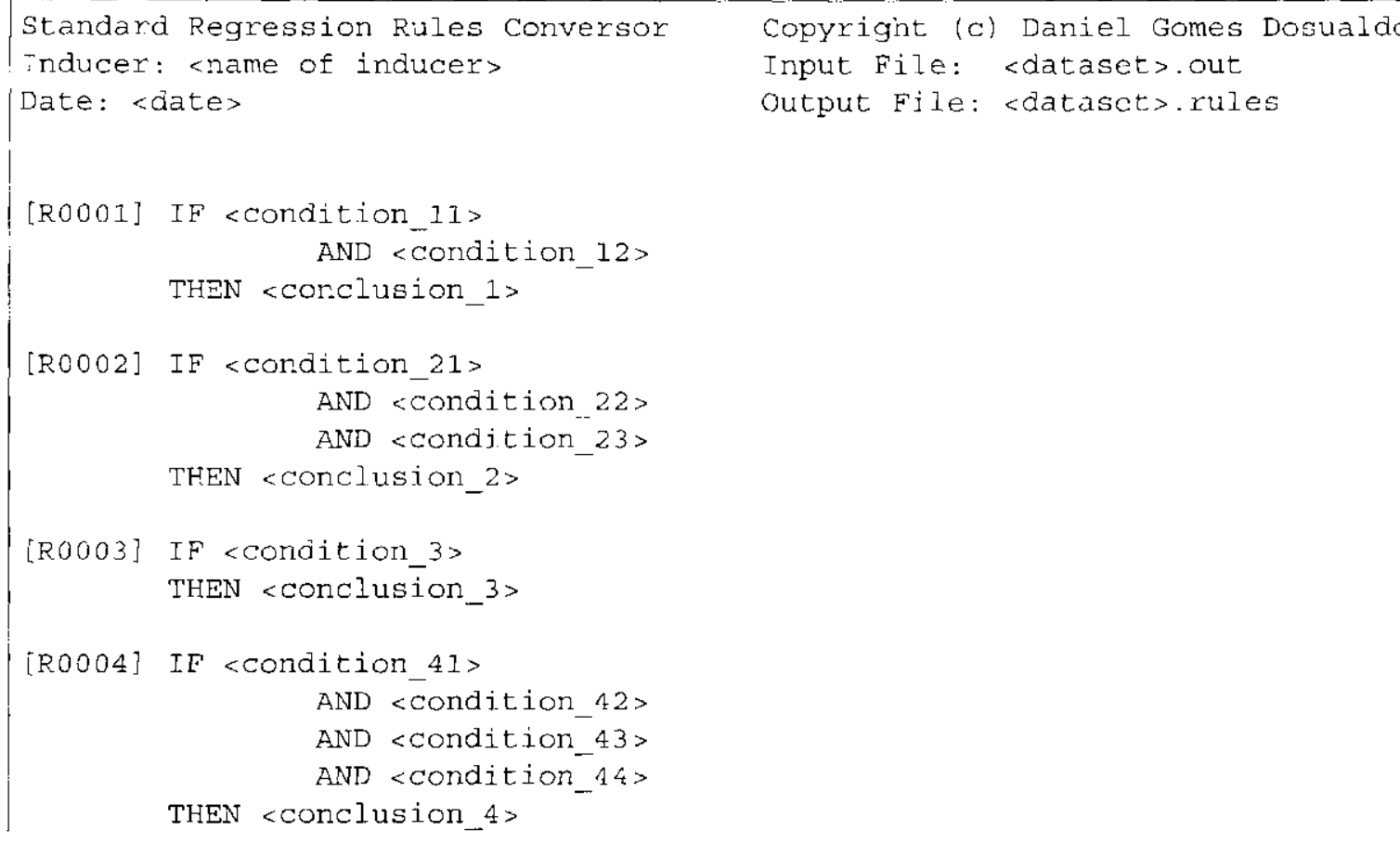

Figura 5.3: Conjunto de regras padronizadas

contendo as regras semanticamente tratadas.

\subsubsection{Atributos Numéricos}

O problema com os atributos numéricos acontece quando existem várias condiçōes em uma regra sobre um mesmo atributo numérico com diferentes valores sobre um mesmo operador $(<,<=,>$, $>=)$, fazendo com que tais condições se sobreponham. A solução nesse caso consiste em encontrar o intervalo correto para esse atributo numérico.

Por exemplo, seja um conjunto de dados $\operatorname{com} x_{1}, x_{2}$ e $x_{3}$ atributos numéricos, e uma regra de regressão como apresentada na Figura 5.4 .

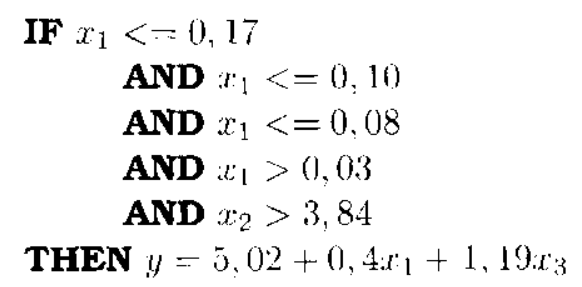

Figura 5.4: Regra de regressão com condições desnecessárias sobre atributo numérico

Logo, percebe-se que as duas primeiras condiçōes da regra não sāo necessárias, uma vez que a terceira condição $\left(x_{1}<=0,08\right)$ sobrepõe as duas primeiras. Dessa maneira, após o tratamento semântico, obtém-se a regra de regressão da Figura 5.5. 


$$
\begin{aligned}
& \text { IF } x_{1}<=0,08 \\
& \text { AND } x_{1}>0.113 \\
& \text { AND } x_{2}>3.84 \\
& \text { THEN } y-5,02+0.4 x_{1}+1,19 x_{3}
\end{aligned}
$$

Figura 5.5: Regra de regressão com tratamento semântico sobre atributo numérico

\subsubsection{Atributos Nominais}

Com os atributos nominais, o problema ocorre quando existe mais de uma condição sobre um mesmo atributo nominal em uma determinada regra. A solução aqui consiste em encontrar a intersecção dos valores nominais entre todas as condições que aparecem naquela regra para o atributo nominal em questão.

Seja um conjunto de dados sobre automóveis com dois atributos numéricos $x_{1}$ e $x_{2}$ e um atributo nominal $x_{3}$ assumindo os valores $\mathrm{gm}$, ford, fiat, wolksvagem, toyota, peugeot. audi e renaux. Agora considere a regra de regressão apresentada na Figura 5.6.

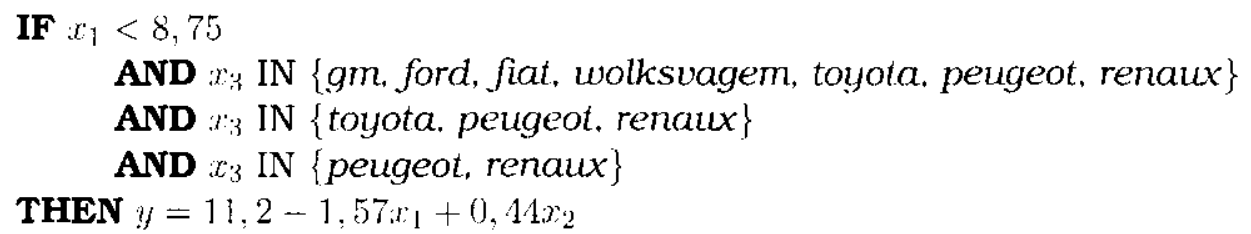

Figura 5.6: Regra de regressão com condições desnecessárias sobre atributo nominal

Analisando a regra, nota-se que para um exemplo de teste ser coberto por essa regra, o atributo nominal $x_{3}$ deve assumir os valores peugeot ou renaux. Assim sendo, com o tratamento semântico, obtém-se a regra da Figura 5.7. Nota-se claramente a maior compreensibilidade dessa regra, comparando-a com a regra antes da aplicação do tratamento semântico.

$$
\begin{aligned}
& \text { IF } x_{1}<8.75 \\
& \quad \text { AND } x_{3} \text { IN \{toyota, peugeot\} } \\
& \text { THEN } y-11,2-1,57 x_{1}+0,14 x_{2}
\end{aligned}
$$

Figura 5.7: Regra de regressão com tratamento semântico sobre atributo nominal

\subsection{Cálculo de Medidas de Regressão}

Neste seção são apresentadas algumas medidas implementadas no ambiente de regressão simbólica do DISCOVER utilizadas para calcular a precisāo e a compreensibilidade dos regressores gerados. As medidas de precisão aqui descritas, MAD e MSE, são baseadas na diferença entre o valor real do 
atributo-meta e o valor predito pelo algoritmo. As medidas MAD e MSE, assim como algumas medidas de compreensibilidade, podem ser calculadas por intermédio da classe RegMeasures implementada neste trabalho.

\subsubsection{Medidas de Precisão}

As regras de regressão, apesar de serem semelhantes às regras de classificação, predizem um valor numérico ao invés de um valor nominal, envolvendo um grau de incerteza quanto à classe predita (Cheng, 1998).

As medidas mais utilizadas para avaliar a precisão das hipóteses induzidas em problemas de regressāo sāo: MAD (Mean Absolute Deviation) e MSE (Mean Squared Error) (Merz, 1998; Torgo, 1995).

A medida MAD consiste na média da diferença (em módulo) entre os valores reais e preditos para um atributo-meta. Seja $h_{i}$ a hipótese construída pelo algoritmo na $i$-ésima partiçāo. O valor da MAD calculado em cada uma das partições é obtido por meio da Equaçāo 5.1.

$$
M A D\left(h_{i}\right)=\frac{1}{n_{\text {teste }}} \sum_{j=1}^{u_{t}: s+e}\left|y_{j}^{\prime}-y_{j}\right|
$$

na qual $n_{t c s t,}$ corresponde ao número de exemplos do arquivo de teste; $y_{j}^{\prime}$ corresponde ao valor predito pelo algoritmo no $j$-ésimo exemplo de teste; e $y_{j}$ é o valor real do atributo-meta desse mesmo exemplo.

A medida MSE consiste na média da diferença ao quadrado entre os valores reais e preditos para um atributo-meta. Novamente, considerando $h_{i}$ como sendo a hipótese gerada na $i$-ésima partição, o valor da MSE calculado em cada partição é obtido por meio da Equaçāo 5.2.

$$
M S E\left(h_{i}\right)=\frac{1}{n_{\text {teste }}} \sum_{j=1}^{n_{\text {teteste }}}\left(y_{j}^{\prime}-y_{j}\right)^{2}
$$

Analisando as fórmulas dessas duas medidas, nota-se que a medida MSE valoriza as hipóteses cujas diferenças entre os valores reais e preditos do atributo-meta não são muito discrepantes. Por exemplo. considere duas hipóteses $h_{1}$ e $h_{2}$ e um conjunto de cinco exemplos com os seguintes valores reais do atributo-meta: $3,74,1,26,2,79,2,13$ e 1,75. Nas Tabelas 5.2 e 5.3 sāo apresentados, respectivamente, os valores preditos pelas hipóteses $h_{1} \mathrm{e}$ $h_{2}$, bem como o cálculo das medidas MAD e MSE. De acordo com as tabelas, verifica-se que a hipótese $h_{1}$ apresenta uma MAD menor e uma MSE maior que $h_{2}$. Isso acontece porque, apesar de quatro exemplos do conjunto de dados serem melhor preditos pela hipótese $h_{1}$ do que pela $h_{2}$, fazendo com que $h_{1}$ apresente uma MAD menor, a diferença entre o valor real e o valor predito por $h_{1}$ no quarto exemplo do conjunto de teste é muito grande, o que acarreta em grande aumento da medida MSE. Já a hipótese $h_{2}$ não apresenta ncnhuma 
diferença tāo grande entre os valores reais e preditos, o que faz com que o valor da medida MSE seja menor que a mesma medida para $h_{1}$, porém com a MAD maior.

\begin{tabular}{|c|c|c|c|}
\hline Valor Real $\left(y_{j}\right)$ & Valor Predito $\left(y_{j}^{\prime}\right)$ & $\left|y_{j}^{\prime}-y_{j}\right|$ & $\left(y_{j}^{\prime}-y_{j}\right)^{2}$ \\
\hline \hline 3,74 & 4,97 & 1,23 & 1,5876 \\
\hline 1,26 & 1,82 & 0,56 & 0,3136 \\
\hline 2,79 & 3.15 & 0.36 & 0.1296 \\
\hline 2,13 & 7.99 & 5.85 & 34,2225 \\
\hline 1,75 & 2.79 & 1.04 & 1.0816 \\
\hline \hline$M A D=(9,05 / 5)=1,81$ & \\
$M S E$ & $=(37,3349 / 5)=7.46698$ \\
\hline
\end{tabular}

Tabela 5.2: Cálculo das medidas MAD e MSE sobre uma hipótese $h_{1}$

\begin{tabular}{|c|c|c|c|}
\hline Valor Real $\left(y_{j}\right)$ & Valor Predito $\left(y_{j}^{\prime}\right)$ & $y_{j}^{\prime}-y_{j}$ & $\left(y_{j}^{\prime}-y_{j}\right)^{2}$ \\
\hline 3.74 & 5,02 & 1.28 & 1,6384 \\
\hline 1.26 & 4,14 & 2,88 & 8,2944 \\
\hline 2,79 & 4,93 & 2.14 & 4,5796 \\
\hline 2,13 & 5.28 & 3,15 & 9.9225 \\
\hline 1,75 & 3,85 & 2,10 & 4,4100 \\
\hline \multicolumn{4}{|c|}{$M A D=(11,55 / 5)=2,31$} \\
\hline
\end{tabular}

Tabela 5.3: Cálculo das medidas MAD e MSE sobre uma hipótese $h_{2}$

Por se tratarem das medidas mais comumente utilizadas para calcular a precisão em problemas de regressāo, as medidas MAD e MSE descritas podem ser calculadas por meio da classe RegMeasures.

\subsubsection{Medidas de Compreensibilidade}

Medir a compreensibilidade de uma hipótese induzida, tanto para um problema de regressāo quanto de classificaçāo, não é uma tarefa fácil. No que diz respeito aos métodos de aprendizado simbólico, existe uma antiga discussão sobre qual forma de representar uma hipótcse é mais compreensivel ao usuário: uma árvore ou uma regra? Em (Information Discovery, 2003), são apresentadas uma série de vantagens das regras sobre as árvores, porćm, essa discussāo nāo faz parte do âmbito deste trabalho.

A compreensibilidade é dependente de vários fatores, como:

- a capacidade de abstração do usuário;

- a forma de representação da hipótese induzida;

- o tamanho e a variaçāo dos valores do conjunto de dados. Por exemplo, quanto maior o número de exemplos e maior a variaçāo dos valores de 
seus atributos, maior tende a ser a árvore induzida, e portanto, mais dificil tende a ser sua compreensão.

Para regras de regressão, um fator de compreensibilidade pode ser o número de condiçōes da regra, visto que quanto maior o número de condições, mais dificil seu entendimento por parte do usuário. Além disso, o número de termos existentes na equação linear que prediz o valor do atributo-meta (para as regras que utilizam uma equação para fazer a prediçāo) também está relacionado com a compreensibilidade da regra, uma vez que um número muito grande de termos compromete a compreensão da conclusāo da regra. Já para as regras que predizem o valor do atributo-meta por meio de um valor constante, esse fator nāo pode ser aplicado.

Dessa maneira, a classe RegMeasures possibilita que o usuário saiba qual o número de condições de cada regra de regressão, assim como o número de termos da equação linear, quando a regra prediz o valor do atributo-meta por meio de uma equação.

\subsection{Tabela de Contingência para Regras de Regressão}

Diferentemente de outros problemas, como os de classificação, existem poucas medidas que podem ser utilizadas em problemas de regressão. Nesta seção é descrito um procedimento que permite construir uma tabela de contingência para uma regra de regressão. Após construída essa tabela, torna-se possivel calcular várias medidas, que normalmente não poderiam ser aplicadas aos problemas de regressão.

Para isso, primeiramente será definida uma tabela de contingência, como ela é calculada, e quais são as medidas derivadas a partir dela. Em seguida, é apresentado o algoritmo P-Class, utilizado na definição dessa tabela. Por fim, é detalhado o processo de geração da tabela de contingencia para regras de regressāo.

\subsubsection{Tabela de Contingência e Medidas Derivadas}

Como descrito na Sub-seção 3.3.1, considere uma regra de decisāo $B \rightarrow H$, em que $\|$ é a classe associada. Diz-se que um exemplo é coberto por uma regra $B \rightarrow H$ quando todas as condições da regra são satisfeitas.

Dessa maneira, calcula-se a tabela de contingência para uma regra conforme a Tabela 5.4. Nessa tabela, $B$ denota o conjunto de exemplos para os quais todas as condiçōes da regra sāo verdadeiras e $\bar{B}$ denota seu complemento (conjunto de exemplos para os quais pelo menos uma das condições e falsa). Analogamente, $I$ denota o conjunto de exemplos para os quais a conclusāo da regra é verdadeira (ou seja, a classe é predita corretamente) e $\bar{H}$ seu complemento. Conseqüentemente, $I J B$ denota o conjunto de exemplos 
em que $B$ e $H$ são verdadeiros, $\bar{H} B$ denota o conjunto de exemplos em que $B$ é verdadeiro e $H$ é falso, e assim por diante. Finalmente, $N$ denota o número total de exemplos (Lavrac, Flach, \& Zupan, 1999).

$$
\begin{array}{c|c|c|c} 
& B & \bar{B} & \\
\hline H & n(I I B) & n(I \bar{B}) & n(I I) \\
\bar{I} & n(\bar{H} B) & n(\overline{I I B}) & n(\bar{M}) \\
\hline & n(\bar{B}) & n(\bar{B}) & N
\end{array}
$$

Tabela 5.4: Tabela de contingência para a regra $B \rightarrow I I$

De um modo geral, a freqüência relativa associada ao conjunto $X$ é calculada como $n(X) / N$ e denotada por $p(X)$, podendo ser utilizada como uma estimativa da probabilidade. Sendo assim, considerando o conjunto $H B$, a probabilidade $p(H B)$ é determinada de acordo com a Equaçāo 5.3.

$$
p(H B)=\frac{n(H B)}{N}
$$

A partir da tabela de contingência apresentada são definidas então uma sćrie de medidas sobre regras calculadas em termos de estimativas de probabilidade, descritas a seguir.

\section{Precisão (AcC)}

A precisão de uma regra $B \rightarrow H$ é definida como a probabilidade condicional de $I I$ ser verdade dado que $B$ é verdade. É definida por:

$$
A c r(B \rightarrow H)=\frac{n(H B)}{n(B)}=\frac{\frac{n(H B)}{N}}{\frac{n(H)}{N}}=\frac{p(H B)}{p(B)}-p(H \mid B)
$$

\section{Erro (Err)}

Como pode ser visualizado na equação dada a seguir, quanto maior o erro, menor a precisāo da regra. O erro é calculado por:

$$
\operatorname{Lrr}(B \rightarrow H)=1 \cdots \frac{n(I I B)}{n(B)}=1 \cdots p(I I \mid B)=1-\frac{p(I I B)}{p(B)}=\frac{p(I I I B)}{p(B)} \cdot p\left(\overline{I H}_{\mid} B\right)
$$

\section{Confiabilidade Negativa (NegRel)}

Essa medida é definida como sendo a probabilidade condicional de $H$ ser falso dado que $B$ é falso. A confiabilidade negativa representa a confiança de que, se o exemplo não é coberto pela regra, então a conclusão é falsa. E dada por:

$$
\operatorname{Neglacl}(B \rightarrow H)-\frac{n(\overline{H I B})}{n(\bar{B})}-\frac{p(\bar{H} B)}{p(\bar{B})}=p(\bar{H} \mid \bar{B})
$$




\section{Sensitividade (Sens)}

A sensitividade é definida como a probabilidade condicional de $B$ ser verdade dado que $I I$ é verdade. É representada por:

$$
\operatorname{Sens}(B \rightarrow H)=\frac{n(H B)}{n(I H)}=\frac{p(H B)}{p(I I)}=p(B \mid H)
$$

\section{Especificidade (Spec)}

Essa medida é definida como sendo a probabilidade condicional de $B$ ser falso dado que $H$ também é falso. É definida por:

$$
\operatorname{Spccc}(B \rightarrow I I)=\frac{n(\overline{H \bar{B}})}{n(\bar{H})}=\frac{p(\overline{H B})}{p(\bar{H})}=p(\bar{B} \mid \bar{H})
$$

\section{Cobertura (COv)}

A cobertura de uma regra representa a fração de todos os exemplos que são cobertos pela regra, podendo ser considerada como uma medida de generalidade da regra. Guanto maior o valor dessa medida. maior o número de exemplos cobertos pela regra. É dada por:

$$
\operatorname{Cov}(B \rightarrow I I)=\frac{n(B)}{N}=p(B)
$$

\section{Suporte (Sup)}

O suporte de uma regra indica a fração de todos os exemplos que sāo cobertos corretamente pela regra. E representada por:

$$
\operatorname{Sup}(B \rightarrow H)=\frac{n(H B)}{N}=p(H B)
$$

Novidade (Nov)

Essa medida tem como objetivo identificar o quanto uma regra é interessante, inovadora ou não usual. Ela ê definida pela comparação entre o valor esperado da medida suporte $-p(H B)$ - e os valores de $p(B)$ e $p(H)$. Quanto maior a diferença entre o valor esperado e o valor observado, maior a probabilidade de existir uma correlaçāo inesperada e verdadeira entre $B$ e $1 /$. E dada por:

$$
N o v(B \rightarrow H)=\frac{n(H B)}{N}-\frac{n(B) \times n(H)}{N^{2}}=p(H B)-p(H) \times p(B)
$$

\section{Satisfação (Sat)}

A satisfação da regra representa a queda relativa na precisāo entrc a regra $B \rightarrow$ verdade e a regra $B \rightarrow H$. Pode ser observado que a satisfaçāo 
de uma regra está relacionada com a precisão, pois $\operatorname{Sut}(B \rightarrow H)=1$ se e somente se $A c c(B \rightarrow H)=1$. Essa maneira está mais relacionada com a descoberta de conhecimento. Ela é definida por:

$$
\operatorname{Sal}(B \rightarrow H)=1-\frac{N \times n(\overline{I I} B)}{n(B) \times n(\bar{H})}=\frac{p(\bar{H})-p(\bar{H} \mid B)}{p(\bar{H})}
$$

No entanto, não é trivial construir uma tabela de contingência para uma regra de regressāo, pois como o atributo-meta a ser predito é um valor numérico, diferentemente da classificaçāo, nāo se pode dizer se a conclusão da regra está correta ou não. Dessa maneira, também não é possível calcular as medidas descritas.

Como existem poucas medidas para avaliar o conhecimento extraido de problemas de regressāo, surgiu então a idéia de se definir uma tabela de contingência para regras de regressão. Uma vez que a tabela fosse construída, tornar-se-ia possivel calcular as medidas dela derivadas. A seguir é apresentado o algoritmo P-Class, utilizado para definir uma estratégia que permite calcular tabela de contingência para regras de regressão.

\subsubsection{Algoritmo P-Class}

$O$ algoritmo P-Class (Algoritmo 1) é utilizado para gerar um conjunto do "pseudo-classes" em um processo de discretização descrito em (Weiss \& Indurkhya, 1995). O objetivo desse algoritmo é associar os valores do atributometa $y$ às pseudo-classes de modo a minimizar a distância entre cada $y_{i}$ e a média de sua pseudo-classe.

O P-Class descreve como associar um conjunto de valores $\left\{y_{i}\right\}$ a $k$ classes da seguinte maneira:

a. ordena os valores de $\{y\}$;

b. associa aproximadamente um número igual de valores de $\left\{y_{i}\right\}$ vizinhos para cada pseudo-classe;

c. move um valor $y_{i}$ para uma pseudo-classe vizinha quando isso reduz a distância de $y_{i}$ para a média de sua pseudo-classe;

d. concatena pseudo-classes com médias iguais.

Fornecido o valor de $k$, o algoritmo P-Class associa de maneira relativamentc rápida os $y$ valores de modo que as distâncias totais sejam minimizadas. No entanto, uma questão-chave é como determinar $k$, ou scja, o número de pseudo-classes a serem geradas. Em (Weiss \& Indurkhya. 1995) são realizados alguns experimentos para determinar o melhor número de pseudoclasses. Na Figura 5.8 é apresentado um gráfico do erro relativo versus o 
número de pseudo-classes. Como pode ser visualizado nesse gráfico, à medida que o número de pseudo-classes aumenta, os resultados melhoram, até alcançar o valor 6 , sendo que logo em seguida os resultados começam a piorar.

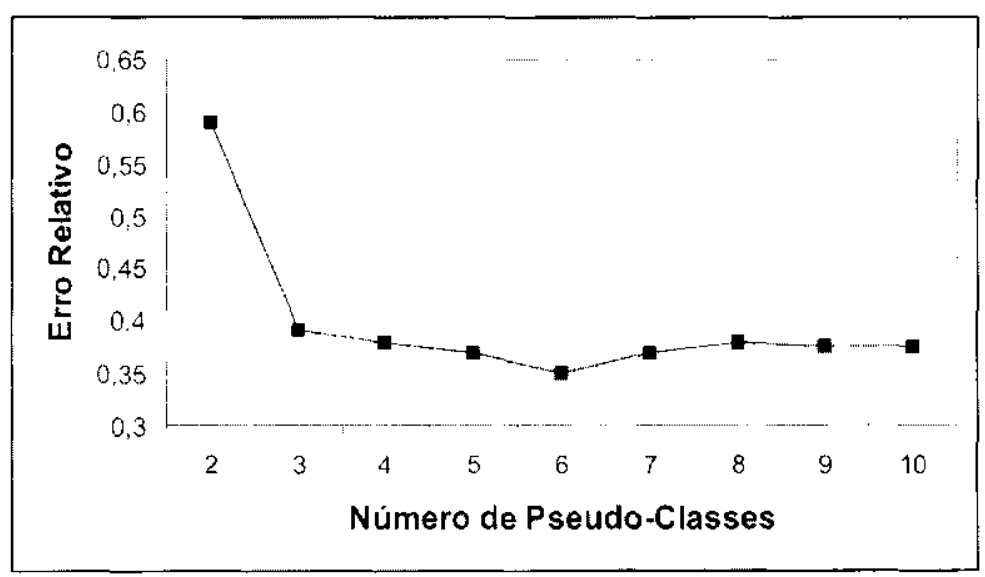

Figura 5.8: Desempenho de acordo com o número de pseudo-classes (Weiss \& Indurkhya, 1995)

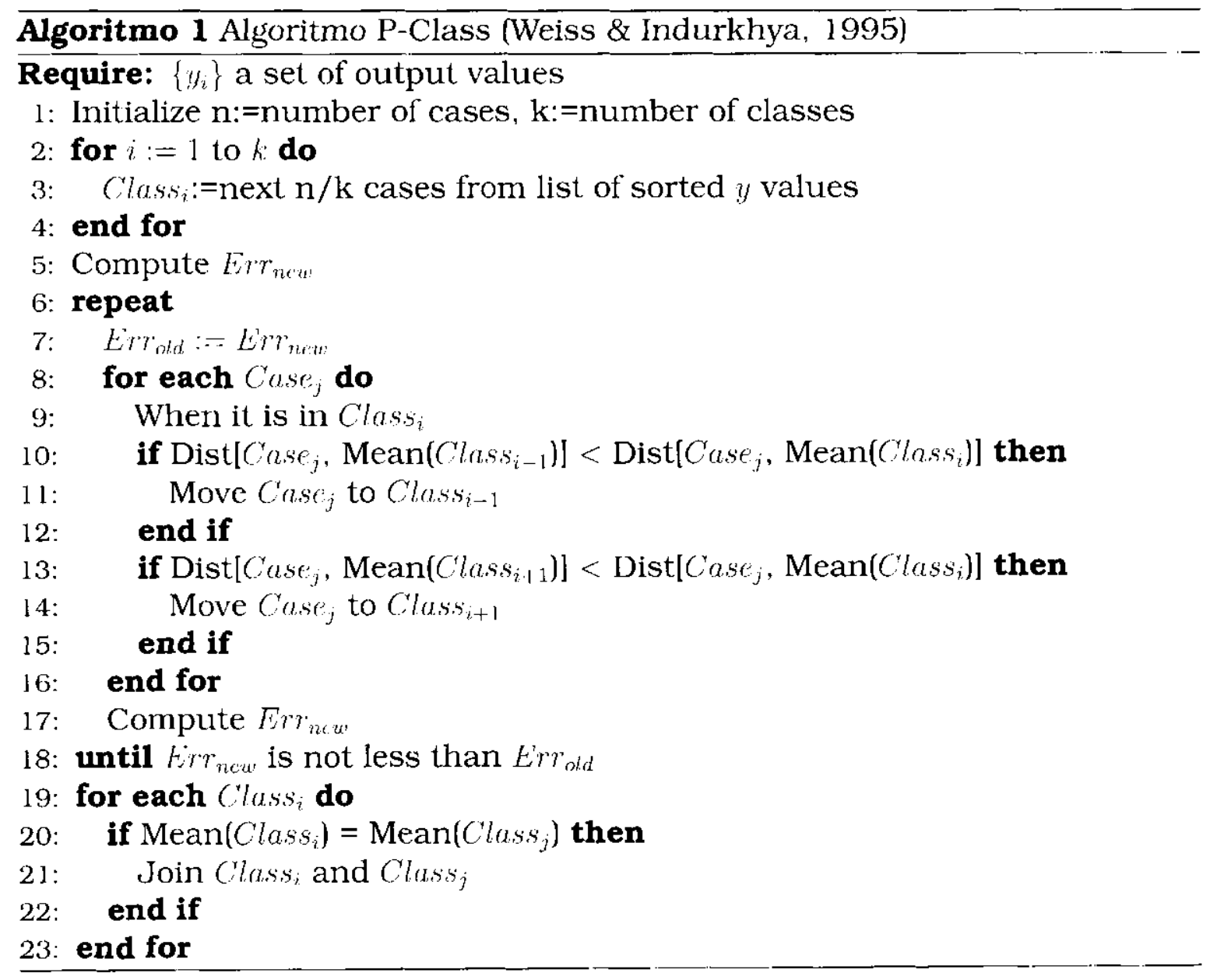

Esse algoritmo P-Class foi desenvolvido com o intuito de transformar um problema de regressão em um problema de classificação. Para isso, os valores numéricos do atributo-meta passam por um processo de discretização, em que 
são geradas as pseudo-classes. Realizada a discretização dos valores (geradas as pseudo-classes), um algoritmo de indução de regras de decisão como o C4.5 (Quinlan, 1993a) ou o CN2 (Clark \& Niblett, 1989), pode ser utilizado para gerar as regras. Com as regras induzidas, no processo proposto $\mathrm{cm}$ (Weiss \& Indurkhya, 1995) sāo aplicados entāo procedimentos de poda c otimização para produzir um conjunto otimizado de regras.

\subsubsection{Processo de Geração da Tabela de Contingência para Regras de Regressão}

Como citado, o algoritmo P-Class apresentado foi desenvolvido para transformar um problema de regressão em um problema de classificaçāo, gerando um conjunto de pseudo-classes por meio da discretizaçāo dos valores do atributo-meta.

Porém, neste trabalho, o P-Class foi utilizado com um propósito diferente. Os valores do atributo-meta do conjunto de treinamento sāo, primeiramente. ordenados, e em seguida, fornecidos ao algoritmo P-Class. Depois de geradas as pseudo-classes, são então armazenados o menor e o maior valor do atributo-meta de cada uma dessas pseudo-classes. Esses valores constituem então os "pseudo-intervalos", que são utilizados posteriormente para construir a tabela de contingência de cada regra. O número de pseudo-intervalos a serem gerados é definido pelo usuário, sendo o padrão 6 adotado se nenhum valor for especificado. Conforme descrito anteriormente, o valor 6 obteve empiricamente a menor taxa de erro.

Gerados os pseudo-intervalos, começa então o processo de construçāo da tabela de contingência para cada regra de regressão, como descrito no $\mathrm{Al}$ goritmo 2. Primeiramente, verifica se a regra realiza suas prediçōes por intermédio de um valor constante ou por meio de uma equaçāo linear: se for por intermédio de uma constante, calcula-se o pseudo-intervalo a que pertence aquela regra, pois se o valor é constante, ele será o mesmo para todos os exemplos de teste.

Em seguida, para cada exemplo de teste, o Algoritmo 2 faz o seguinte:

1. se a regra prediz valores por meio de uma equação linear, substitui os atributos presentes na equaçāo linear pelos seus respectivos valores do exemplo de teste em questāo, e entāo, calcula-se o pseudo-intervalo a que pertence a regra para aquele excmplo de teste;

2. se todas as condições da regra forem verdadeiras, o valor de $B$ na tabela de contingência é incrementado, e caso conträrio, incrementa-se o valor de seu complemento $\bar{B}$;

3. calcula a qual pseudo-intervalo pertence o exemplo de teste (verificando a 


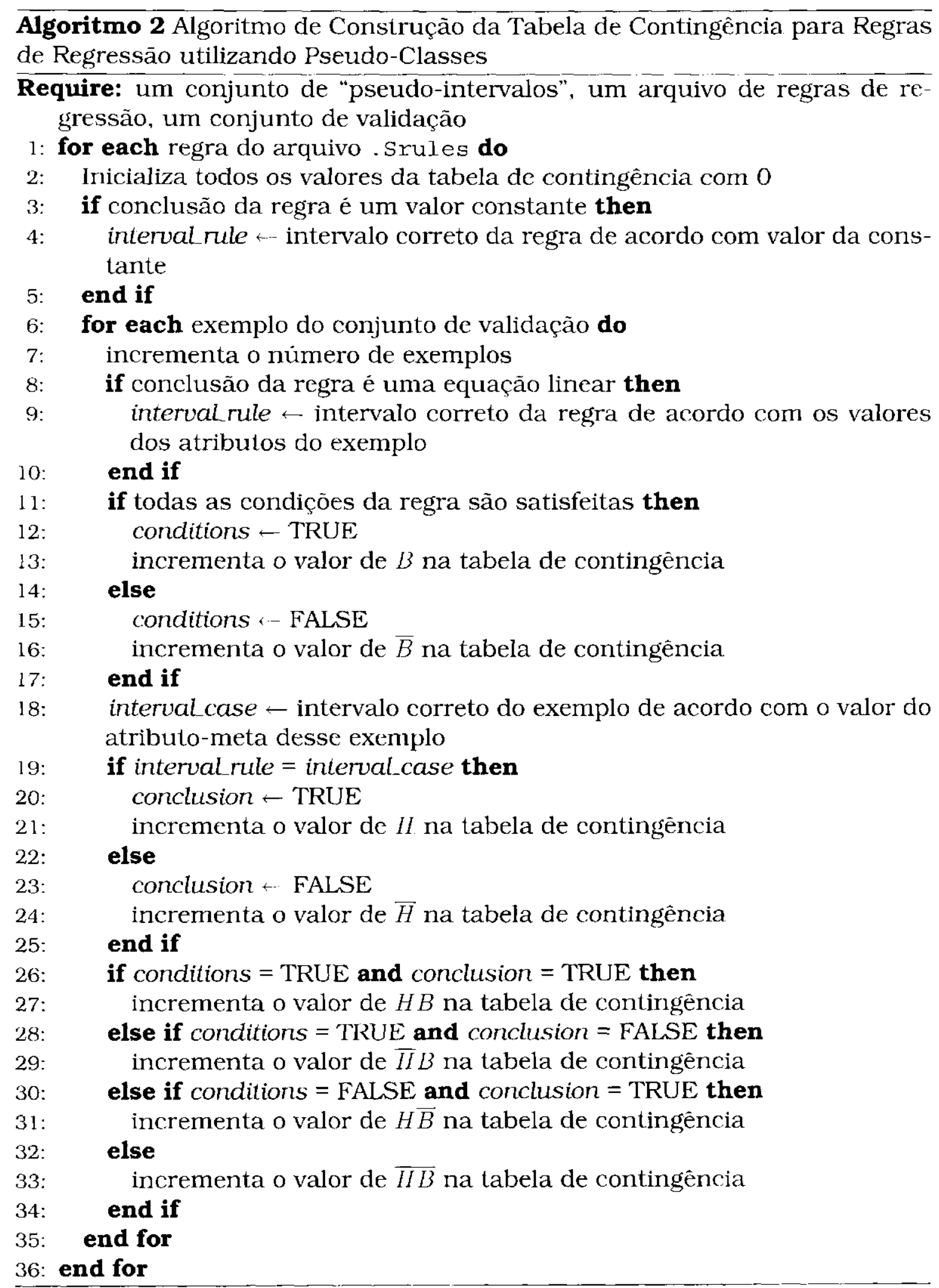

qual pseudo-intervalo pertence o valor do atributo-meta daquele exemplo de teste);

4. se o valor calculado para a regra (valor predito) e o valor real do atributometa pertencem ao mesmo pseudo-intervalo, então incrementa-se o valor 
de $H$ na tabela de contingência, senão, o valor de $\bar{H}$ é incrementado;

5. baseado nos valores de $B, \bar{B}, H$ e $\bar{H}$, calcula-se então os demais valores da tabela de contingència para aquela regra $(I I B, \overline{I I} B, H \bar{H}$ e $\overline{H B})$.

Uma vez que foram construídas as tabelas de contingência para cada regra de regressão do conjunto de dados, torna-se entāo possivel calcular as medidas descritas anteriormente aplicando-se as respectivas fórmulas.

Para construir as tabelas de contingência e efetuar os cálculos das medidas derivadas utiliza-se a classe RegTableMeasures implementada neste trabalho, que gera um arquivo contendo o menor $\mathrm{c}$ o maior valor de cada pseudo-intervalo, alèm da tabela de contingência e das medidas dela calculadas para cada regra de regressāo do arquivo . Srules, que contém as regras semanticamente tratadas.

Ressalta-se que a realizaçāo de experimentos comparando a estratégia baseada em pseudo-classes com outras cstratégias utilizadas para calcular tabela de contingência para regras de regressão é descrita em (Pugliesi \& Rezende, 2003).

\subsubsection{Interpretação das Medidas}

Para auxiliar na interpretação das medidas derivadas da tabela de contingência descritas na Sub-seçāo 5.4.1 para problemas de regressão utilizando pseudo-classes, será utilizada como exemplo uma pequena amostra do conjunto de dados mpg. O conjunto original foi retirado da biblioteca StatLib, que ê mantida pela Universidade Carnegie Mellon. Esse conjunto é utilizado para predizer a quantidade de milhas por galāo (mpg - milles per gallon) que gastam os carros europeus, americanos e japoneses, com o objetivo de identificar os fatores de maior consumo de combustivel. O conjunto de dados mpg é formado por 398 exemplos e 8 atributos, sendo 5 atributos contínuos e 3 nominais. Os seguintes atributos são utilizados para predizer o atributo-meta mpg:

- cylinders: número de cilindros do carro, assume os valores $3,4,5,6$ e 8:

- displacement: valor numérico relacionado à taxa de combustão;

- horsepower: valor numérico que indica a força do motor;

- weight: peso do carro;

- acceleration: valor numérico correspondente ao tempo de aceleração do carro $(0-60 \mathrm{seg})$;

- model: modelo do carro (ano), assume os valores entre 70 e 82: 
- origin: origem do automóvel, assume os valores 1, 2 e 3, que significam, respectivamente, EUA, Japão e Europa.

O conjunto de treinamento utilizado nesse exemplo, apresentado na Tabela 5.5, foi composto por 20 exemplos. Para induzir as regras de regressão foi utilizado o Cubist, descrito no Capítulo 4. O Cubist, executado com esses 20 exemplos de treinamento, gerou um conjunto de três regras $(R 1, R 2$ e $R: 3)$, quc foram então convertidas para o formato padrão de regras de regressão. Essas regras convertidas podem ser visualizadas na Figura 5.9.

\begin{tabular}{|c|c|c|c|c|c|c|c|}
\hline cylinders & displacement & horsepower & weight & acceleration & model & origin & mpg \\
\hline$\overline{3}$ & 70 & 97 & $2 \overline{330}$ & 13.5 & $7 \overline{2}$ & 3 & 19 \\
\hline 4 & 72 & 69 & 1613 & 18 & 71 & 3 & 35 \\
\hline 4 & 68 & 49 & 1867 & 19.5 & 73 & 2 & 29 \\
\hline 4 & 98 & 83 & 2219 & 16.5 & 74 & 2 & 29 \\
\hline 4 & 85 & 52 & 2035 & 22.2 & 76 & 1 & 29 \\
\hline 4 & 97 & 67 & 1985 & 16.4 & 77 & 3 & 30 \\
\hline 4 & 85 & 70 & 2070 & 18.6 & 78 & 3 & 39.4 \\
\hline 4 & 89 & 62 & 1845 & 15.3 & 80 & 2 & 29.8 \\
\hline 4 & 85 & 65 & 1975 & 19.4 & 81 & 3 & 37 \\
\hline 4 & 140 & 92 & 2865 & 16.4 & 82 & 1 & 24 \\
\hline 4 & 105 & 74 & 1980 & 15.3 & 82 & 2 & 36 \\
\hline 5 & 131 & 103 & 2830 & 15.9 & 78 & 2 & 20.3 \\
\hline 6 & 232 & 100 & 2634 & 13 & 71 & 1 & 19 \\
\hline 6 & 250 & 72 & 3158 & 19.5 & 75 & 1 & 15 \\
\hline 6 & 250 & 88 & 3021 & 16.5 & 73 & 1 & 18 \\
\hline 6 & 163 & 125 & 3140 & 13.6 & 78 & 2 & 17 \\
\hline 8 & 454 & 220 & 4354 & 9 & 70 & 1 & 14 \\
\hline 8 & 429 & 208 & 4633 & 11 & 72 & 1 & 11 \\
\hline 8 & 304 & 150 & 3672 & 11.5 & 73 & 1 & 14 \\
\hline 8 & 350 & 155 & 4360 & 14.9 & 79 & 1 & 16.9 \\
\hline
\end{tabular}

Tabela 5.5: Exemplos de treinamento do conjunto de dados mpg

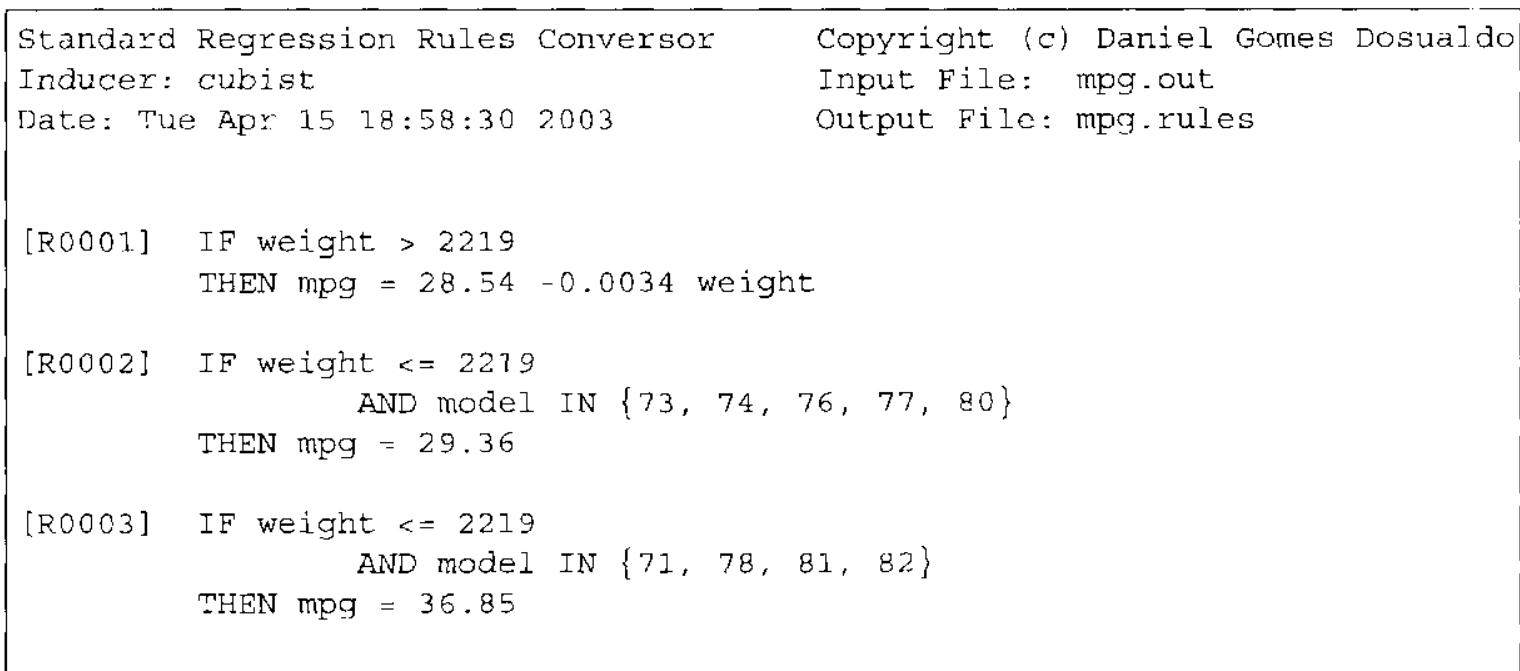

Figura 5.9: Regras geradas pelo Cubist com o conjunto de treinamento mpg da Tabela 5.5

Depois das regras terem sido induzidas e convertidas para o formato padrāo de regras de regressão, utilizou-se a classe RegTableMeasures para construir as tabelas de contingência das três regras geradas. Utilizando os exemplos 
de treinamento do conjunto mpg descrito, foram gerados 4 pseudo-intervalos, apresentados na Tabela 5.6. O valor 4 foi escolhido devido ao tamanho muito pequeno do conjunto de treinamento.

\begin{tabular}{|c|c|c|}
\hline Intervalo & Valor Mínimo & Valor Máximo \\
\hline 1 & 11 & 15 \\
\hline 2 & 16,9 & 20,3 \\
\hline 3 & 24 & 30 \\
\hline 4 & 35 & 39,4 \\
\hline
\end{tabular}

Tabcla 5.6: Pseudo-intervalos gerados com o conjunto de dados mpg

Baseado então nos 4 pseudo-intervalos gerados, foram utilizados $20 \mathrm{excm}$ plos de teste do conjunto $\mathrm{mpg}$, apresentados na Tabela 5.7, para construir então a tabela de contingência das regras de regressão $R 1, R 2$ e $R: 3$. $\Lambda$ s tabelas obtidas para essas regras são apresentadas na Tabela 5.8, seguindo a mesma notaçāo da tabcla de contingência descrita anteriormente.

\begin{tabular}{|cccccccc|}
\hline cylinders & displacennent & horsepower & weight & acceleration & model & origin & mp pg \\
\hline 3 & 70 & 100 & 2120 & 12.5 & 80 & 3 & 23.7 \\
4 & 110 & 87 & 2672 & 17.5 & 70 & 2 & 25 \\
4 & 97 & 46 & 1950 & 21 & 73 & 2 & 26 \\
4 & 79 & 67 & 1950 & 19 & 74 & 3 & 31 \\
4 & 151 & 85 & 2855 & 17.6 & 78 & 1 & 23.8 \\
4 & 105 & 70 & 2150 & 14.9 & 79 & 1 & 34.5 \\
4 & 120 & 75 & 2542 & 17.5 & 80 & 3 & 31.3 \\
4 & 98 & 76 & 2144 & 14.7 & 80 & 2 & 41.5 \\
4 & 107 & 75 & 2210 & 14.4 & 81 & 3 & 33.7 \\
4 & 116 & 75 & 2158 & 15.5 & 73 & 2 & 24 \\
4 & 120 & 79 & 2625 & 18.6 & 82 & 1 & 28 \\
5 & 131 & 103 & 2830 & 15.9 & 78 & 2 & 20.3 \\
6 & 258 & 110 & 2962 & 13.5 & 71 & 1 & 18 \\
6 & 232 & 100 & 2914 & 16 & 75 & 1 & 20 \\
6 & 225 & 100 & 3651 & 17.7 & 76 & 1 & 20 \\
6 & 146 & 120 & 2930 & 13.8 & 81 & 3 & 24.2 \\
8 & 360 & 215 & 1615 & 14 & 70 & 1 & 10 \\
8 & 360 & 170 & 4654 & 13 & 73 & 1 & 13 \\
8 & 400 & 180 & 4220 & 11.1 & 77 & 1 & 16 \\
8 & 260 & 90 & 3420 & 22.2 & 79 & 1 & 23.9 \\
\hline \hline
\end{tabular}

Tabela 5.7: Exemplos de teste do conjunto de dados mpg

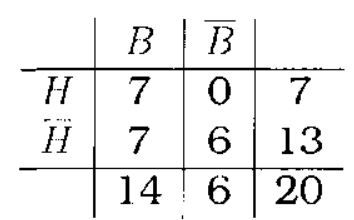

\begin{tabular}{c|c|c|c} 
& $B$ & $\bar{B}$ & \\
\hline$H$ & 3 & 7 & 10 \\
$\bar{H}$ & 1 & 9 & 10 \\
\hline & 4 & 16 & 20
\end{tabular}

\begin{tabular}{c|c|c:c} 
& $B$ & $\bar{B}$ & \\
\hline$H$ & 1 & 2 & 3 \\
$\bar{H}$ & 0 & 17 & 17 \\
\hline & 1 & 19 & 20
\end{tabular}

Tabela 5.8: Tabelas de contingència das regras R1, R2 e R3

Depois de construida a tabela de contingência de cada regra, torna-se possivel calcular as medidas dela derivadas. A seguir são apresentadas algumas interpretaçōes das medidas para os problemas de regressão utilizando a estratégia de pseudo-classes. Além disso, sāo apresentados também os valores dessas medidas calculadas sobre as regras $R 1, R 2 \mathrm{e} R 3 \mathrm{com}$ o conjunto de dados mpg. 
Precisão ( $A C c)$ : no caso dos problemas de regressāo utilizando pseudo-intervalos, a precisão indica a fraçāo dos exemplos cobertos pela regra em que o valor predito pela regra e o valor real do atributo-meta pertencem ao mesmo pseudo-intervalo. Guanto maior o valor dessa medida, maior é a precisāo da regra. É muito importante ressaltar que a precisão da regra, nesse caso, depende muito do número de pseudo-intervalos defìnido, pois quanto maior esse valor, menor tende a ser a precisāo da regra. Considerando as regras $R 1, R 2$ e $R 3$, obtêm-se os seguintes valores para a precisāo:

$$
\begin{aligned}
& \operatorname{Acc}(R 1)=\frac{7}{14}=0,50 \\
& \operatorname{Acc}(R 2)=\frac{3}{4}=0,75 \\
& \operatorname{Acc}(R 3)=\frac{1}{1}=1
\end{aligned}
$$

Erro (Err): o erro é calculado pela fórmula 1 - Acc, portanto, quanto maior a precisāo, menor o erro da regra. De acordo com as regras apresentadas, o erro resulta nos seguintes valores:

$$
\begin{gathered}
\operatorname{Err}(R 1)=1-0,50=0,50 \\
\operatorname{Err}(R 2)=1-0,75=0,25 \\
\operatorname{Err}(R 3)=1-1=0
\end{gathered}
$$

Confiança Negativa (NegRel): a confiança negativa é definida como a probabilidade condicional de $I I$ ser falso dado que $B$ é falso. Assim sendo, nesse caso, corresponde dizer que se o exemplo não é coberto pela regra. então o pseudo-intervalo a que pertence o valor predito pela regra é diferente do pseudo-intervalo a que pertence o valor real do atributo-meta. Levando-se em consideraçāo as regras $R 1, R 2$ e $R 3$, a confiança negativa resulta em:

$$
\begin{gathered}
\operatorname{NegRel}(R 1)=\frac{6}{6}=: 1 \\
\operatorname{NegRel}(R 2)=\frac{9}{16}=0,562 \\
\operatorname{NegRel}(R 3)=\frac{17}{19}=0,894
\end{gathered}
$$

Sensitividade (Sens): uma vez que a sensitividade é a probabilidade condicional de $B$ ser verdade dado que $I I$ é verdade, entāo, no caso da regressāo 
com pseudo-intervalos, indica a fração de todos os exemplos em que, se o valor predito pela regra e o valor real do atributo-meta pertencem ao mesmo pseudo-intervalo, então o exemplo é coberto pela regra. Bascado nas regras descritas, obtêm-se os seguintes valores para essa medida:

$$
\begin{gathered}
\operatorname{Sens}(R 1)=\frac{7}{7}=1 \\
\operatorname{Sens}(R 2)=\frac{3}{10}=0,3 \\
\operatorname{Sens}(R 3)=\frac{1}{3}=0,333
\end{gathered}
$$

Especificidade (Spec): essa medida é definida como sendo a probabilidade condicional de $B$ ser falso dado que $H$ também é falso. No caso dos problemas de regressāo aqui descritos, corresponde dizer que, se o valor predito pela regra e o valor real do atributo-meta não pertencem ao mesmo pseudo-intervalo, então o exemplo não é coberto pela regra. De acordo com as regras $R 1, R 2$ e $R 3$, os valores da medida especificidade resultam em:

$$
\begin{gathered}
\operatorname{Spec}(R 1)=\frac{6}{13}=0,461 \\
\operatorname{Spec}(R 2)=\frac{9}{10}=0,9 \\
\operatorname{Spec}(R 3)=\frac{17}{17}=1
\end{gathered}
$$

Cobertura (Cov): a medida cobertura para uma regra de regressão nāo apresenta diferença da definição dada anteriormente para essa medida, ou seja, representa a fração de todos os exemplos que sāo cobertos pela regra, o que significa dizer que, quanto maior o seu valor, maior o número de exemplos cobertos pela regra. Levando-se em conta as regra $R 1, R 2 \mathrm{e}$ $R 3$, obtém-se os seguintes valores para essa medida:

$$
\begin{aligned}
& \operatorname{Cov}(R 1)=\frac{14}{20}=0.7 \\
& \operatorname{Cov}(R 2)=\frac{4}{20}=0.2 \\
& \operatorname{Cov}(R 3)=\frac{1}{20}=0,05
\end{aligned}
$$

Suporte (Sup): o suporte de uma regra indica a fraçāo de todos os exemplos que são cobertos corretamente pela regra. Nesse caso, indica a fração dos exemplos que são cobertos pela regra e que o valor predito pela regra 
e o valor real do atributo-meta pertencem ao mesmo pseudo-intervalo. Baseado nas regras $R 1, R 2$ e $R 3$, os valores do suporte resultam em:

$$
\begin{aligned}
& \operatorname{Sup}(R 1)=\frac{7}{20}=0.35 \\
& \operatorname{Sup}(R 2)=\frac{3}{20}=0,15 \\
& \operatorname{Sup}(R 3)=\frac{1}{20}=0,05
\end{aligned}
$$

Novidade (Nov): como descrito, a novidade objetiva identilicar o quanto uma regra é interessante, inovadora ou não usual. Quanto maior a diferença entre o valor esperado e o valor observado, maior a probabilidade de existir uma correlaçāo inesperada e verdadeira entre $B$ e $H$. De acordo com as regras aqui descritas, os valores da medida novidade sāo dados por:

$$
\begin{aligned}
& \operatorname{Non}(R 1)=\frac{7}{20}-\frac{14 \times 7}{400}=0,105 \\
& \operatorname{Non}(R 2)=\frac{3}{20}-\frac{4 \times 10}{400}=0,05 \\
& \operatorname{Nov}(R 3)=\frac{1}{20}-\frac{1 \times 3}{400}=0,042
\end{aligned}
$$

Satisfação (Sat): a satisfaçāo da regra representa a queda relativa na precisão entre a regra $B \rightarrow$ verdade e a regra $B \rightarrow H$. Como citado, essa medida está mais relacionada com a descoberta de conhecimento. Os valores obtidos para essa medida com as regras $1 R 1,122$ e $12: 3$ sāo os seguintes:

$$
\begin{aligned}
& \operatorname{Sal}(R 1)=1-\frac{20 \times 7}{14 \times 13}=0,23 \\
& \operatorname{Sat}(R 2)=1-\frac{20 \times 1}{4 \times 10}=0,5 \\
& \operatorname{Sal}(R 3)=1-\frac{20 \times 0}{1 \times 17}=1
\end{aligned}
$$

Na Tabela 5.9 ê apresentado um resumo das medidas calculadas a partir da tabela de contingência para as regras $R 1, R 2$ e $R 3$. De acordo com essa tabela, nota-se que a regra $R 3$ obteve o maior valor para a medida precisão, $\mathrm{c}$ portanto, o menor erro. Essa regra obteve também o maior valor da medida especificidade e da satisfação, pois essa medida só é igual a 1 se a precisão da regra também apresenta esse valor. A regra $k 1$ apresentou os maiores valores para as medidas confiança negativa, sensitividade e cobertura, visto que ela 
cobre aproximadamente $70 \%$ dos exemplos. Essa regra também obteve os maiores valores para as medidas suporte e novidade.

\begin{tabular}{|c|c|c|c|}
\hline Medida & R1 & R2 & R3 \\
\hline $\operatorname{Acc}(B \rightarrow H)$ & 0,5 & 0,75 & 1 \\
\hline $\operatorname{Err}(B \rightarrow H)$ & 0,5 & 0,25 & 0 \\
$\operatorname{NegRel}(B \rightarrow H)$ & 1 & 0,562 & 0,895 \\
\hline $\operatorname{Sens}(B \rightarrow H)$ & 1 & 0,3 & 0,333 \\
\hline $\operatorname{Spcc}(B, H)$ & 0,461 & 0,9 & 1 \\
\hline $\operatorname{Cov}(B ; H)$ & 0.7 & 0,2 & 0,05 \\
\hline $\operatorname{Sup}(B \rightarrow H)$ & 0,35 & 0,15 & 0,05 \\
\hline $\operatorname{Nov}(B \rightarrow I I)$ & 0,105 & 0,05 & 0,042 \\
$\operatorname{Sat}(B \rightarrow H)$ & 0,23 & 0,5 & 1 \\
\hline
\end{tabular}

Tabela 5.9: Valores das medidas calculadas para as regras R1, R2 e R3

\subsection{Teste de Hipóteses}

Neste capítulo, até agora, foram apresentadas várias de medidas utilizadas para avaliar o conhecimento em problemas de regressāo, como medidas de crro. No entanto, nāo é fácil perceber se um algoritmo é melhor que outro levando-sc cm consideração apenas medidas de crro, como as medidas MAD e MSE, no caso da regressão.

A metodologia descrita a seguir é comumente utilizada pela comunidade de aprendizado de máquina para fazer avaliação de algoritmos. Essa metodologia compara os algoritmos dois a dois, baseando-se na idéia de amostragem. sendo que neste trabalho, a técnica utilizada foi a de 10-fold cross-validation.

Considere A um algoritmo e erro( $\left.h_{i}\right)$ equivalente à medida MAD calculada sobre a hipótese induzida $h_{i}$ na $i$-ésima partição. A média da medida MAD calculada sobre os regressores obtidos com o algoritmo A é dada pela Equaçāo 5.4

$$
\operatorname{media}(A)=\frac{1}{k} \sum_{i=1}^{k} \operatorname{crro}\left(h_{i}\right)
$$

em que $k$ corresponde ao número de partiçōes do conjunto de dados, nesse caso $k:=10$.

Em seguida, baseado no valor da média, calcula-se a variância da medida $\mathrm{MAD}$ de cada regressor gerado pelo algoritmo por meio da Equação 5.5.

$$
\operatorname{var}(A)=\left[\frac{1}{k-1} \sum_{i=1}^{k}\left(\operatorname{erro}\left(h_{i}\right)-\operatorname{media}(A)\right)^{2}\right]
$$

Por lim, calcula-se o desvio-padrão da medida MAD obtido sobre cada al- 
goritmo baseado na variância, como mostra a Equação 5.6.

$$
d p(A)=\sqrt{\operatorname{var}(A)}
$$

Para decidir qual algoritmo é melhor que outro com um grau de confiança de $95 \%$ é assumido o caso geral para determinar se a diferença entre dois algoritmos - $A_{s}$ e $A_{\psi}$ - é significante ou não, assumindo uma distribuição normal. Em geral, a comparaçāo é feita de modo que $A_{F}$, é o algoritmo proposto e $A_{S}$ é o algoritmo padrão. Para isso, a média e desvio padrão combinados são calculados de acordo com as Equações 5.7 e 5.8, respectivamente. Então, a diferença absoluta, em desvios padrōes, é calculada por meio da Equação 5.9 .

$$
\begin{gathered}
\operatorname{mcdia}\left(A_{S}-A_{\nu}\right)=\operatorname{media}\left(A_{S}\right)-\operatorname{media}\left(A_{P}\right) \\
\operatorname{dp}\left(A_{S}-A_{P}\right)=\sqrt{\frac{d p\left(A_{S}\right)^{2} \cdots d p\left(A_{P}\right)^{2}}{2}} \\
a d\left(A_{S}-A_{P}\right)=\frac{\operatorname{media}\left(A_{S}-A_{\mu}\right)}{d p\left(A_{S}-\Lambda_{P}\right)}
\end{gathered}
$$

Dessa maneira, se $\operatorname{ad}\left(A_{S}-A_{P}\right)>0$ entāo $A_{P}$ supera $A_{S}$. Porém, se $a d\left(A_{S}-\right.$ $\left.A_{P}\right) \geq 2$ desvios padrōes, então $A_{1}$, supera $A_{S}$ com grau de confiança de $95 \%$. Por outro lado, se $\operatorname{ud}\left(A_{S}-A_{\mu}\right) \leq 0$. então $A_{S}$ supera $A_{\mu}$, e sc $\operatorname{ad}\left(A_{S}-A_{P}\right) \leq 2$, então $A_{S}$ supera $A_{P}$ com grau de confiança de $95 \%$.

Para realizar esse teste de hipóteses, utiliza-se a classe RegHypothesis implementada neste trabalho. A realização do teste por meio dessa classe fornece um arquivo de saida contendo os resultados da comparaçāo efetuada entre os algoritmos de regressão escolhidos pelo usuário, relatando quais algoritmos superam os outros e se existe algum algoritmo que supera todos os demais, e ainda, se essa supcraçāo é comprovada com grau de confiança de 95\%.

\subsection{Considerações Finais}

Os modelos de regressāo simbólicos, sejam eles regras ou árvores, gerados por diferentes algoritmos de regressão, são representados de diferentes formas. Assim, qualquer avaliaçāo que precise ser efetuada sobre uma hipótese (cálculo de medidas, estatisticas, entre outras) deve ser feita diversas vezes, uma para cada algoritmo. Nesse sentido, baseada na sintaxe padrāo de regras de regressāo do Discover (Pugliesi, Dosualdo, \& Rezende, 2003), a classe RegConvert converte a saída dos algoritmos de regressão RT, CAR'T, RETIS, Cubist e M5 para esse formato padrão de regras de regressão.

Mesmo com as regras padronizadas em um único formato, podem ocorrer ainda sobreposiçōes de condiçōes em uma determinada regra, diminuindo a 
compreensibilidade dessa regra e acarretando em uma queda no desempenho nos cálculos efetuados sobre o arquivo de regras. A classe RegSemantic realiza um tratamento semântico sobre o conjunto de regras com o objetivo de diminuir o número de condiçōes das regras, sempre que possivel.

Depois de gerado um modelo simbólico de regras, ele precisa ser avaliado para verificar alguns fatores, por exemplo, sua precisão na predição do valor do atributo-meta de novos exemplos e sua compreensibilidade. A classe RegMeasures calcula algumas medidas de precisão (baseadas na diferença entre o valor real do atributo e o valor predito pelo algoritmo) e algumas medidas de compreensibilidade para cada regra do modelo, além de calcular a precisāo do modelo como um todo.

Porêm, existem poucas medidas que podem ser calculadas para os problemas de regressão. Nessc sentido, foi apresentado neste capítulo um processo para a construção de tabelas de contingência para regras de regressāo. A tabela de contingência é tipicamente calculada para regras de decisāo, e a partir dela, sāo definidas uma série de medidas. Assim. por intermédio da classe RegTableMeasures é possivel construir uma tabela de contingência para cada regra de regressão, bem como calcular as medidas dela derivadas.

A última classe descrita foi a classe RegHypothesis. que implementa um teste de hipóteses para comparar algoritmos dois a dois baseando-se na idćia de amostragem. Esse teste permite afirmar se um algoritmo é melhor que outro com um grau de confiança de 95\%, o que não seria fácil fazer levandose em conta apenas medidas de erro.

Todas as classes descritas neste capítulo constituem o ambiente DIPER integrado ao Dıscover. Elas implementam uma série de métodos que auxiliam na etapa de pós-processamento do conhecimento. Como neste capítulo essas classes foram apresentadas de uma mancira mais teórica, no próximo capítulo são descritos alguns experimentos realizados com diferentes conjuntos de dados com o objetivo de facilitar o entendimento das funcionalidades disponibilizadas por essas classes. Para isso serão apresentados exemplos com os resultados obtidos na utilização de cada classe. 


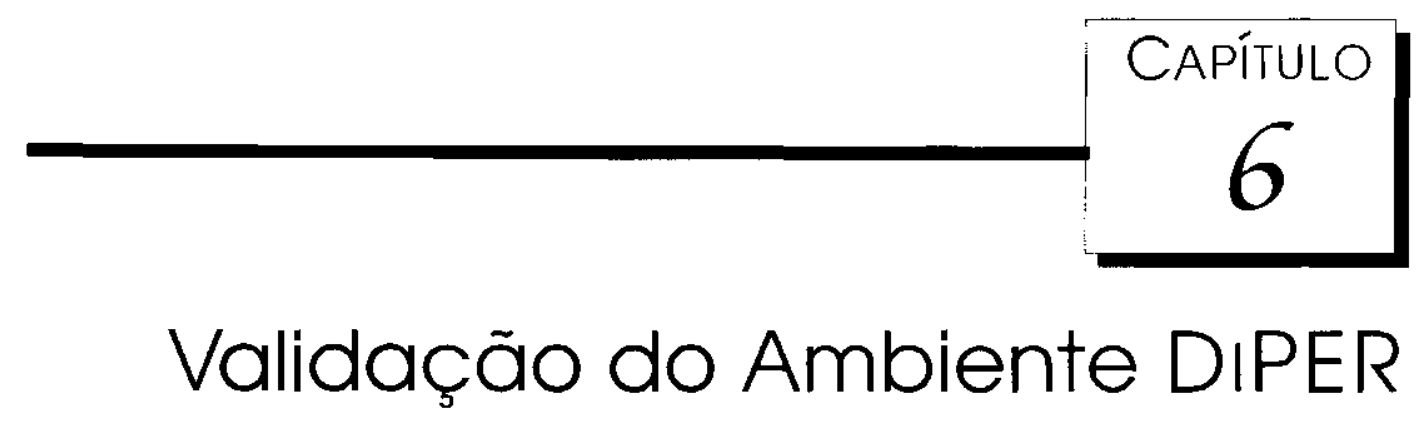

ambiente DIPER descrito no capitulo anterior é composto por uma biblioteca de classes que fornece métodos para auxiliar na etapa de pós-processamento do conhecimento. Nestc capítulo são descritos alguns experimentos realizados com o objetivo de exemplificar as funcionalidades dessas classes. Um esquema das funcionalidades dessas classes é apresentado na Figura 6.1.

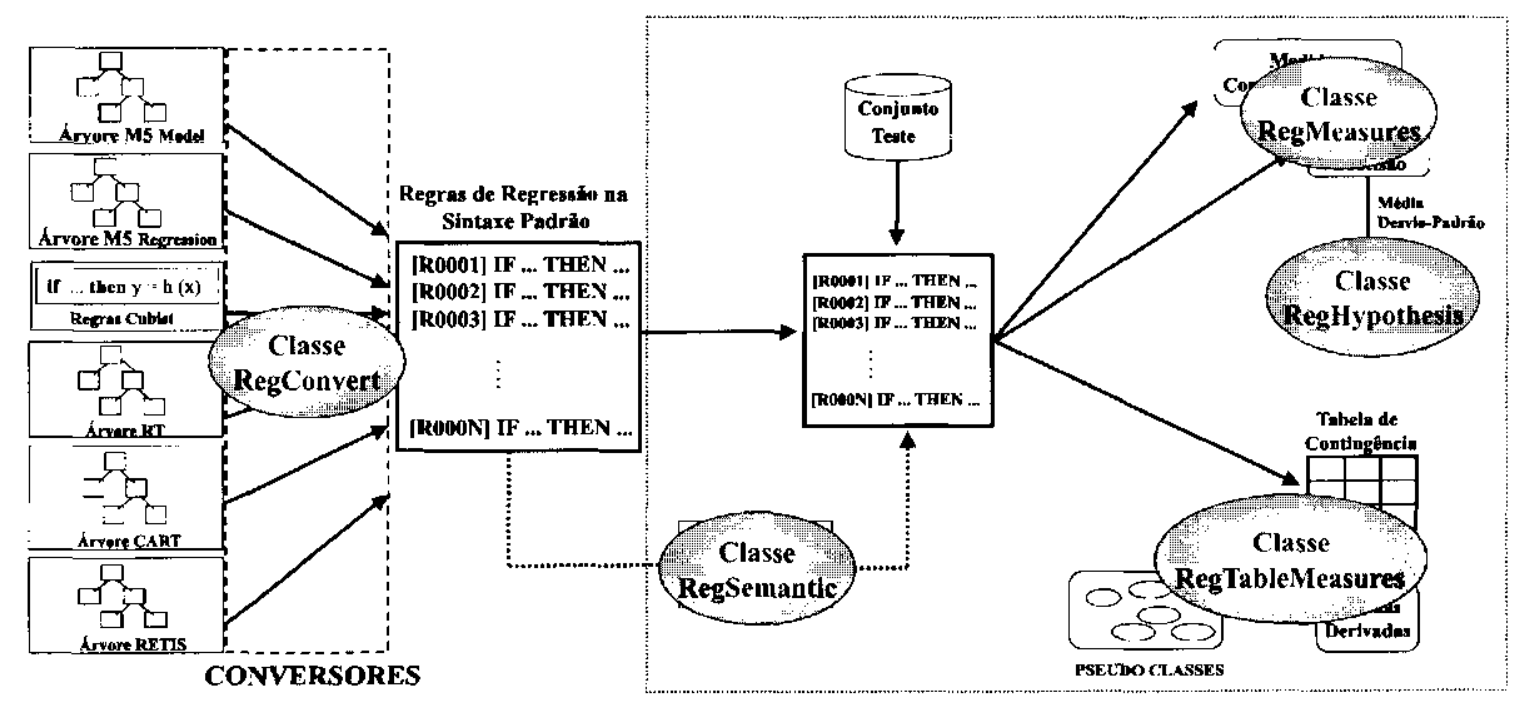

Figura 6.1: Classes do ambiente DIPER

Para a realizaçāo dos experimentos os conjuntos de dados utilizados foram divididos em 2 conjuntos: o primeiro, composto por $75 \%$ dos exemplos, foi utilizado como conjunto de treinamento e teste; e o segundo, formado pelos $25 \%$ dos exemplos restantes, constituía o conjunto de validação. A partir desses conjuntos os experimentos foram realizados em duas fases, descritas a seguir.

Na primeira fase, para calcular a precisão dos modelos de regressão e efetuar o teste de hipóteses, o regressor é visto como uma "caixa-preta". Nesse caso, o conjunto de treinamento é submetido a algum algoritmo para a geraçăo 
de um regressor, que é então convertido para o formato padrāo de regras de re gressāo. Em seguida sāo utilizados os exemplos do conjunto de teste para calcular a precisāo desse regressor. O regressor é visto como uma "caixa-preta" porque nesse caso interessa apenas a sua precisão na predição do atributometa dos exemplos de teste, não importando o número de regras gerado, a compreensibilidade dessas regras, etc. Para o cálculo da precisão e realização do teste de hipóteses foi utilizada a técnica de 10-fold cross-validation. A configuração dessa primeira etapa dos experimentos pode ser visualizada na Figura 6.2.

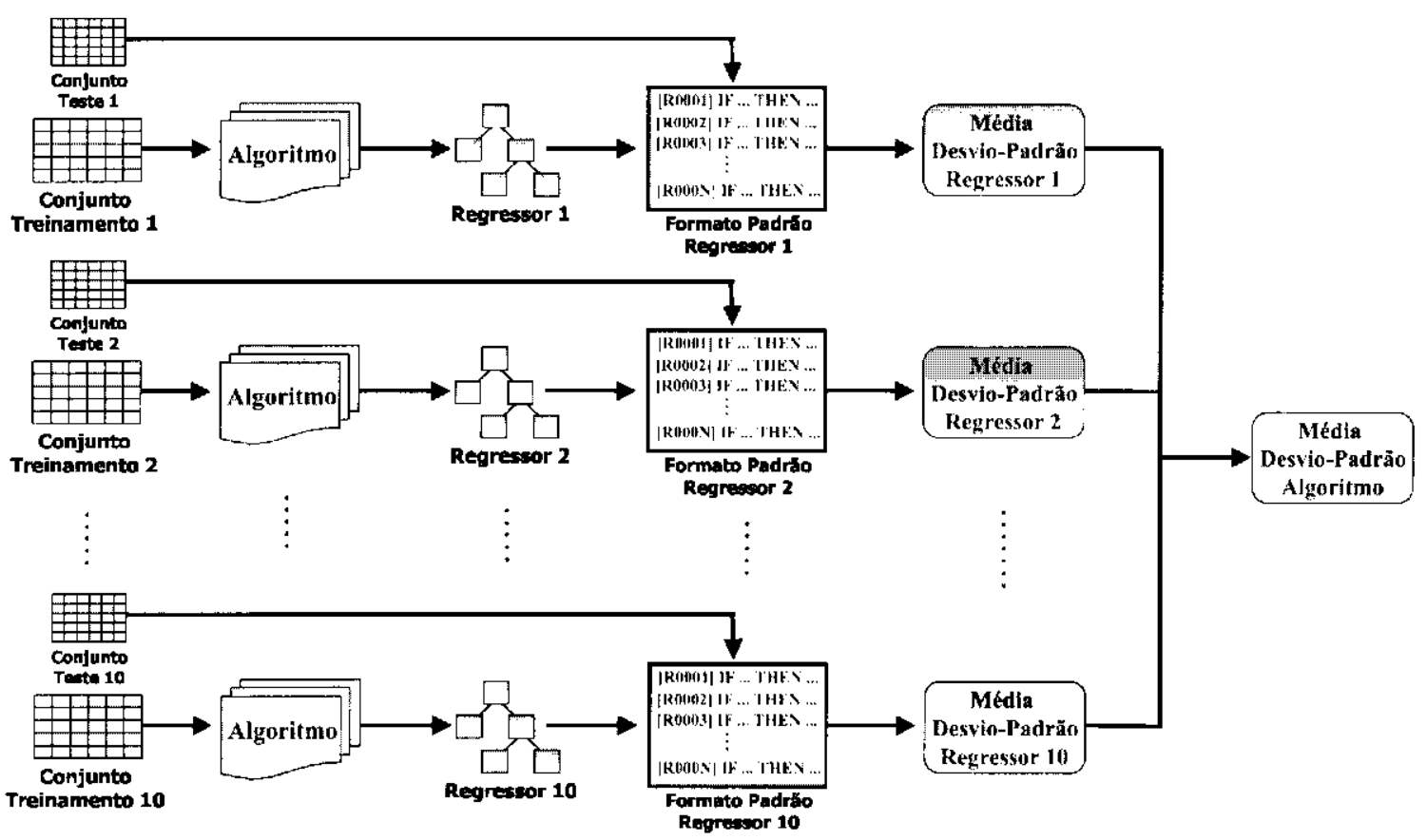

Figura 6.2: Primeira fase dos experimentos

Na segunda fase dos experimentos, para calcular as medidas de comprecnsibilidade, construir a tabela de contingência das regras de regressão e calcular as medidas dela derivadas, torna-se necessário "abrir" o regressor antes chamado de "caixa-preta" com o intuito de examinar o conjunto de regras gerado. Para isso, utilizou-se os conjuntos de treinamento e teste para gerar um regressor para cada algoritmo, que foi então avaliado. No caso da tabela de contingência, os conjuntos de treinamento e teste foram utilizados para gerar o regressor e os pseudo-intervalos, enquanto que o conjunto de validaçāo, que não possui exemplos em comum com esses dois conjuntos, foi então utilizado para construir as tabelas de contingência e as medidas derivadas. Essa configuração dos experimentos é apresentada na Figura 6.3.

Neste capitulo sāo descritos dois ciclos de experimentos realizados utilizando conjuntos de dados retirados do repositório de dados da UCI (University of California, Irvine) (Blake \& Merz, 1998). Em cada ciclo são descritas 


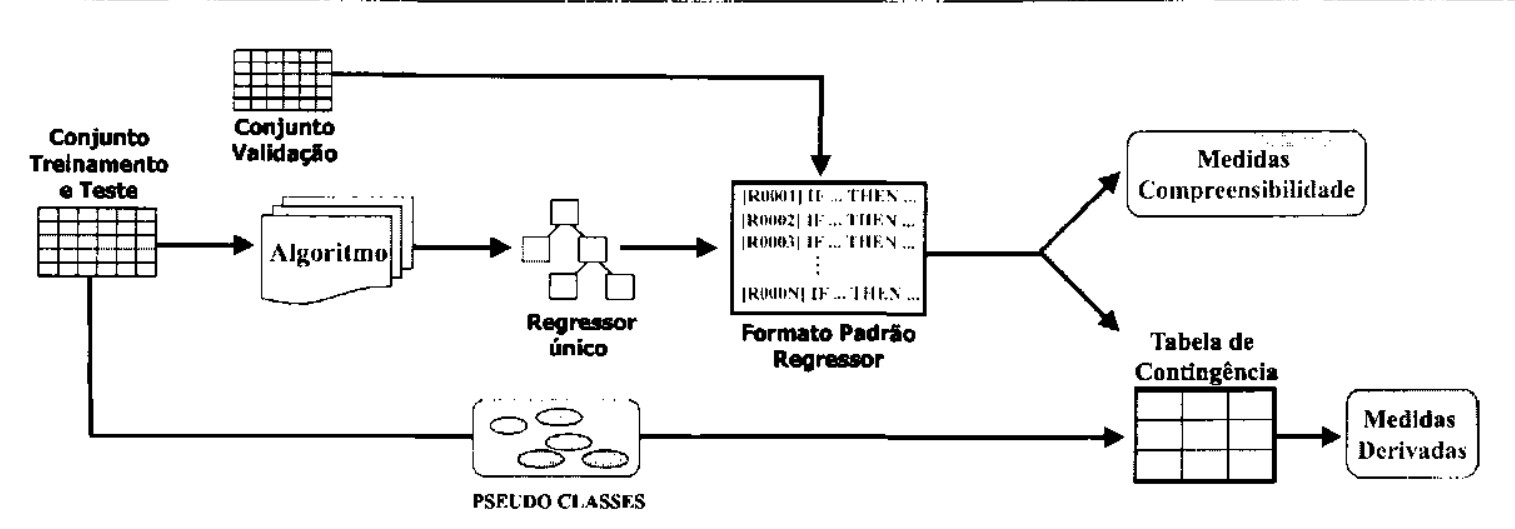

Figura 6.3: Segunda fase dos experimentos

as etapas de conversão dos regressores para o formato padrão, tratamento semântico das regras, cálculo das medidas de precisão e teste de hipóteses (analisando o regressor como uma "caixa-preta"), cálculo de medidas de compreensibilidade, construção das tabelas de contingência e das medidas derivadas (nesses casos, levando-se em consideração um único regressor gerado a partir dos conjuntos de treinamento e teste). Em cada uma dessas etapas são feitas algumas considerações a respeito dos resultados obtidos.

O primeiro ciclo de experimentos, apresentado na Seção 6.1, foi realizado utilizando o conjunto de dados abalone. Esse conjunto é utilizado para tentar predizer a idade de um abalone (um tipo de molusco). Na Seção 6.2 é descrito o segundo ciclo de experimentos, realizado com o conjunto de dados housing, utilizado para tentar predizer o valor de um imóvel na cidade de Boston. Estados Unidos. Na Seção 6.3 é feita uma avaliação geral dos resultados obtidos por meio desses experimentos. Por fim, na Seção 6.4, são feitas as consideraçōes finais do capitulo. Os experimentos foram realizados com os algoritmos Cubist, RT, CART, RETIS, M5 Model e M5 Regression.

\subsection{Experimentos com o Conjunto de Dados Abalone}

Esse primeiro ciclo de experimentos foi realizado utilizando o conjunto de dados abalone, obtido a partir do repositório de dados da UCI. Esses dados são provenientes de um estudo original descrito em (Nash et al., 1994).

o conjunto de dados abalone é utilizado para predizer a idade de um abalone a partir de um conjunto de medidas físicas. O abalone é um molusco da classe dos gastrópodes, bastante usado nas culinárias chinesa e japonesa. Para detcrminar a idade de um abalone aplica-se o seguinte procedimento: primeiramente, corta-se a concha e conta-se o número de anéis com a ajuda de um microscópio (uma tarefa árdua c que consome bastante tempo) e em seguida, soma ao número de anéis o valor 1,5, obtendo, dessa maneira, a idade em anos de um abalone. Outras medidas, como comprimento e peso, mais fáceis de serem obtidas, são utilizadas para predizer a idade (The Abalone da- 
taset, 2003). Esse conjunto é composto de 4177 exemplos e 8 atributos. Na Tabela 6.1 é feita uma descriçāo detalhada de todos os atributos do conjunto de dados abalone, utilizado para predizer o valor do atributo-meta rings. $O$ atributo nominal sex assume os valores M, F e I (Infantil).

\begin{tabular}{|l|c|c|cc|c|}
\hline Atributo & Descrição & Tipo & Mínimo & Máximo & Média + DP \\
\hline sex & scxo do abalone & nominal & - & - & \\
\hline length & comprimento da concha & continuo & 0.075 & 0,815 & $0.524 \pm 0,120$ \\
\hline diameter & diâmetro & contínuo & 0,055 & 0,650 & $0,408 \pm 0.099$ \\
\hline heightht & altura & contínuo & 0,000 & 1.130 & $0.140 \pm 0.042$ \\
\hline whole_weight & peso total & contínuo & 0,002 & 2,826 & $0,829 \pm 0,490$ \\
\hline shucked_weight & peso da carne & contínuo & 0,001 & 1,488 & $0.359 \pm 0.222$ \\
\hline viscera_weight & peso sem as visceras & contínuo & 0,001 & 0,760 & $0,181 \pm 0.110$ \\
\hline shell_weight & peso da conchá seca & contínuo & 0,002 & 1.005 & $0.239 \pm 0.139$ \\
\hline rings & número de anéis & continuo & 1 & 29 & $9,934 \pm 3.224$ \\
\hline
\end{tabular}

Tabela 6.1: Descrição detalhada dos atributos do conjunto de dados abalone

Dcpois de detalhado o conjunto de dados abalone, inicia-se entāo a apresentação dos resultados obtidos por meio das classes do ambiente DIPER.

\subsubsection{Conversão dos Regressores e Tratamento Semântico}

Para realizar a conversão dos regressores gerados pelos algoritmos de regressāo Cubist, RT, CART, REIIS, M5 Model e M5 Regression para o formato padrāo de regras de regressão utiliza-se a classe RegConvert descrita no capítulo anterior. Em seguida, por meio da classe RegSemantic aplica-se um tratamento semântico ao conjunto de regras já convertido no formato padrão. $\mathrm{Na}$ Figura 6.4 são apresentadas algumas regras geradas pelo algoritmo $\mathrm{Cu}-$ bist e na Figura 6.5 pode-se visualizar essas mesmas regras convertidas para o formato padrão de regras de regressão. Já na Figura 6.6 é apresentada a Model Tree gerada pelo algoritmo M5 do WEK $\Lambda$. Por meio dessa árvore, tornase mais fácil explicar um problema, descrito a seguir, que acontece com as árvores de regressão gcradas pelo WEKA e que precisou ser resolvido neste trabalho.

O algoritmo M5 do WEKA utiliza atributos nominais nos nós internos da árvore como pode ser visualizado na linhas 6 e 7 da Figura 6.6. No primeiro caso (linha 6), a condição sex $=\mathrm{M}, \mathrm{F} \ll=0.5$ equivale à condição sex $\ll \mathrm{M}, \mathrm{F}$. ou ainda, no caso do conjunto de dados abalone, que assume os valores $M, F$ e $l$ para o atributo sex, é o mesmo que sex IN $\{I\}$. O segundo caso (linha 7), a condição $\operatorname{sex}=M, F>0.5$ equivale à condição sex $I N\{M, F\}$. Portanto, as ârvores de regressāo geradas pelo algoritmo M5 do WEKA utilizam as expressōes $<=0 . \overline{\mathrm{e}}>0.5$ para dividir a ârvore em 2 sub-regiōes disjuntas. Ainda com relação à Figura 6.6, pode-se notar que o M5 Model utiliza atributos nominais nas equaçōes lineares que predizem o valor do atributo-meta. Por exemplo, na primeira equaçāo da árvorc (LM1), na linha 24, o segundo termo 


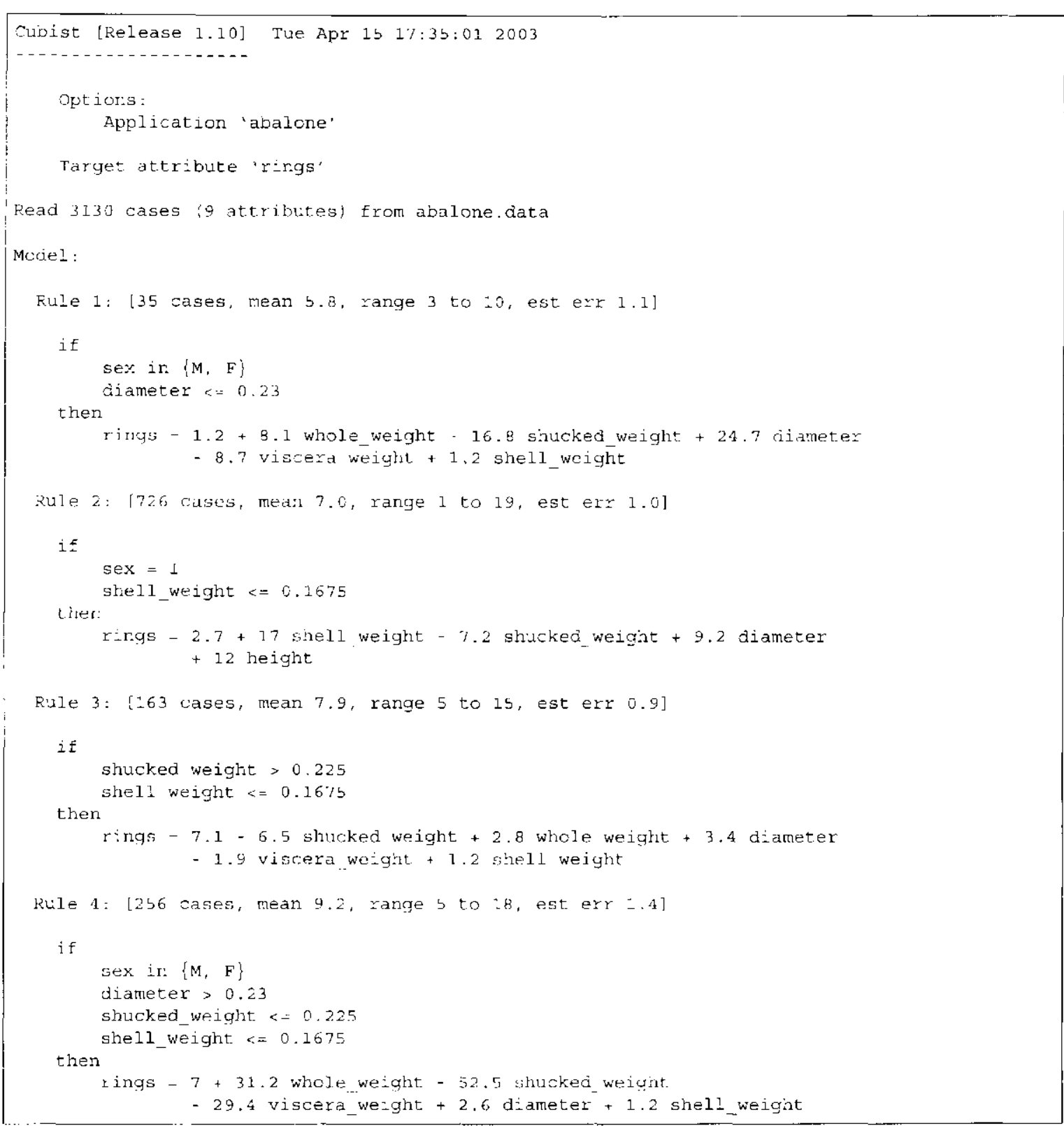

Figura 6.4: Regras geradas pelo Cubist com o conjunto de dados abalone

dessa equação é $0.0617 \mathrm{sex}=\mathrm{M}$, F. Isso significa que: se um exemplo cujo valor do atributo-meta a ser predito assume os valores $M$ ou $F$ para o atributo sex, então a constante 0.0617 deve ser adicionada à equação linear. Caso contrário (no caso do conjunto de dados abalone, se o atributo sex assumir o valor I), entāo o atributo-meta deve ser predito pela mesma equaçāo, porém, sem a soma dessa constante. Portanto, para converter uma árvore de regressāo desse tipo para o formato padrāo de regras de regressảo. para cada nó-folha que apresenta um atributo nominal desse tipo na equação linear devem ser geradas 2 regras: uma primeira, com a condiçāo assumindo os valores nominais cxplícitos (sex IN $\{M, F\})$ e uma equação linear associada com a constante (0.0617), e uma segunda regra, com a condição assumindo os demais valores 


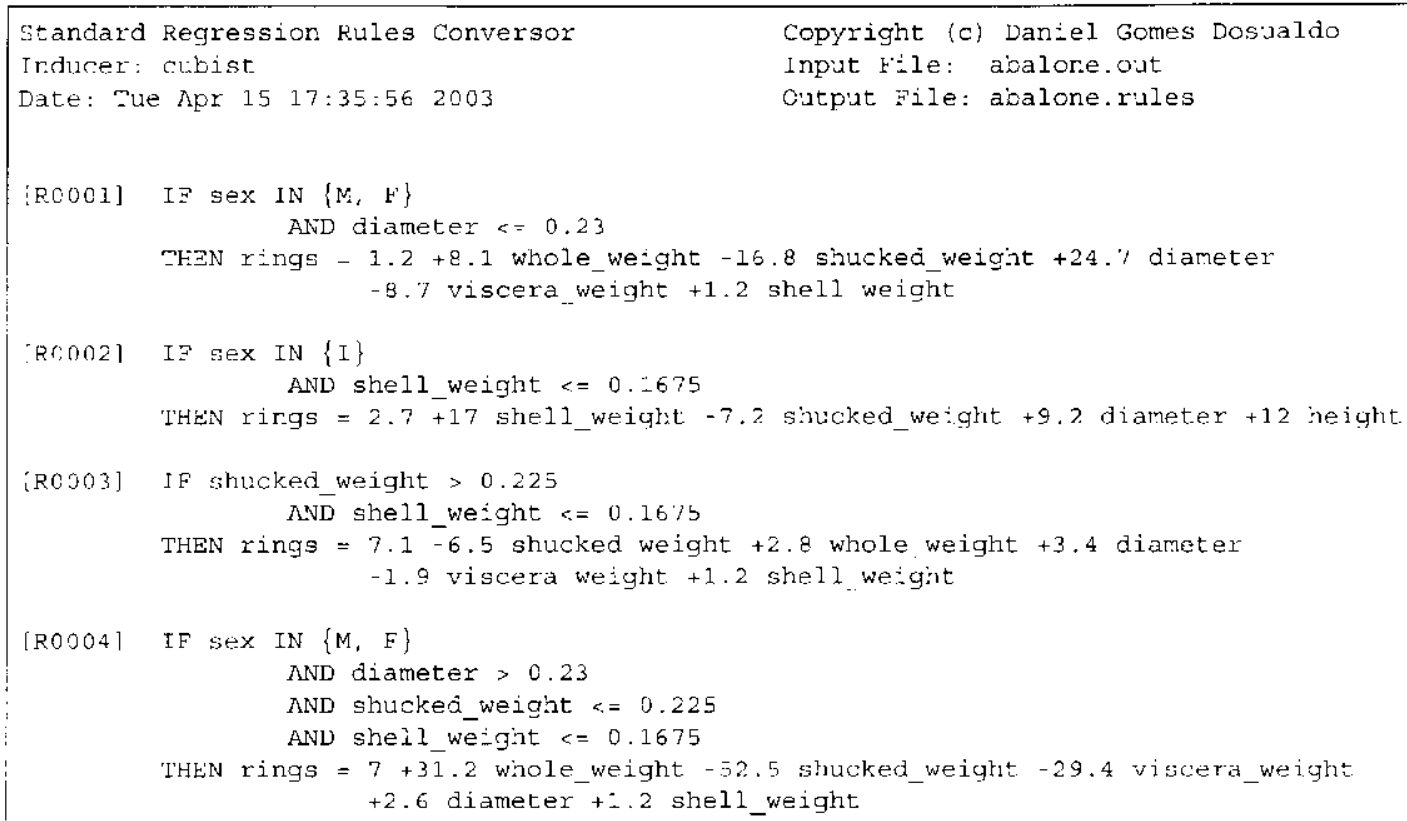

Figura 6.5: Regras convertidas do formato do Cubist para o formato padrão com o conjunto de dados abalone

nominais do atributo (sex IN $\{$ I $\}$ ) e com uma equação associada sem a constante. Essas 2 regras, correspondem, respectivamente, às regras [R0002] e [R0001] da Figura 6.7. No entanto, podem ocorrer ainda outras situaçōes:

- para alcançar o segundo nó-folha da árvore (LM2), uma das condições, apresentada na linha 6 da Figura 6.6 è sex $=M, F<=0.5$. Nesse caso, equivale à condição sex IN $\{I\}$. Acontcce que a equação linear associada à esse nó-folha, apresentada na linha 27, possui um termo 0.0631 sex $=M, F$, cuja parte sem a constante significa sex IN $\{M, F\}$. Porém, essa situação nunca acontecerá. Nesse caso, deve ser gerada uma única regra com a condição sex IN $\{$ I $\}$ associada com a equação linear LM2 scm a constante 0.0631, que corresponde à regra [R0003] da Figura 6.7;

- para alcançar o terceiro nó-folha da árvore (LM3), uma das condições, apresentada na linha 7 , è sex $=\mathrm{M}, \mathrm{F}>0.5$, portanto, sex $I N\{\mathrm{M}, \mathrm{F}\}$. Acontece que na equação linear LM3 associada à esse nó-folha, apresentada na linha 30 da Figura 6.6, existe o termo 0.0858 sex=M, F, ou seja, a mesma condição. Nesse caso, deve ser gerada uma única regra com a condiçāo sex IN $\{M, F\}$ associada da equação linear LM3 adicionada da constante 0.0858 , que corresponde à regra [R0004] da Figura 6.7;

No caso da Model Tree apresentada na Figura 6.6. como os demais nósfolha (LM4 até LM9) não apresentam condiçōes como as acima descritas, então 


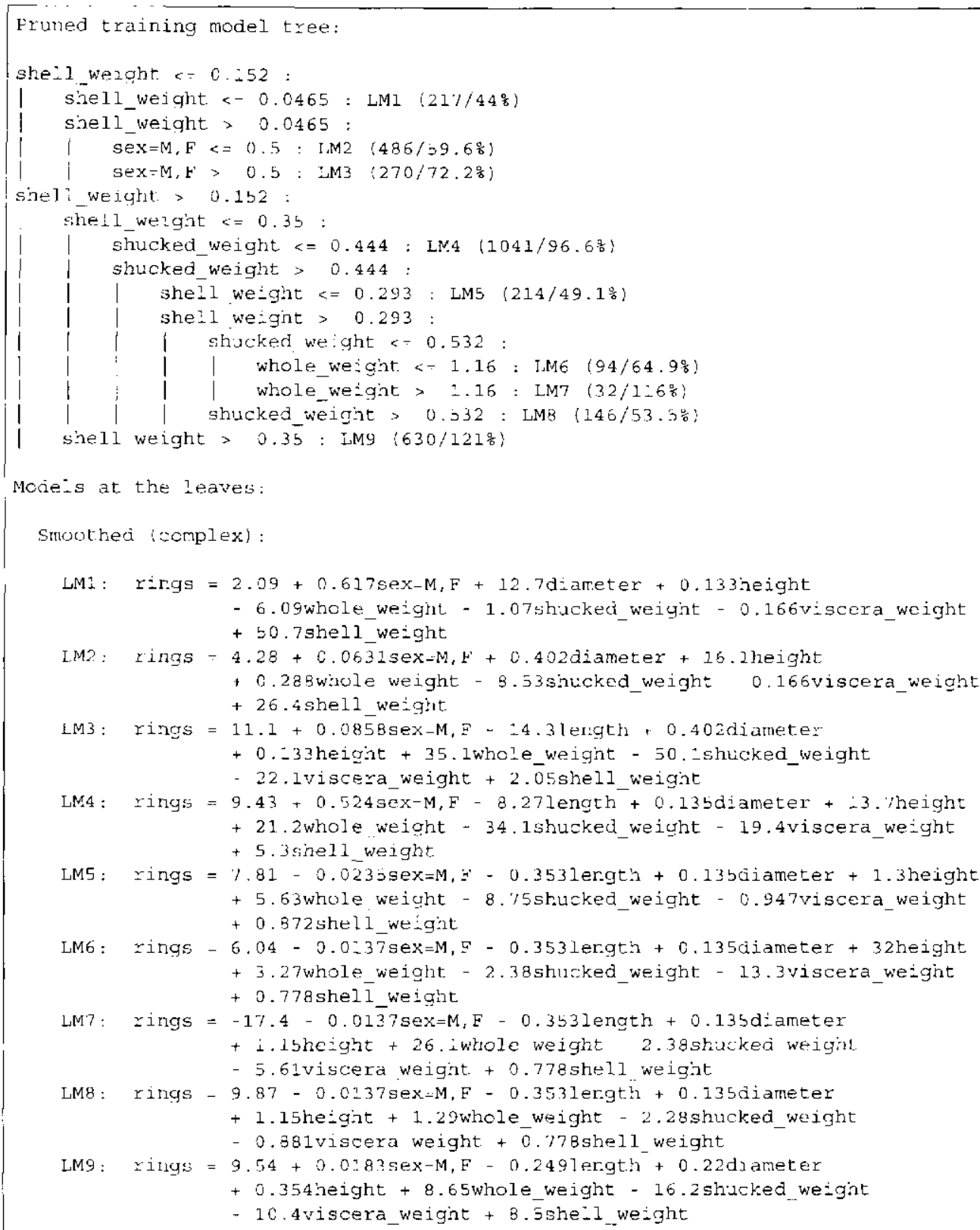

Figura 6.6: Model Tree gerada pelo M5 com o conjunto de dados abalone

para cada um desses nós-folha foram geradas 2 regras, uma com a constante e outra sem. Portanto, a partir dessa Model Tree com 9 nós-folha foram geradas 16 regras no formato padrão de regras de regressão.

A Model Tree gerada pelo algoritmo RETIS pode ser utilizada para mostrar a utilidade da classe RegSemantic, responsável pelo tratamento semântico. De acordo com a Figura 6.8, nota-se que para alcançar o primeiro nó-folha dessa árvore, na linha 18, são 3 as condiçōes presentes nos nós-internos da árvore: shell_weight $<=0.19$, na linha 12 ; shell_weight $<=0.07$, na linha $14 ; \mathrm{e}$ shell_weight $<=0.03$, na linha 16 . No entanto, é fâcil notar que a terceira condição sobrepõe as duas primeiras, pois o valor do atributo shell..weight 


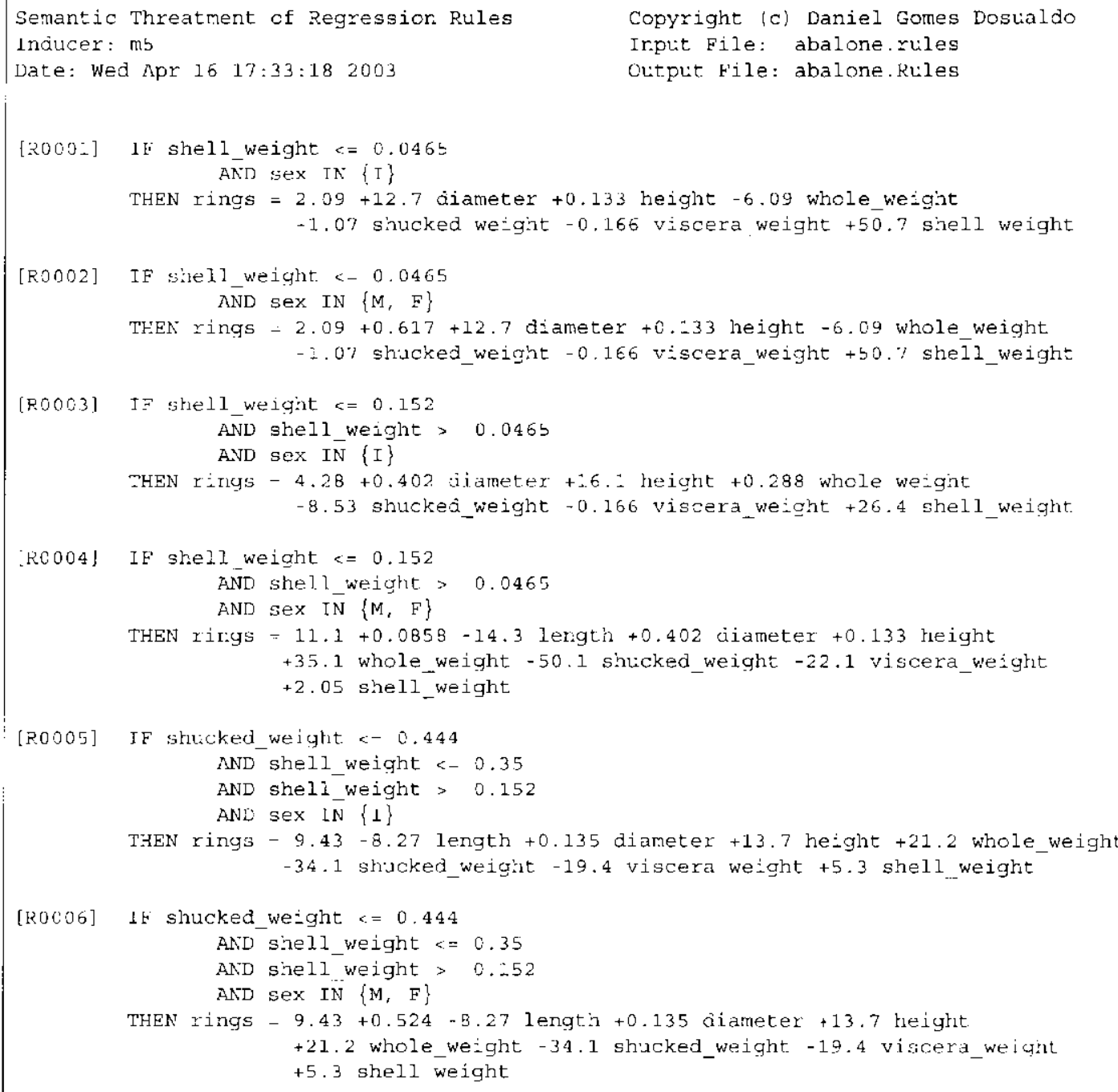

Figura 6.7: Algumas regras convertidas para o formato padrão a partir da Model Tree gerada pelo algoritmo M5 com o conjunto de dados abalone e semanticamente tratadas

precisa ser menor do que 0.03. Logo, após o tratamento semântico. esse nófolha gera a regra [R0001] da Figura 6.9, que apresenta o conjunto de regras gerado a partir da Model Tree da Figura 6.8.

\subsubsection{Precisāo dos Regressores no Conjunto de Dados Abalone}

Uma vez que os regressores foram convertidos para o formato padrão de regras de regressão, e o conjunto de regras passou pelo processo de tratamento semântico, o próximo passo consiste em avaliar esses regressores. $O$ primeiro fator a ser analisado é a precisão desse modelo. Como na regressão o atributo-meta a ser predito assume valores numéricos, então as medidas utilizadas são geralmente baseadas na diferença entre o valor predito pelo algoritmo e o valor real do atributo. As medidas mais utilizadas para calcular a precisāo em problemas de regressāo são as medidas MAD e MSE implementa- 


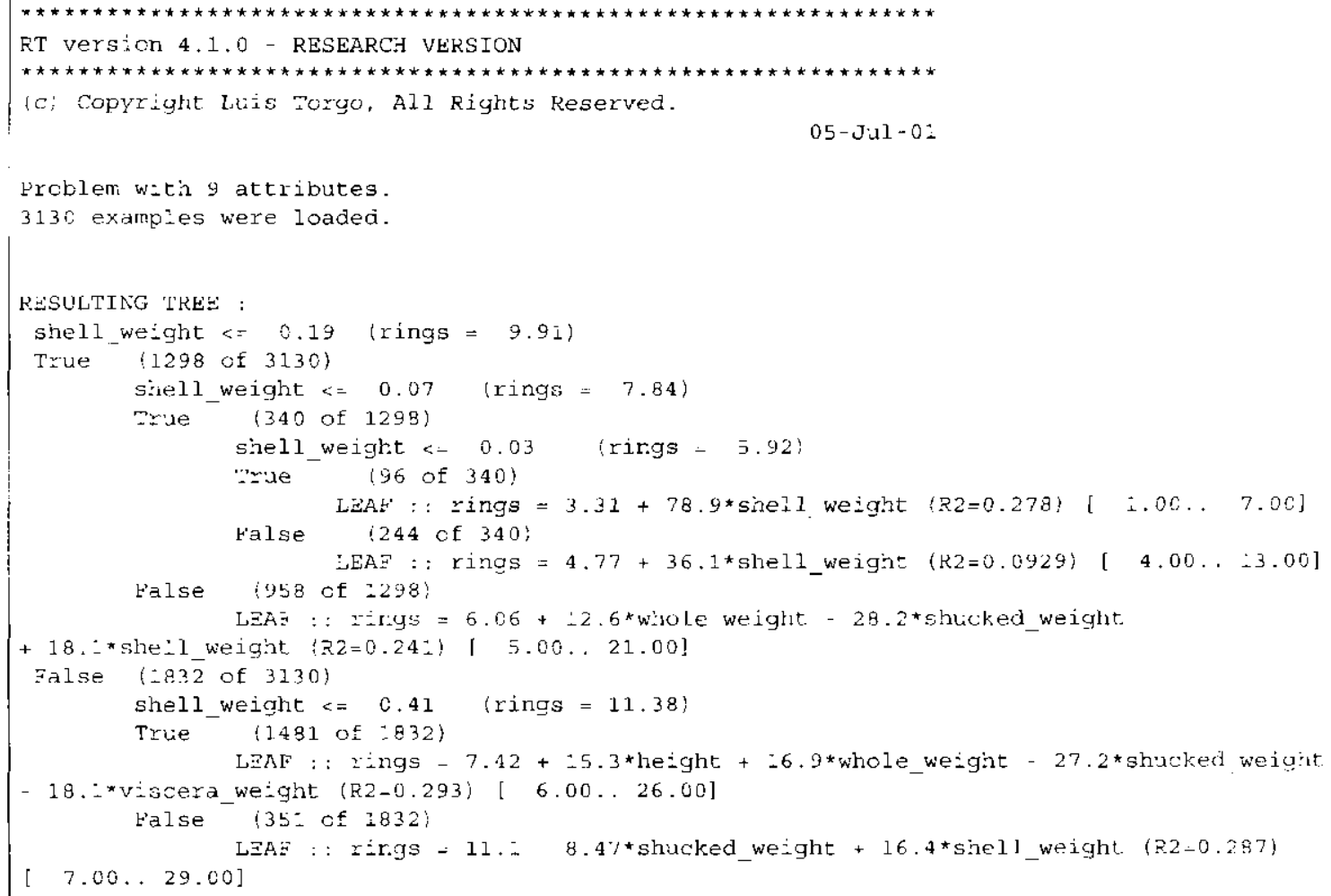

Figura 6.8: Model Tree gerada pelo RETIS com o conjunto de dados abalone

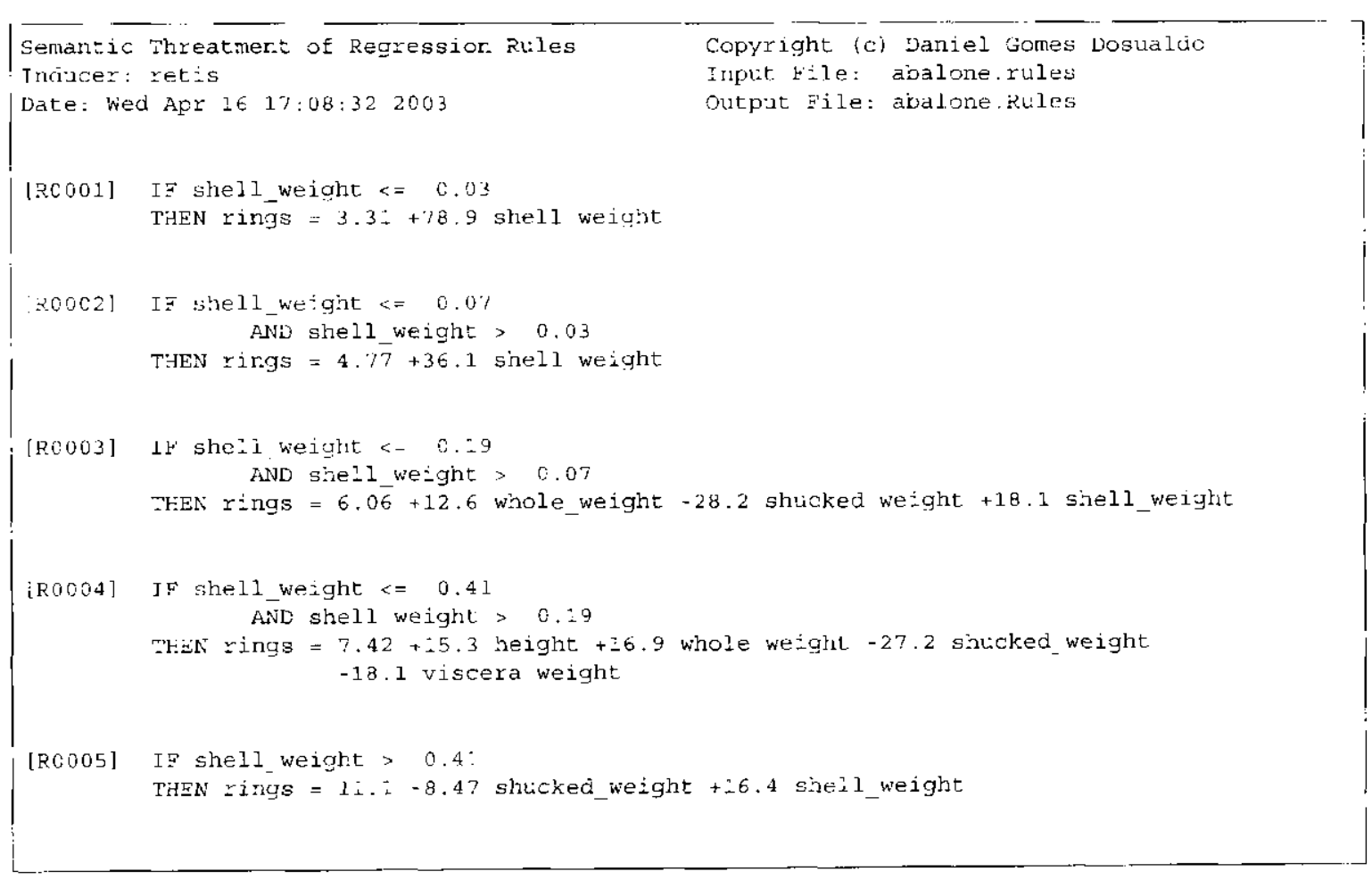

Figura 6.9: Conjunto de regras convertidas para o formato padrão a partir da Model Tree gerada pelo RETIS com o conjunto de dados abalone 
das na classe RegMeasures do ambiente DIPER. Como apresentado no início deste capítulo, para efeito do cálculo das medidas de precisão utilizou-se 10fold cross-validation. Na Tabela 6.2 sāo apresentados os valores da medida MAD calculada sobre cada um dos algoritmos de regressão executados. Nessa tabela é apresentado o valor da MAD em cada uma das dez partições, a média e o desvio-padrão (DP) desses valores.

\begin{tabular}{|c|c|c|c|c|c|c|}
\hline Partição & Cubist & RT & CART & RETIS & M5 Model & M5 Reg \\
\hline 1 & $1 . \overline{20}$ & 1,29 & 1,42 & 1,40 & 1,30 & 1,20 \\
\hline 2 & 1,07 & 1,13 & 1.70 & 1,15 & 1,18 & 1,10 \\
\hline 3 & 2.35 & 2,40 & 2,83 & 2.24 & 2,44 & 2,50 \\
\hline 4 & 1,34 & 1.52 & 1,52 & 1,45 & 1.47 & 7.50 \\
\hline 5 & 1.42 & 1,60 & 1,61 & 1,49 & 1,40 & 1,50 \\
\hline 6 & 1,08 & 1.22 & 1.52 & 1,30 & 1,20 & 1.20 \\
\hline 7 & 1.25 & 1,28 & 1,86 & 1,34 & 1.29 & 1.20 \\
\hline 8 & 1,76 & 1,85 & 2,46 & 1,70 & 1,88 & 1,90 \\
\hline 9 & 2,68 & 2,77 & 3.03 & 2.60 & 2,61 & 2.70 \\
\hline 10 & 2.00 & 2.07 & 2,16 & 1,79 & 2.11 & 2,10 \\
\hline$\overline{M e ́ d i a} \pm \overline{D P}$ & $1.6010,60$ & $1.71 \dashv 0,54$ & $2,01 \pm 0.56$ & $1,60 \div 0,60$ & $1,69 \pm 0.50$ & $1.70 \perp 0.40$ \\
\hline
\end{tabular}

Tabela 6.2: MAD calculada no conjunto de dados abalone

Já na Tabela 6.3 pode-se visualizar os valores da medida MSE calculada em cada partição para cada algoritmo executado, a média c o desvio-padrão desses valores.

\begin{tabular}{|c|c|c|c|c|c|c|}
\hline Partiçāo & Cubist & RT & CART & RETIS & M5 Model & M5 Reg \\
\hline 1 & $2.1 \overline{60}$ & 2,960 & $\overline{3,014}$ & $\begin{array}{l}3,218 \\
\end{array}$ & 3,029 & 2,880 \\
\hline 2 & 1,905 & 2,230 & 4,120 & 2,179 & 2,308 & 2,160 \\
\hline 3 & 9,591 & 10.310 & 14.476 & 9,526 & 10.709 & 11,450 \\
\hline 4 & 3,646 & 4,460 & 4.392 & $4, \overline{945}$ & 4.249 & 4.320 \\
\hline 5 & $3,6 \overline{64}$ & 4,580 & 3,781 & 3.481 & 3.342 & 3,840 \\
\hline 6 & 1,987 & 2,560 & 3,322 & 2,850 & 2.446 & 2,490 \\
\hline 7 & 2,488 & 2.660 & 4,670 & 2,934 & 2,737 & 2,510 \\
\hline 8 & 6.583 & 7.270 & 11,142 & 6.150 & 6.486 & 7.830 \\
\hline 9 & 13,280 & 14,010 & 16,420 & 12,400 & 12,704 & $13,7 \overline{30}$ \\
\hline 10 & 7,870 & 7.920 & 9.449 & 6,211 & 8,154 & 7.800 \\
\hline$\overline{\text { Média+DP }}$ & $5.35+3.86$ & $5,89+3,92$ & $7,48+5,08$ & $5.39 \pm 3.31$ & $5,62 \pm 3,74$ & $5.90 \pm 4.11$ \\
\hline
\end{tabular}

Tabela 6.3: MSE calculada no conjunto de dados abalone

Como pode ser visualizado nas Tabela 6.2 e 6.3, os algoritmos Cubist, RETIS e M5 Model obtiveram os valores mais baixos na média, tanto da medida MAD quanto da MSE. Isso pode ser explicado pclo fato de que esses algoritmos geralmente realizam suas predições por meio de uma equação linear. o que lhes permite associar pesos aos atributos mais significantes do conjunto de dados nessas equaçōes.

\subsubsection{Teste de Hipóteses com o Conjunto de Dados Abalone}

Como comentado no capítulo anterior, nāo se pode afirmar se um algoritmo è melhor que outro levando-sc em consideração apenas medidas de erro. Para compará-los é necessária a realizaçāo de um teste de hipóteses. Para comparar a precisāo dos algoritmos de regressão e decidir qual deles apresenta melhor desempenho sobre o conjunto de dados abalone, realizou-se o teste 
que foi implementado na classe RegHypothesis. Na Tabela 6.4 são apresentados os resultados desse teste sobre o conjunto de dados abalone. Nessa tabela são descritos os valores obtidos na comparação dois a dois entre os algoritmos, a média, desvio-padrão e diferença cntre esses dois algoritmos e qual deles supera o outro.

\begin{tabular}{|c|c|c|c|c|c|}
\hline$A_{S}$ & $A_{\Gamma^{\prime}}$ & mediu $\left(A_{S}-A_{P}\right)$ & $d p\left(A_{S}-A_{P}\right)$ & $a d\left(A_{S}-A_{P}\right)$ & Melhor \\
\hline \hline Cubist & RT & $-0,1$ & 0,57 & $-0,2$ & Cubist \\
\hline Cubist & CART & $-0,4$ & 0,58 & -0.7 & Cubist \\
\hline Cubist & RETIS & 0 & 0,6 & 0 & - \\
\hline Cubist & M5 Model & $-0,1$ & 0,55 & $-0,2$ & Cubist \\
\hline Cubist & M5 Reg & $-0,1$ & 0,50 & $-0,2$ & Cubist \\
\hline RT & CART & -0.3 & 0,55 & $-0,55$ & RT \\
\hline R'T & RETIS & 0,1 & 0.57 & 0.2 & RETIS \\
\hline RT & M5 Model & 0.02 & 0,52 & 0,04 & M5 Model \\
\hline RT & M5 Reg & 0 & 0,47 & 0 & - \\
\hline CART & RETIS & 0,4 & 0,58 & 0,7 & RETIS \\
\hline CART & M5 Model & 0,32 & 0,53 & 0,6 & M5 Model \\
\hline CART & M5 Reg & 0.3 & 0,48 & 0,6 & M5 Reg \\
\hline RETIS & M5 Model & $-0,1$ & 0,55 & $-0,2$ & RETIS \\
\hline RETIS & M5 Reg & $-0,1$ & 0,51 & $-0,2$ & RETIS \\
\hline M5 Model & M5 Reg & 0 & 0,45 & 0 & - \\
\hline
\end{tabular}

Tabela 6.4: Resultado do teste de hipóteses realizado com o conjunto de dados abalone

Analisando a Tabela 6.4 pode-se verificar que nenhum algoritmo pode ser considerado melhor que todos os demais com relação ao conjunto de dados abalone. Os algoritmos que apresentaram melhores resultados foram o $\mathrm{Cu}$ bist, RETIS e M5 Model, que já haviam obtido os valores mais baixos da medida MAD. Porém, não se pode afirmar qual deles foi o melhor nos experimentos realizados com o conjunto de dados abalone. Além disso, nota-se também que o algoritmo $\mathrm{C} \Lambda \mathrm{RT}$ foi superado por todos os demais algoritmos de regressāo utilizados neste trabalho.

\subsubsection{Compreensibilidade das Regras geradas a partir do Conjunto de Dados Abalone}

Além da precisão, outro fator que deve ser avaliado é a compreensibilidade do regressor. Neste trabalho, a compreensibilidade foi calculada de acordo com o número de condições de uma regra e do número de termos existentes na equação linear, no caso dos algoritmos que realizam suas prediçōes desse modo. Portanto, as regras geradas pelos algoritmos RT, CART e M5 Regression não podem ser avaliados por esse segundo fator. Para calcular as medidas de compreensibilidade também utiliza-se a classe RegMeasures. Como descrito, para avaliar a compreensibilidade, foi gerado um regressor para cada algoritmo utilizando os conjuntos de treinamento e teste. Na Tabela 6.5 são apresentados o número de condições antes do tratamento semântico (\#Cond 
antes), o número de condiçōes depois do tratamento semântico (\#Cond depois) e o número de atributos na equação linear (\#Atrib equaçāo) de cada regra de regressão gerada pelos algoritmos M5 Model, Cubist e RETIS. Por meio dessa tabela verifica-se que o número de condições das regras geradas pelo Cubist nāo se alteraram após o tratamento semântico, uma vez que esse algoritmo já gera um conjunto de regras.

\begin{tabular}{|c|c|c|c|c|c|c|c|c|c|}
\hline & \multicolumn{3}{|c|}{ M5 Model } & \multicolumn{3}{|c|}{ Cubist } & \multicolumn{3}{|c|}{ RETIS } \\
\hline $\begin{array}{c}\# \\
\text { Rcgra }\end{array}$ & $\begin{array}{l}\text { \#Cond } \\
\text { antes }\end{array}$ & $\begin{array}{l}\text { \#Cond } \\
\text { depois }\end{array}$ & $\begin{array}{l}\text { \#Atrib } \\
\text { equação }\end{array}$ & $\begin{array}{l}\text { \#Cond } \\
\text { aniles }\end{array}$ & $\begin{array}{l}\text { \#Cond } \\
\text { depois }\end{array}$ & $\begin{array}{l}\text { \#Atrib } \\
\text { equaçăo }\end{array}$ & $\begin{array}{l}\text { \#Cond } \\
\text { antes }\end{array}$ & $\begin{array}{l}\text { \#Cond } \\
\text { depois }\end{array}$ & $\begin{array}{l}\text { \#Atrib } \\
\text { equaçāo }\end{array}$ \\
\hline 1 & 3 & 2 & 6 & 2 & 2 & 5 & 3 & 1 & 1 \\
\hline 2 & 3 & 2 & 6 & 2 & 2 & 4 & 3 & 2 & 1 \\
\hline 3 & 3 & 3 & 6 & 2 & 2 & 5 & 2 & 2 & 3 \\
\hline 4 & 3 & 3 & 7 & 4 & 4 & 5 & 2 & 2 & 4 \\
\hline 5 & 4 & 4 & 7 & 4 & 4 & 5 & 2 & 1 & 2 \\
\hline 6 & 4 & 4 & 7 & 3 & 3 & 5 & - & - & - \\
\hline 7 & 5 & 4 & 7 & 1 & 1 & 3 & - & - & - \\
\hline 8 & 5 & 4 & 7 & 2 & 2 & 4 & - & - & - \\
\hline 9 & 7 & 6 & 7 & 4 & 4 & 5 & & & \\
\hline 10 & 7 & 6 & 7 & 2 & 2 & 5 & - & - & - \\
\hline 11 & 7 & 6 & 7 & 3 & 3 & 4 & - & - & - \\
\hline 12 & 7 & 6 & 7 & 3 & 3 & 5 & - & - & - \\
\hline 13 & 6 & 4 & 7 & 3 & 3 & 5 & & & \\
\hline 14 & 6 & 4 & 7 & - & -- & -- & - & - & - \\
\hline 15 & 3 & 2 & 7 & - & - & - & - & - & -. \\
\hline 16 & 3 & 2 & 7 & - & - & - & - & - & - \\
\hline
\end{tabular}

Tabela 6.5: Compreensibilidade calculada no conjunto de dados abalone

$\Lambda$ nalisando a Tabela 6.5 , nota-se que a regra mais comprecnsivel é a regra \#1 gerada pelo RETIS, que possui uma única condição e apenas um atributo na equaçāo linear. Depois dessa aparecem as regras \#2 e \#5 geradas pelo RETIS e a regra \#7 gerada pelo Cubist. A regra mais compreensivel gerada pelo M5 Model é a regra \#1. que apresenta uma única condiçāo. mas que possui 6 atributos na equação linear.

\subsubsection{Tabela de Contingência para Regras de Regressão do Conjunto de Dados Abalone}

Portanto, para construir as tabclas de contingência das regras de regressāo. também foi levado em consideração um único regressor para cada algoritmo, como mostrado na Figura 6.3. Para analisar as tabelas de contingência geradas foram utilizados os regressores gerados pelos algoritmos Cubist, M5 Model, RETIS e CART. Os regressores gerados pelos algoritmos RT e M5 Regression foram omitidos devido ao grande número de regras gerado por eles, 48 e 47 , respectivamente.

Para a geraçāo dos pseudo-intervalos foram utilizados os valores do atributo-meta dos conjuntos de treinamento e teste, os mesmos utilizados na geraçāo dos regressores. O valor adotado para o número de pseudo-intervalos foi 3, porque o atributo-meta rings do conjunto de dados abalone assume valores inteiros no intervalo de 1 a 29, constituindo assim, um pequeno intervalo do conjunto de dados. Dessa maneira, primeiramente foi utilizado o valor 4 
para o número de pseudo-intervalos, porém, com esse número, um dos intervalos gerado era composto apenas pelos números 8 e 9 . Assim, optou-se por utilizar 3 pseudo-intervalos, descritos na Tabela 6.6.

\begin{tabular}{|c|c|c|}
\hline Intervalo & Valor Mínimo & Valor Máximo \\
\hline \hline 1 & 1 & 8 \\
\hline 2 & 9 & 12 \\
\hline 3 & 13 & 29 \\
\hline
\end{tabular}

Tabela 6.6: Pseudo-intervalos gerados com o conjunto de dados abalone

Depois de gerados os pseudo-intervalos, utilizou-se o conjunto de validação, que ainda não fora utilizado, para construir as tabelas de contingência e calcular as medidas derivadas. Para avaliar a precisāo dos resultados obtidos por meio da tabela de contingência gerada com 3 pseudo-intervalos, nas Tabelas 6.7, 6.8 e 6.9 são apresentados, respectivamente, para o Cubist, M5 Model e RETIS: os valores da medida MAD calculada com a classe RegMeasures, a precisāo normalizada calculada por meio da medida MAD, a precisão (Acc) calculada por meio da tabela de contingência com 3 pseudo-intervalos e as demais medidas derivadas dessa tabela.

\begin{tabular}{|c|c|c|c|c|c|c|c|c|c|c|c|}
\hline Regra & \#Extmplos & MAD & Precisāo & Acc & Negkel & Sens & sper & $\overline{C O U}$ & Sup & Nov & Sut \\
\hline 1 & 10 & 1,08 & 0,75 & $0,9 \overline{0}$ & $0, \overline{376}$ & $0,0 \overline{13}$ & 0.997 & $\overline{0,009}$ & 0,008 & 0,002 & 0,732 \\
\hline 2 & 227 & 0.89 & 0.93 & 0.93 & 0,375 & 0,270 & 0,889 & 0,217 & 0,181 & 0,035 & 0,493 \\
\hline 3 & 53 & 1.05 & 0.89 & 0.75 & 0.481 & $0.0 \overline{72}$ & $0,97 \overline{3}$ & 0,050 & 0,038 & 0,011 & $0 . \overline{480}$ \\
\hline 4 & 70 & 1.68 & 0.77 & $0,71^{\circ}$ & 0.380 & $\overline{0,066}$ & 0.932 & 0,067 & 0,04 & $0,0 \overline{3}$ & -0.011 \\
\hline 5 & 163 & 1,57 & 0.79 & 0,68 & 0.417 & 0,156 & 0.844 & $0 . \overline{156}$ & 0,090 & 0,006 & 0,001 \\
\hline 6 & 96 & 1,55 & 0.80 & 0.62 & 0,347 & 0,088 & 0,901 & 0.091 & 0,057 & -0.02 & $-0, \overline{072}$ \\
\hline 7 & 35.3 & 1.57 & 0.79 & 0.75 & 0.360 & 0,376 & 0,743 & 0,338 & 0,255 & 0.026 & $0 . \overline{240}$ \\
\hline 8 & 114 & 1,93 & $0 . \overline{72}$ & 0,66 & $0,3 \overline{83}$ & 0,117 & $0 . \overline{0.903}$ & 0.109 & 0,072 & $0, \overline{004}$ & $0, \overline{118}$ \\
\hline 9 & 30 & 2,20 & 0.67 & 0,53 & 0,623 & 0,040 & $0 . \overline{978}$ & 0,028 & 0.015 & 0,004 & 0.245 \\
\hline 10 & 145 & 2.08 & 0,69 & 0,55 & $\overline{0,406}$ & 0,151 & 0.873 & 0,138 & 0,090 & 0,007 & $0 . \overline{132}$ \\
\hline 11 & 29 & 2,91 & 0.54 & 0.55 & 0,819 & $0,080^{\circ}$ & $\overline{0.984}$ & 0,027 & 0,015 & 0,010 & 0,446 \\
\hline 12 & 54 & 2.49 & 0.62 & 0.53 & 0.552 & 0,061 & 0,956 & 0,051 & 0.027 & 0,004 & 0.155 \\
\hline 13 & 24 & 2,98 & $0 . \overline{53}$ & 0,54 & 0,657 & 0,035 & 0,983 & 0.022 & 0.012 & 0,004 & $0 . \overline{298}$ \\
\hline
\end{tabular}

Tabela 6.7: Medidas calculadas sobre o regressor gerado pelo Cubist com o conjunto de dados abalone

No geral, analisando as Tabelas 6.7, 6.8, 6.9 e 6.10, verifica-se que os valores da precisāo calculados pela tabela de contingência construída com 3 pseudo-intervalos acompanharam a variação da medida MAD calculada sobre as regras. Por exemplo, com relação ao regressor gerado pelo algoritmo RETIS, com exceçāo da regra \#3, que apresentou valores um pouco diferentes entre as precisões calculadas por meio da MAD e pela tabela de contingência, as demais regras apresentaram valores muito próximos. A única regra em que os valores foram bem diferentes foi na regra \#2 gerada pelo algoritmo CART, sendo que nessa regra, a precisão calculada por meio da medida MAD foi 0,74 e a precisão obtida pela tabela de contingência foi 0,43 . 


\begin{tabular}{|c|c|c|c|c|c|c|c|c|c|c|c|}
\hline Regrad & \# Exemplos & MAD & Precisão & $A C C$ & NegRel & Sens & Spec & Cov & Sup & Nov & Sut \\
\hline 1 & 60 & $0, \overline{84}$ & 1 & 0.98 & 0.653 & 0,147 & 0,998 & 0,057 & 0,056 & 0,034 & $0 . \overline{972}$ \\
\hline 2 & 8 & 0,99 & 0.96 & 1 & 0,655 & 0,021 & 1 & 0,007 & 0,007 & 0,004 & 1 \\
\hline 3 & 163 & 0,89 & 0.98 & 0,80 & 0,374 & 0,193 & 0.914 & 0,156 & 0.126 & 0,024 & 0,449 \\
\hline 4 & 82 & 1,57 & 0.79 & 0,62 & 0,427 & 0.084 & 0,929 & 0,078 & 0,048 & 0.003 & 0.107 \\
\hline 5 & 353 & 1,71 & 0,75 & 0.59 & 0,408 & 0,340 & 0,665 & 0.338 & 0,202 & 0.001 & 0,009 \\
\hline 6 & 249 & 1.87 & 0,70 & 0,58 & 0.483 & 0,262 & 0.788 & 0,238 & 0.139 & 0,012 & 0,113 \\
\hline 7 & 59 & 0,95 & 0,96 & 0,79 & 0,359 & 0,069 & $0, \overline{967}$ & 0,056 & 0,045 & 0,008 & 0,419 \\
\hline 8 & 52 & 0,94 & 0,97 & 0,78 & 0.355 & 0.060 & 0,969 & 0,049 & 0.039 & 0.006 & 0,393 \\
\hline 9 & 36 & 1,15 & 0.91 & 0,88 & 0,438 & 0,053 & 0,991 & 0,034 & 0.030 & 0.010 & 0,739 \\
\hline 10 & 34 & 1,15 & 0,91 & 0,88 & 0.436 & 0,050 & 0.991 & 0,032 & 0.028 & 0,010 & 0.723 \\
\hline 11 & 20 & 2,33 & 0.58 & 0.65 & 0.556 & 0.029 & 0,989 & 0,019 & 0,013 & 0.004 & 0,456 \\
\hline 12 & 20 & 2,33 & 0.58 & 0,65 & 0,556 & 0.031 & 0,991 & 0.019 & 0,014 & 0.005 & 0,546 \\
\hline 13 & 47 & 1,38 & 0,85 & 0,74 & 0.500 & 0,065 & 0.976 & 0,045 & 0,033 & 0,010 & 0.478 \\
\hline 14 & 45 & 1,39 & 0,84 & 0.73 & 0,499 & 0,061 & 0,976 & 0,043 & 0.031 & 0.009 & 0,455 \\
\hline 15 & 224 & 1,97 & 0.68 & 0.71 & 0,515 & 0,287 & 0,868 & 0,214 & 0,153 & 0.038 & 0,387 \\
\hline 16 & 217 & 1,92 & 0.70 & 0.71 & 0,515 & 0.280 & 0,874 & 0.207 & 0,149 & 0,038 & 0,397 \\
\hline
\end{tabular}

Tabela 6.8: Medidas calculadas sobre o regressor gerado pelo M5 Model com o conjunto de dados abalone

\begin{tabular}{|c|c|c|c|c|c|c|c|c|c|c|c|}
\hline Regra & "Exemplos & MAD & Precisầ & Acc & Negkel & Serls & Spec & $\mathrm{Cou}$ & Sup & Nov & Sat \\
\hline 1 & 30 & 0,63 & 1 & 1 & 0,730 & 0,099 & 1 & 0,028 & 0.028 & 0,020 & 1 \\
\hline 2 & 84 & 1,14 & 0,87 & 0.85 & 0,617 & 0.164 & 0,980 & 0,080 & 0,068 & 0,035 & 0.753 \\
\hline 3 & 301 & 1.37 & 0,82 & 0,68 & 0,359 & 0,283 & 0,702 & 0.288 & 0,180 & $-0,003$ & -0.031 \\
\hline 4 & 517 & 1.69 & 0.74 & 0,66 & 0.574 & 0.611 & 0,647 & 0.495 & 0.337 & 0,063 & 0.288 \\
\hline 5 & 112 & 2,16 & 0,62 & 0,64 & 0.188 & 0.131 & 0.919 & 0,107 & 0.068 & 0.012 & 0.246 \\
\hline
\end{tabular}

Tabela 6.9: Medidas calculadas sobre o regressor gerado pelo RETIS com o conjunto de dados abalone

\begin{tabular}{|c|c|c|c|c|c|c|c|c|c|c|c|}
\hline Regra & HExemplos & MAD & Precisão & AcC. & NegRel & Sens & Spec & $\mathrm{CoO}$ & Sup & Nov & Sat \\
\hline l & 114 & 1,25 & 0,88 & $\overline{0,89}$ & 0.752 & 0.307 & 0,983 & 0,109 & $0,0 \overline{97}$ & $\overline{0.062}$ & 0.845 \\
\hline 2 & 301 & 1.64 & 0,74 & 0,43 & 0,429 & 0,203 & 0,623 & 0,288 & 0,103 & $-0,043$ & $-0,307$ \\
\hline 3 & 517 & 1,98 & 0,62 & 0,66 & 0,639 & 0,642 & 0,658 & 0,495 & 0.327 & 0.075 & 0.309 \\
\hline 4 & 112 & 2,73 & 0.35 & 0.36 & 0,850 & 0.227 & 0,917 & 0,107 & 0,039 & 0,020 & 0,234 \\
\hline
\end{tabular}

Tabela 6.10: Medidas calculadas sobre o regressor gerado pelo CART com o conjunto de dados abalone

\subsection{Experimentos com o Conjunto de Dados Housing}

O conjunto de dados utilizado para realizar o segundo ciclo de experimentos foi o conjunto denominado housing (ou Boston Housing). também retirado do repositório de dados da UCI (Blake \& Merz, 1998).

O conjunto de dados housing é formado por fatores sócio-econômicos que determinam a compra de imóveis no subúrbio da cidade de Boston, nos Estados Unidos. Baseado nesses fatores, o objetivo é tentar predizer o valor de um imóvel na cidade de Boston. Esse conjunto foi utilizado em um trabalho descrito em (Quinlan, 1993b) sobre a combinação de aprendizados baseados em regras e exemplos para melhorar a precisão das regras. Ele é formado por 506 exemplos e 14 atributos, todos eles continuos. Na Tabela 6.11 é feita uma descrição detalhada de todos os atributos do conjunto de dados housing. utilizados para predizer o valor do atributo-meta MedHouseVal. Nessa tabcla foi omitido o tipo do atributo, já que todos são contínuos.

Novamente, detalhado o conjunto de dados utilizado, inicia-se então a 
6.2 Experimentos com o Conjunto de Dados Housing

\begin{tabular}{|c|c|c|c|c|}
\hline Atributo & Descrição & Mínimo & Máximo & Média \pm DP \\
\hline CRIM & taxa de crime por regiāo & 0,00632 & $8 \overline{88,9762}$ & $3,61 \pm 8,60$ \\
\hline$Z N$ & indice de ocupação por área & 0,0 & 100,0 & $\overline{11,36} \pm 23,32$ \\
\hline INDUS & indice de comércio por ârea & $0, \overline{46}$ & 27.74 & $11,14 \pm 6.86$ \\
\hline CHAS & atributo simulado Charles River & $\overline{0}$ & l & - \\
\hline NOX & concentração de óxidos nitricos & $0, \overline{385}$ & 0,871 & $0,55 \pm 0,12$ \\
\hline $\mathrm{RM}$ & número de cômodos por habitaçāo & $3, \overline{561}$ & 8.78 & $6,28 \pm 0,70$ \\
\hline$\overline{A G E}$ & $\begin{array}{l}\text { proporção de unidades ocupadas } \\
\text { pelo dono antes de } 1940\end{array}$ & 2,9 & 100,0 & $68,57 \perp 28,15$ \\
\hline DIS & $\begin{array}{l}\text { distância para } 5 \text { grandes } \\
\text { centros de trabalho }\end{array}$ & $1,1 \overline{296}$ & 12,1265 & $3,79 \pm 2,10$ \\
\hline RAD & $\begin{array}{l}\text { indice de acessibilidade } \\
\text { às rodovias radiais }\end{array}$ & 1,0 & 24.0 & 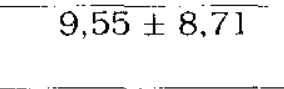 \\
\hline TAX & taxa sobre o valor do imóvel & 187,0 & 711,0 & $408.24 \pm 168,54$ \\
\hline PIRATIO & taxa professor-aluno por região & 12,6 & 22.0 & $18,45+2,16$ \\
\hline $\mathrm{B}$ & proporção de negros por cidade & 0,32 & 396.9 & $356,67 \pm 91,29$ \\
\hline ISTAT & porcentagem de população pobre & 1,73 & 37,97 & $12,65 \pm 7.14$ \\
\hline MedHouseVal & valor do imóvel & 5,0 & 50,0 & $22.53+9,20$ \\
\hline
\end{tabular}

Tabela 6.1 1: Descrição detalhada do conjunto de dados housing

apresentação dos resultados obtidos.

\subsubsection{Conversão dos Regressores e Tratamento Semântico}

As classes RegConvert e RegSemantic sāo utilizadas para converter os regressores gerados pelos algoritmos de regressão para o formato padrão de regras de regressão, e posteriormente, aplicar o tratamento semântico ao conjunto de regras já nesse formato. Na Figura 6.10 é apresentada a Regression Tree gerada pelo algoritmo M5 do WEKA com o conjunto de dados housing. A Figura 6.10 foi modificada em virtude do número de nós-folha gerado: as tags LM1, LM2,... LM22 foram substituidas nessa figura pelos valores das constantes associados à cada nó-folha, uma vez que na saída original do WEKA essas constantes aparecem logo abaixo da representação da árvore, assim como na Figura 6.6, que apresentava a Model Tree gerada pelo WEKA no primeiro ciclo de experimentos. Na Figura 6.11 pode-se visualizar algumas regras que foram convertidas a partir dessa Regression Tree para o formato padrão. Porém, nota-se que as regras [R0011], [R0012], [R0015] e [R0016] apresentam muitas condiçōes desnecessárias. Assim, na Figura 6.12 são apresentadas essas mesmas regras depois do tratamento semântico. Por fìm, nas Figuras 6.13 e 6.14 são apresentados, respectivamente, a Regression Tree gerada pelo algoritmo CART, e o conjunto de regras convertido para o formato padrão a partir dessa árvore.

\subsubsection{Precisão dos Regressores no Conjunto de Dados Housing}

Assim como no primeiro ciclo de experimentos, para calcular as medidas de precisão foi utilizado o método 10-fold cross-validation. Na Tabela 6.12 são apresentados os valores da medida MAD calculada sobre cada um dos 


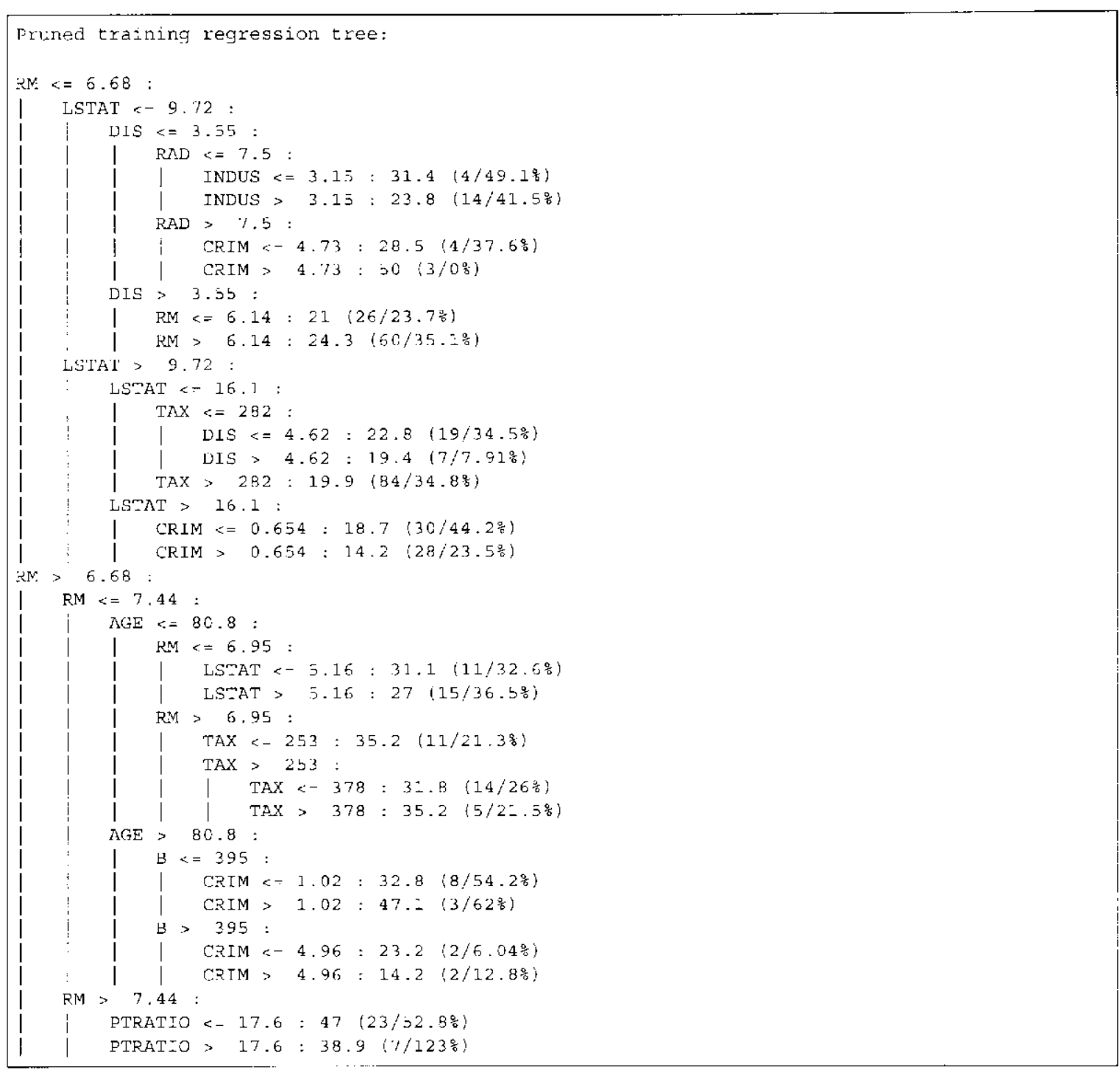

Figura 6.10: Regression Tree gerada pelo M5 com o conjunto de dados housing

algoritmos de regressão executados com o conjunto de dados housing, a média e o desvio-padrão desses valores.

\begin{tabular}{|c|c|c|c|c|c|c|}
\hline Partição & Cubist & RT & CART & RETIS & M5 Model & M5 Reg \\
\hline 18 & 10.47 & 6,73 & 7.23 & $7 \overline{7,62}$ & 7.92 & $6 . \overline{50}$ \\
\hline 2 & 1,84 & 2,79 & 3,36 & 1.97 & 2,09 & 2.20 \\
\hline 3 & 2,68 & 2.62 & 2,94 & 2,37 & 1,95 & 2,40 \\
\hline 4 & 2.84 & 2,75 & 2,60 & 2,56 & 2.16 & 2.30 \\
\hline 5 & 2,66 & 3,81 & 3,66 & 3.78 & 2,81 & 4.40 \\
\hline 6 & 3,67 & $4, \overline{54}$ & 4,45 & 6.93 & 4,39 & 4,30 \\
\hline 7 & 5.33 & 1,86 & 2,63 & 1.70 & 1,53 & 1.80 \\
\hline 8 & 1.80 & 1.70 & 2,25 & 1.80 & 1.90 & 2.90 \\
\hline 3 & 1.67 & 1.76 & 2,46 & 1.75 & $1 . \overline{8}]$ & 2,00 \\
\hline 10 & 2,62 & 3,34 & 3,46 & 3.51 & 2.65 & 3.40 \\
\hline Media $\pm \overline{D P}$ & $3,56 \pm 2,52$ & $3,19 \pm 1,46$ & $3,50 \pm 1,40$ & $3,40 \pm 2.06$ & $2.92 \pm 1.83$ & $3.20 \perp 1, \overline{40}$ \\
\hline
\end{tabular}

Tabela 6.12: MAD calculada no conjunto de dados housing

Já na Tabela 6.13 pode-se visualizar os valores da medida MSE calculados em cada partição dos algoritmos executados, a média e o desvio-padrāo desses 


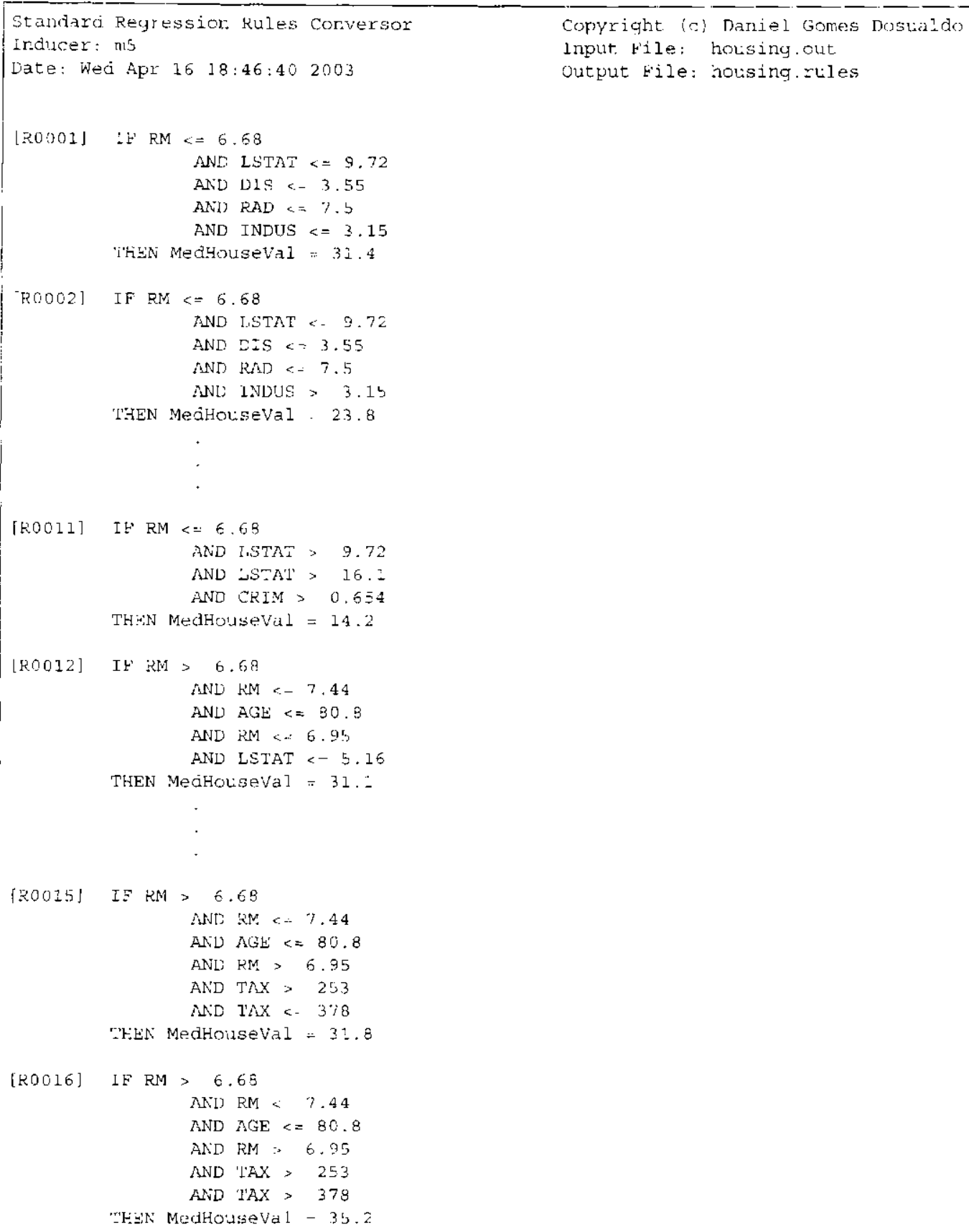

Figura 6.11: Algumas regras convertidas a partir da Regression Tree gerada pelo M5 para o formato padrāo com o conjunto de dados housing

valores.

Analisando a Tabela 6.12, verifica-se que o algoritmo M5 Model obteve o valor mais baixo para a medida MAD, seguido pelos algoritmos RT e M5 Regression. Já com relação à medida MSE, como pode ser visualizado na Tabela 6.13, o RT obteve o valor mais baixo, seguido pelos algoritmos M5 Regression, M5 Model e CART. É interessante notar que os algoritmos Cubist e RETIS, que juntamente com o M5 Model haviam apresentado os valores mais baixos para as duas medidas nos experimentos realizados com o conjunto 


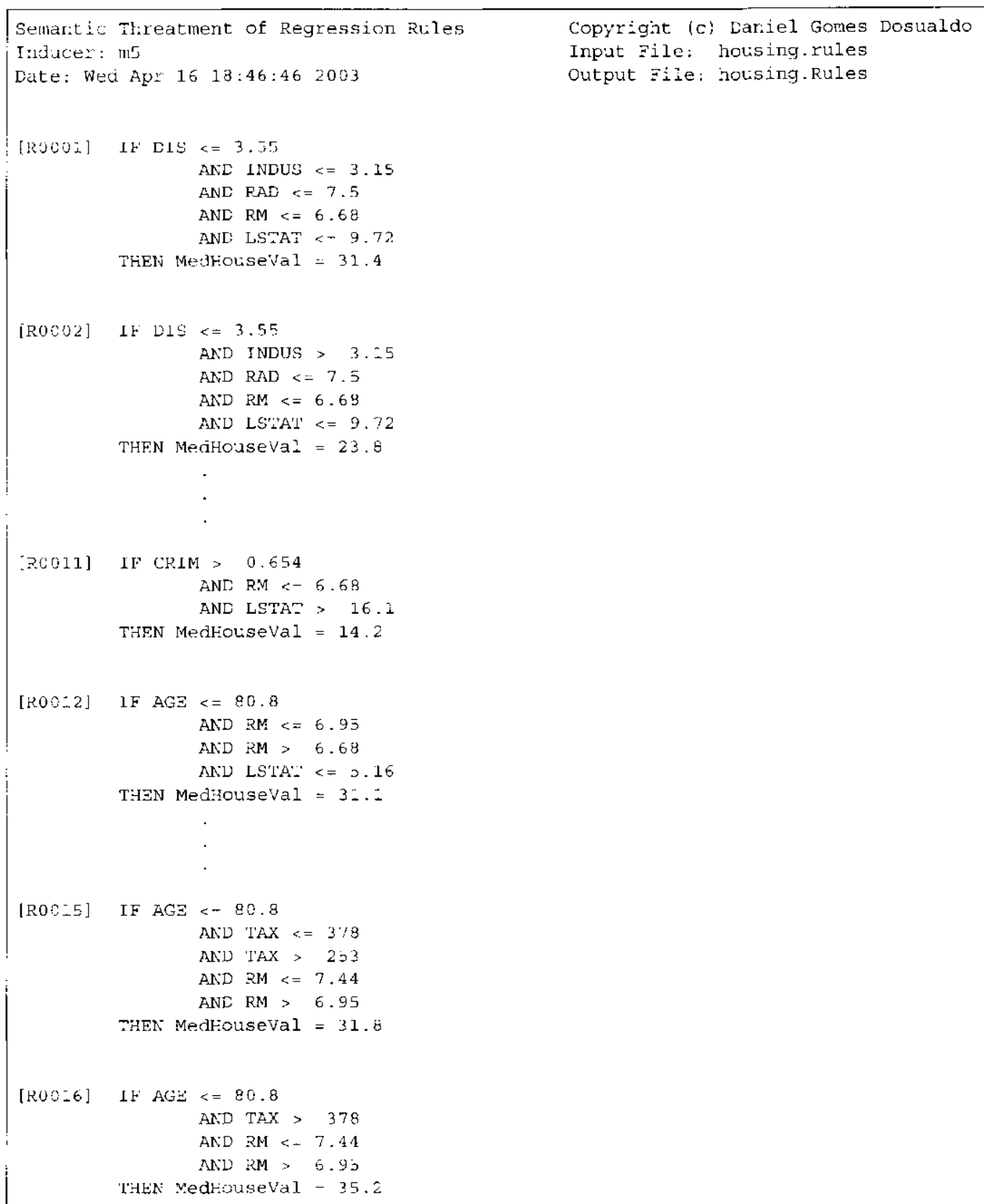

Figura 6.12: Algumas regras semanticamente tratadas a partir do conjunto de regras convertido do M5 com o conjunto de dados housing

\begin{tabular}{|c|c|c|c|c|c|c|}
\hline Partição & Cubist & $\mathbf{R T}$ & CART & RETIS & M5 Model & M5 Reg \\
\hline 1 & 234,427 & 115.739 & 113,736 & 155.2144 & 149,030 & 110,850 \\
\hline 2 & 4.748 & 10,829 & 15,720 & 6,042 & 6,340 & 7.090 \\
\hline 3 & 10.195 & 10.810 & 14,812 & 10.145 & 5,910 & $9.660^{-1}$ \\
\hline 4 & 13.513 & 11.861 & 10,960 & 10,440 & 8.086 & 10,070 \\
\hline 5 & 10,234 & 20.510 & 18,613 & 19.708 & 11,740 & 30.640 \\
\hline 6 & 25,650 & 29,210 & 26.990 & 105,753 & $36.08: 3$ & 27.860 \\
\hline 7 & 67.410 & 5.813 & 10.770 & 1.945 & 4.238 & 5,130 \\
\hline 8 & 5.910 & 6.720 & 9,060 & 7,115 & 6,810 & 15.350 \\
\hline 9 & 5,595 & 4.790 & 9.388 & 4,650 & 4.915 & 6,860 \\
\hline 10 & $9 . \overline{923}$ & 15,799 & 16,676 & 19,700 & 10,779 & 19.210 \\
\hline Média-DP & $38,76=71,27$ & $23,21 \pm 33,35$ & $24,67 \pm 31,75$ & $34,37+52.26$ & $24,39+44.77$ & $24 . \overline{27 \pm 31.68}$ \\
\hline
\end{tabular}

Tabela 6.13: MSE calculada no conjunto de dados housing 


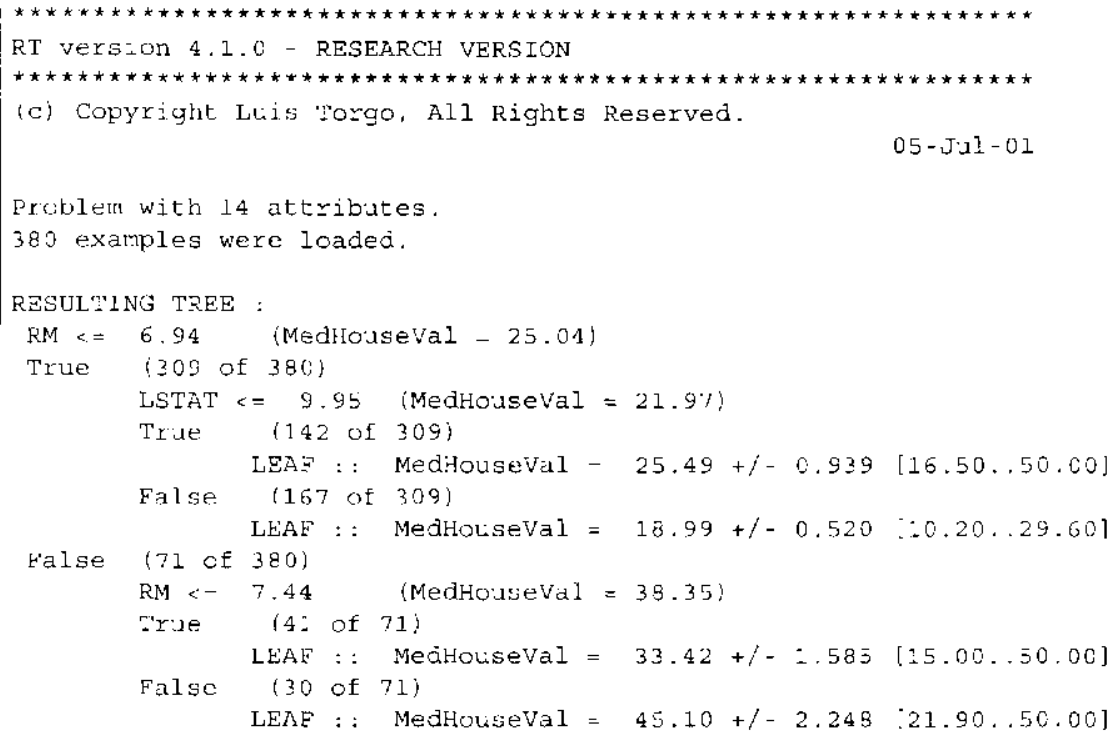

Figura 6.13: Regression Tree gerada pelo CART com o conjunto de dados housing

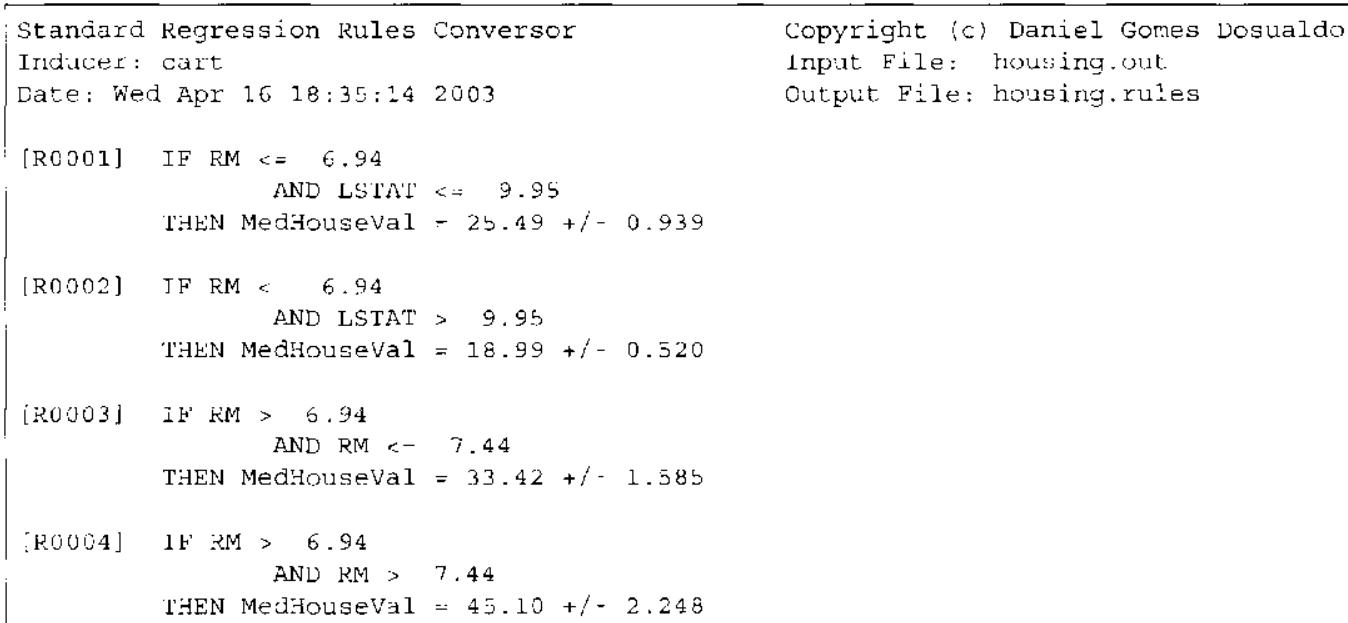

Figura 6.14: Conjunto de regras convertido a partir da Regression Tree gerada pclo CART com o conjunto de dados housing

de dados abalone, obtiveram os valores mais altos tanto para a medida MAD quanto MSE. Além disso, é curioso notar o bom desempenho dos algoritmos RT e M5 Regression, que realizam suas predições por meio de uma constante.

\subsubsection{Teste de Hipóteses no Conjunto de Dados Housing}

Depois de calculadas as medidas de precisão em cada uma das 10 partiçōes do conjunto de dados e calculada a média dos regressores de cada algoritmo, foi realizado mais uma vez o teste de hipóteses para comparar a precisão dos algoritmos de regressão e decidir qual deles apresenta melhor desempenho sobre o conjunto de dados housing. Na Tabela 6.14 sāo apresentados os re- 
sultados desse outro teste.

\begin{tabular}{|c|c|c|c|c|c|}
\hline$A_{S}$ & $A_{P}$ & media $\left(A_{S} \quad A_{P}\right)$ & $d p\left(A_{S}-A_{P}\right)$ & $a d\left(A_{S}-A_{P}\right)$ & Melhor \\
\hline Cubist & RT & 0,37 & 2,06 & 0,18 & RT \\
\hline Cubist & CAR'T & 0,06 & 2,04 & 0,03 & CAR'T \\
\hline Cubist & RETIS & 0,16 & 2,30 & 0.07 & RETIS \\
\hline Cubist & M5 Model & 0.63 & 2,20 & 0,29 & M5 Model \\
\hline Cubist & M5 Rog & 0,40 & 2,04 & 0,20 & M5 Reg \\
\hline $\mathrm{RT}$ & CART & $-0,31$ & 1,43 & $-0,22$ & RT \\
\hline $\mathrm{RT}$ & RETIS & $-0,21$ & 1,78 & $-0,12$ & $\mathrm{RT}$ \\
\hline RT & M5 Model & 0,26 & 1,65 & 0,16 & M5 Model \\
\hline $\mathrm{RT}$ & M5 Reg & 0 & 1,43 & 0 & - \\
\hline CART & RETIS & 0,10 & 1,76 & 0,06 & RETIS \\
\hline CART & M5 Model & 0.58 & 1.63 & 0,36 & M5 Model \\
\hline CART & M5 Rcg & 0.30 & 1,40 & 0.2 & M5 Reg \\
\hline RETIS & M5 Model & 0.48 & 1,95 & 0,25 & M5 Model \\
\hline RETIS & M5 Reg & 0,20 & 1,76 & 0,10 & M5 Reg \\
\hline M5 Model & M5 Reg & $-0,30$ & 1,63 & $-0,20$ & M5 Model \\
\hline
\end{tabular}

Tabela 6.14: Resultado do teste de hipóteses realizado com o conjunto de dados housing

Por meio da Tabela 6.14 verifica-se que o algoritmo M5 Model supera os demais algoritmos de regressāo utilizando o conjunto de dados housing. Porém, em nenhum caso, essa superação é comprovada com grau de confiança de 95\%. Isso pode ser visualizado nessa tabela, uma ve $z$ que $\operatorname{ad}\left(A_{S}-A_{P}\right)$ não è maior que $2 \times d p\left(A_{S}-A_{P}\right)$ e nem menor que $-2 \times d p\left(A_{S}-A_{\mu}\right)$. Além disso, nota-se também que o algoritmo Cubist, que apresentou um bom desempenho no teste de hipóteses realizado com o conjunto de dados abalone, foi superado por todos os demais algoritmos de regressão no conjunto de dados housing.

\subsubsection{Compreensibilidade das Regras geradas a partir do Conjunto de Dados Housing}

O outro fator avaliado neste trabalho, além da precisāo, é a compreensibilidade dos regressores. Na avaliação da compreensibilidade foi gerado apenas um regressor para cada algoritmo utilizando os conjuntos de treinamento e teste. Na Tabela 6.15 são aprescntados o número de condições antes do tratamento semântico e após o tratamento semântico, bem como o número do atributos na equação linear, para cada regra gerada pelos algoritmos M5 Model, Cubist e RETIS. Como os algoritmos M5 Regression. RT e CART realizam suas prediçōes por meio de uma constante, então na Tabela 6.16 são apresentados apenas o número de condiçōes antes e depois do tratamento semântico para esses algoritmos.

Analisando a Tabela 6.15, que apresenta as medidas de compreensibilidade para os algoritmos que predizem o valor do atributo-meta por meio de uma equaçāo linear, verifica-se que a regra mais compreensivel é a regra \#2 gerada pelo RETIS, que possui três condições e dois atributos na equação li- 
6.2 Experimentos com o Conjunto de Dados Housing

\begin{tabular}{|c|c|c|c|c|c|c|c|c|c|}
\hline & \multicolumn{3}{|c|}{ M5 Model } & \multicolumn{3}{|c|}{ Cubist } & \multicolumn{3}{|c|}{ RETIS } \\
\hline $\begin{array}{c}\# \\
\text { Regrat } \\
\end{array}$ & $\begin{array}{l}\# \text { Cond } \\
\text { antes }\end{array}$ & $\begin{array}{l}\text { \#Cond } \\
\text { depois }\end{array}$ & $\begin{array}{l}\text { HAtrib } \\
\text { equação }\end{array}$ & $\begin{array}{l}\# \text { Cond } \\
\text { antes }\end{array}$ & $\begin{array}{l}\text { \#Cond } \\
\text { depois }\end{array}$ & $\begin{array}{l}\text { HAlrib } \\
\text { equaçāo }\end{array}$ & $\begin{array}{l}\# \text { Cond } \\
\text { antes }\end{array}$ & $\begin{array}{l}\text { HCond } \\
\text { depois }\end{array}$ & $\begin{array}{l}\text { \#Atrib } \\
\text { equaçāo }\end{array}$ \\
\hline$\overline{1}$ & 5 & 5 & 9 & 2 & 2 & 7 & $-\overline{3}$ & 3 & 0 \\
\hline 2 & 5 & 5 & 9 & 2 & 2 & 0 & 3 & 3 & 2 \\
\hline 3 & 5 & 5 & 9 & 2 & 2 & 10 & 3 & 3 & 0 \\
\hline 4 & 5 & 5 & 9 & 1 & 1 & 8 & 4 & 3 & 0 \\
\hline 5 & 3 & 3 & 9 & 4 & 4 & 8 & 4 & 3 & 0 \\
\hline 6 & 2 & 2 & 9 & 2 & 2 & 5 & 2 & 2 & 0 \\
\hline 7 & 4 & 3 & 10 & 3 & 3 & 9 & 2 & 1 & 0 \\
\hline 8 & 4 & 3 & 11 & 2 & 2 & 9 & ... & ... & \\
\hline 9 & 4 & 4 & 10 & 3 & 3 & 7 & - & & \\
\hline 10 & 5 & 5 & 10 & 4 & 4 & 0 & $\cdots$ & - & - \\
\hline 11 & 5 & 5 & 10 & - & -- & - & - & - & - \\
\hline 12 & 2 & 1 & 10 & - & $-\ldots$ & - & & - & \\
\hline
\end{tabular}

Tabela 6.15: Compreensibilidade calculada no conjunto de dados housing por meio dos algoritmos M5 Model, Cubist e RETIS

\begin{tabular}{|c|c|c|c|c|c|c|}
\hline \multirow[b]{2}{*}{$\begin{array}{c}\# \\
\text { Regra }\end{array}$} & \multicolumn{2}{|c|}{ M5 Regression } & \multicolumn{2}{|c|}{$\mathbf{R T}$} & \multicolumn{2}{|c|}{ CART } \\
\hline & $\begin{array}{l}\text { \#Cond } \\
\text { antes }\end{array}$ & $\begin{array}{l}\text { HCond } \\
\text { depois }\end{array}$ & $\begin{array}{l}\text { \#Cond } \\
\text { antes }\end{array}$ & $\begin{array}{l}\text { \#Cona } \\
\text { depois }\end{array}$ & $\begin{array}{l}\text { \#cound } \\
\text { antes }\end{array}$ & $\begin{array}{l}\text { HConld } \\
\text { depois }\end{array}$ \\
\hline$\frac{1}{1}$ & 5 & 5 & 3 & 3 & 2 & 2 \\
\hline 2 & 5 & 5 & 6 & 3 & 2 & 2 \\
\hline 3 & 5 & 5 & 6 & 4 & 2 & 2 \\
\hline$A$ & 5 & 5 & 6 & 5 & 2 & 1 \\
\hline 5 & 4 & 3 & 6 & 5 & - & - \\
\hline 6 & 4 & 4 & 5 & 5 & - & - \\
\hline 7 & 5 & 5 & 6 & 5 &.- & -- \\
\hline 8 & 5 & 5 & 6 & 5 & -.. & - \\
\hline 9 & 4 & 4 & 4 & 4 & - & .. \\
\hline 10 & 4 & 3 & 6 & 5 & - & - \\
\hline 11 & 4 & 3 & 6 & 5 & - & - \\
\hline 12 & 5 & 4 & 7 & 6 & & \\
\hline 13 & 5 & 4 & 7 & 6 & - & - \\
\hline 14 & 5 & 4 & G & 5 & - - & - \\
\hline 15 & 6 & 5 & 5 & 4 & - & \\
\hline 16 & 6 & 4 & 5 & 4 & &.- \\
\hline 17 & 5 & 5 & 4 & 3 & - & - \\
\hline 18 & 5 & 5 & 3 & 3 & - & - \\
\hline 19 & 5 & 5 & 3 & 3 & - & \\
\hline 20) & 5 & 5 & 3 & 2 & - & - \\
\hline 21 & 3 & 2 & 3 & 2 & $\ldots$ & - \\
\hline 22 & 3 & 2 & - & - & -. & - \\
\hline
\end{tabular}

Tabela 6.16: Compreensibilidade calculadas no conjunto de dados housing por meio dos algoritmos M5 Regression, RT e CART

near. $E$ interessante notar que essa foi a ünica regra gerada pelo RETIS que utilizou uma equação linear para realizar as predições, sendo que as demais regras por ele geradas utilizaram constantes. Depois dessa, a regra mais compreensivel gerada por esses algoritmos foi a regra \#6 do Cubist, com duas condições e cinco atributos na equação linear. Com relaçāo à Tabela 6.16, que apresenta o número de condições das regras geradas com os algoritmos RT e M5 Regression, nota-se que as duas últimas regras geradas por esses algoritmos foram as mais compreensiveis, com duas condições cada.

\subsubsection{Tabela de Contingência para Regras de Regressão do Conjunto de Dados Housing}

Nos experimentos realizados com o conjunto de dados housing o número de pseudo-intervalos utilizado foi 4 , uma vez que esse valor obteve os resulta- 
dos que melhor acompanharam a variação da precisão calculada por meio da medida MAD e a precisāo calculada pela tabela de contingência. Os valores mínimo e máximo de cada um desses 4 pseudo-intervalos sāo apresentados na Tabela 6.17.

\begin{tabular}{|c|c|c|}
\hline Intervalo & Valor Mínimo & Valor Máximo \\
\hline \hline 1 & 10,2 & 20,0 \\
\hline 2 & 20.1 & 27,5 \\
\hline 3 & 27.9 & 39,8 \\
\hline 4 & 41.3 & 50,0 \\
\hline
\end{tabular}

Tabela 6.17: Pseudo-intervalos gerados com o conjunto de dados housing

Depois de gerados os pseudo-intervalos com os conjuntos de treinamento e teste, foram construídas as tabelas de contingência e calculadas as medidas derivadas utilizando o conjunto de validaçāo. Nas Tabelas 6.18 até 6.21 são apresentados os valores da medida MAD calculados com a classe RegMeasures, a precisāo normalizada calculada por meio da medida MAD, a precisāo (Acc) calculada por meio da tabela de contingência com 4 pseudo-intervalos $\mathrm{c}$ as demais medidas derivadas da tabela.

\begin{tabular}{|c|c|c|c|c|c|c|c|c|c|c|c|}
\hline Regra & \# Exemplos & MAD & Precisāo & $A c c$ & NegRel & Sens & Spec & Cov & Sup & Nol & Sat \\
\hline 1 & 40 & 4.53 & 0,83 & 0.88 & 0,271 & 0,410 & 0.846 & 0.357 & 0,325 & 0,041 & $\overline{0.569}$ \\
\hline 2 & 7 & 4,35 & 0,83 & 0.85 & 0.344 & 0.071 & 0,976 & 0.055 & 0.047 & 0,010 & 0.571 \\
\hline 3 & 3 & 3.26 & 0.86 & 0.66 & 0,113 & 0,018 & 0,933 & 0.023 & 0,015 & -0.005 & -1.8 \\
\hline 4 & 67 & 8,67 & 0.70 & 0.49 & 0,881 & 0.825 & 0,604 & 0.531 & 0,261 & 0,093 & 0.256 \\
\hline 5 & 23 & 2,65 & 0.88 & 0,60 & 0,611 & 0,259 & 0.875 & 0.182 & 0,111 & 0,032 & 0.315 \\
\hline 6 & 0 & - & - & - & $=$ & - & - & - & - & & \\
\hline 7 & 2 & 4.47 & 0.82 & 0.50 & 0,177 & 0,009 & 0,956 & 0.015 & 0.007 & -0.005 & $-1,739$ \\
\hline 8 & 0 & - & - & - & - & - & - & - & - & - & - \\
\hline 9 & 5 & 26,44 & 0.19 & 0 & 0,917 & 0 & 0,956 & 0,039 & 0 & 0.003 & -0.086 \\
\hline 10 & 12 & 33.27 & 0 & 0 & 1 & - & 0.904 & 0,095 & 0 & 0 & 0 \\
\hline
\end{tabular}

Tabela 6.18: Medidas calculadas sobre o regressor gerado pelo Cubist com o conjunto de dados housing

\begin{tabular}{|c|c|c|c|c|c|c|c|c|c|c|c|}
\hline Regra & \# Exemplos & MAI) & Precisâo & Acc & NegRel & Sens & Spec & $\mathrm{Cov}$ & Sup & NOV & Sul \\
\hline 1 & 0 & - & 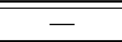 & - & -1 & " - & & & $\overline{c-\cdots}$ & - & - \\
\hline 2 & 3 & 4,12 & 0.66 & 0.66 & 0,894 & 0,133 & 0.990 & 0,023 & 0,015 & 0.013 & 0,621 \\
\hline 3 & 0 & - & - & - & - & - & - & -- & & & \\
\hline 4 & 0 & - & - & - & - & - & & & & & - \\
\hline 5 & 0 & - & - & - & - & $\cdots$ & & - & - & - & - \\
\hline 6 & 109 & 4,36 & 0.62 & 0.73 & 0,352 & 0.879 & 0,171 & 0.865 & 0.634 & 0.010 & 0.042 \\
\hline 7 & 2 & 4.96 & 0.55 & 0.50 & 0.169 & 0,009 & 0.954 & 0,015 & 0.007 & $-0,005$ & -1.863 \\
\hline 8 & 2 & 4.50 & 0.61 & 0,50 & 0,306 & 0.011 & 0.974 & 0,015 & 0,007 & -0.003 & 0.615 \\
\hline 9 & 8 & 6,86 & 0,30 & 0,37 & 0.296 & 0.034 & 0,875 & 0,063 & 0.023 & 0,019 & -0.968 \\
\hline 10 & 1 & 9.17 & 0 & 0 & 0.160 & 0 & 0,952 & 0,007 & 0 & -0.006 & -5 \\
\hline 11 & 1 & 7,69 & 0.19 & 1 & 0,160 & 0.009 & 1 & 0.007 & 0,007 & 0.001 & 1 \\
\hline 12 & 0 & - & - & - & - & - & - & & & - & - \\
\hline
\end{tabular}

Tabela 6.19: Medidas calculadas sobre o regressor gerado pelo M5 Model com o conjunto de dados housing

Analisando as Tabelas 6.18 até 6.23, algumas considerações podem ser feitas a respeito dos resultados obtidos: 


\begin{tabular}{|c|c|c|c|c|c|c|c|c|c|c|c|}
\hline Regra & \# Exemplos & MĀD & Precisão & ACC & NegRel & Seris & Spec & Cov & Sup & Nou & Sat \\
\hline $\bar{l}=$ & $=4$ & 15,64 & $=0$ & $\overline{0}$ & $\overline{0,9} \overline{83}$ & $=\overline{0}=$ & 0,967 & $\overline{0.03 \overline{1}}$ & $=$ & $0, \overline{005}$ & $0 . \overline{016}$ \\
\hline 2 & 1 & 3,35 & 0,96 & 1 & 0,240 & 0.010 & 1 & 0,007 & $\overline{0,0 \overline{0}}$ & 0,001 & 1 \\
\hline 3 & 33 & 2,86 & $\frac{1}{1}$ & $0 . \overline{45}$ & 0,903 & 0,625 & 0,823 & 0,261 & 0.119 & 0.069 & 0.326 \\
\hline 4 & 6 & 6.04 & 0,75 & 0.83 & 0,208 & 0,050 & 0,961 & 0,047 & 0.039 & 0,001 & 0.192 \\
\hline 5 & 77 & 3,56 & 0,34 & 0,97 & 0.489 & 0,750 & 0,923 & 0,611 & 0,595 & 0,110 & 0.874 \\
\hline 6 & 5 & 12.04 & 0,28 & 0,20 & 0.991 & 0,500 & 0,967 & 0,039 & 0.007 & 0,007 & 0.187 \\
\hline 7 & 0 & $=$ & - & - & - & & $\ldots$ & - & - & $=$ & - \\
\hline
\end{tabular}

Tabela 6.20: Medidas calculadas sobre o regressor gerado pelo RETIS com o conjunto de dados housing

\begin{tabular}{|c|c|c|c|c|c|c|c|c|c|c|c|}
\hline Règra & $\# \overline{\text { Exemplos }}$ & $\mathrm{MAD}$ & Precisao & $\overline{A C C}$ & Negrel & Sens & Spec & $\operatorname{Cov}$ & Sip & $N o t$ & Sal \\
\hline 1 & 5 & $5, \overline{37}$ & 0.83 & 0,80 & 0,834 & $0 \overline{166}$ & 0,990 & $\overline{0,039}$ & 0.031 & $\overline{0,02 \overline{1}}$ & $\overline{0.752}$ \\
\hline 2 & $i 16$ & 5,67 & $0.8 \overline{0}$ & 0.83 & 0,700 & 0.970 & $0.2 \overline{69}$ & 0.920 & 0.769 & $0 . \overline{039}$ & 0,206 \\
\hline 3 & 5 & 12,04 & 0,20 & 0,20 & 0.991 & $0, \overline{500}$ & 0,967 & $0,03 \overline{9}$ & 0.007 & 0,007 & 0,187 \\
\hline 4 & 0 & $=$ & 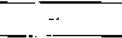 & & $=$ & - & - & & - & - & \\
\hline
\end{tabular}

Tabela 6.21: Medidas calculadas sobre o regressor gerado pelo CART com o conjunto de dados housing

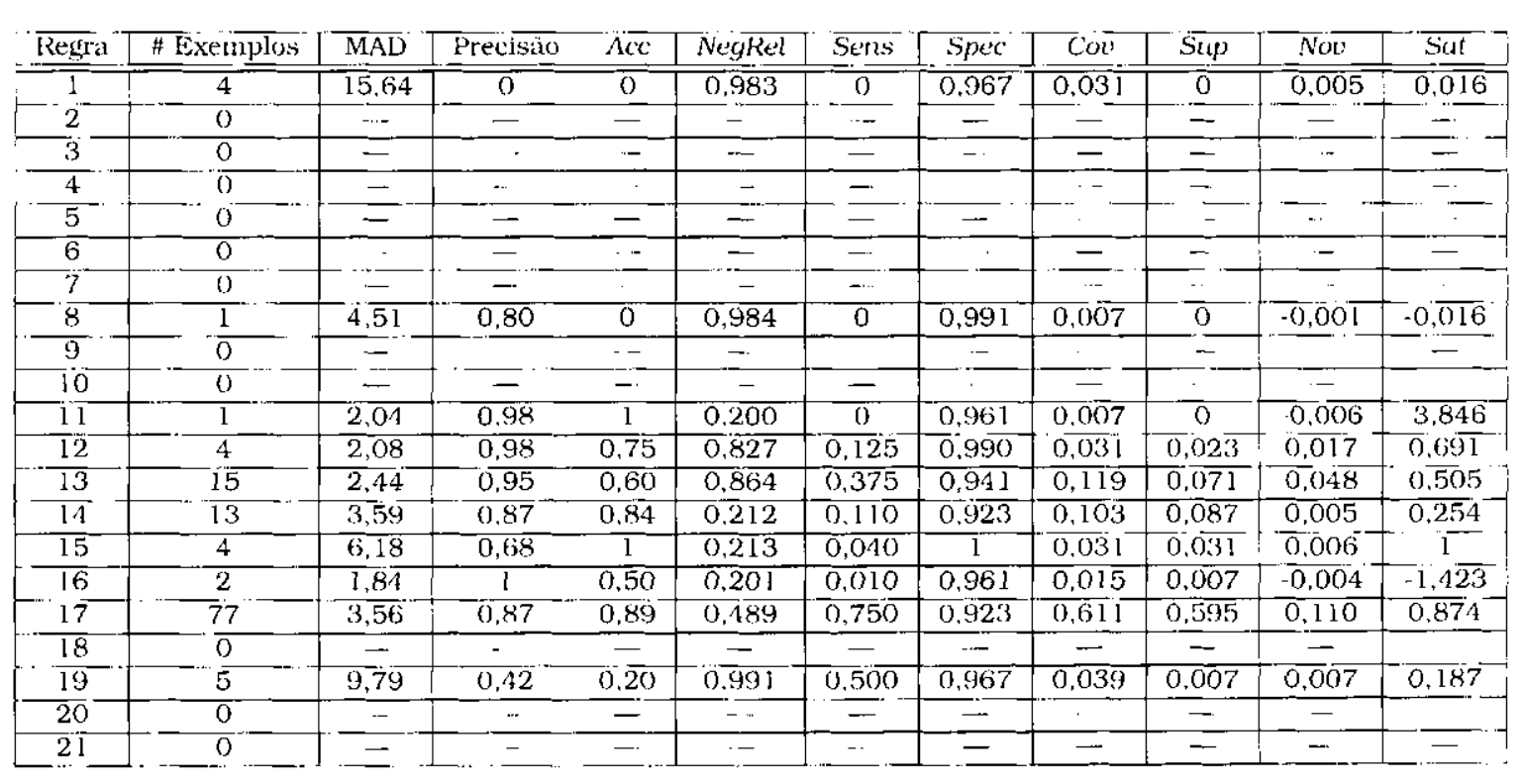

Tabela 6.22: Medidas calculadas sobre o regressor gerado pelo R'T com o conjunto de dados housing

- os algoritmos CART, M5 Model e RETIS foram aqueles cujos valores da precisão calculada pela tabela de contingência com 4 pseudo-intervalos melhor acompanharam a variação dos valores da precisāo calculados por meio da medida MAD, principalmente o CART, cujos valores são muito próximos:

- alguns resultados muito discrepantes entre os valores das precisões. como os valores obtidos pela regra \#8 gerada pelo RT $(0,80$ e 0$)$ e pela regra \# 17 gerada pelo M5 Regression (0,66 e 0) são explicados pelo fato de que cada uma dessas regras cobriu um único exemplo de validação. Isso deve-se ao tamanho relativamente pequeno do conjunto de validaçāo (126 exemplos), diferentemente do conjunto de dados abalone utilizado no primeiro ciclo de experimentos. Além disso, por causa desse número 


\begin{tabular}{|c|c|c|c|c|c|c|c|c|c|c|c|}
\hline Regra & \# Exemplos & MAD & Precisāo & $A C C$ & NegRel & Sens & Spec & Cov & Sup & Nov & Sat \\
\hline 1 & 0 & $1-$ & - - & - & --- & & & " & - & - & -- \\
\hline 2 & 3 & 5.50 & 0,84 & 0,66 & 0,821 & 0,083 & 0,990 & 0,023 & 0,015 & 0,011 & 0.588 \\
\hline 3 & 0 & - & - & - & - & - & - & - & - & - & - \\
\hline 4 & 0 & - & & - & - & - & - & - & - & - & - \\
\hline 5 & 0 & - & - & - & - & - & - & - & - & - & - \\
\hline 6 & 0 & - & - & - & - & - & - & - & - & - & - \\
\hline 7 & 0 & - & - & - & - & - & - & - & - & - & - \\
\hline 8 & 0 & - & - & - & - & - & - & - & - & - & - \\
\hline 9 & 33 & 2,80 & 0,93 & 0,51 & 0,107 & 0.170 & 0,384 & $\overline{0.261}$ & 0.134 & $-0,072$ & -1.349 \\
\hline 10 & 6 & 6,00 & 0,82 & 0.83 & 0,208 & 0,050 & 0,961 & 0,047 & 0.039 & 0.001 & 0.192 \\
\hline 11 & 70 & 3,50 & 0,90 & 0.98 & 0.446 & 0.690 & 0.961 & 0,555 & 0,547 & 0,106 & $0, \overline{930}$ \\
\hline 12 & 0 & - & - & - & - & - & - & - & - & - & \\
\hline 13 & 2 & 10,95 & 0.66 & 0.50 & 0.814 & 0.041 & $\overline{0,990}$ & 0.015 & 0.007 & 0.004 & 0.382 \\
\hline 14 & 0 & - & - & - & - & - & - & - & - & - & $\ldots$ \\
\hline 15 & 0 & - & - & - & - & - & - & - & - & $\ldots$ & - \\
\hline 16 & 2 & 7.80 & 0,76 & 0.50 & 0,991 & 0.500 & 0,991 & 0,015 & 0,007 & 0,007 & 0,491 \\
\hline 17 & 1 & 10.80 & 0,66 & 0 & 0.984 & 0 & 0,991 & 0.007 & 0 & 0,001 & -0.016 \\
\hline 18 & 7 & 31.20 & 0 & $\overline{0}$ & 1 & & 0,944 & 0.055 & 0 & 0 & 0 \\
\hline 19 & I & 0.70 & 1 & 1 & 0.819 & 0,041 & 1 & 0,007 & 0,007 & 0,060 & 1 \\
\hline 20 & 1 & 3.80 & 0,89 & 1 & 0.208 & 0,010 & 1 & 0.007 & 0,007 & 0,001 & 1 \\
\hline 21 & 0 & - & - & - & - & - & - & $\cdots$ & & & - \\
\hline 22 & 0 & - & - & & & & -- & - & - & - & - \\
\hline
\end{tabular}

Tabela 6.23: Medidas calculadas sobre o regressor gerado pelo M5 Regression com o conjunto de dados housing

de exemplos de validaçāo, muitas das regras geradas não cobriram nenhum exemplo, principalmente no caso dos algoritmos R'T e M5 Regression, que geraram um número de regras bem superior aos demais algoritmos;

- sempre que o valor da medida MAD calculada em uma regra foi muito superior ao valor da MAD calculada nas demais regras em um determinado regressor, como nas regras \#9 e \#10 geradas pelo Cubist $(26,44$ e 33,27$)$ e na regra \# 18 gcrada pelo M5 Regression $(31,20)$, a precisão calculada pela tabela de contingência foi 0 .

\subsection{Avaliação Geral dos Resultados}

Esta seçāo tem como objetivo apresentar uma síntese dos resultados obtidos e fazer uma avaliaçāo geral desses resultados. Primeiramente, é apresentado um resumo dos fatores comumente avaliados na etapa de pós-processamento do processo de mineraçāo de dados: precisão. compreensibilidade c interessabilidade.

Precisão: essa medida tem como objetivo avaliar o desempenho do regressor na prediçāo do valor do atributo-meta de novos exemplos. No primeiro ciclo de experimentos realizado com o conjunto de dados abalone, os algoritmos Cubist, RETIS e M5 Model aprescntaram os valores mais baixos para as medidas MAD e MSE calculadas, enquanto que o CART obteve os valores mais altos. Isso se comprovou no teste de hipóteses, em que esses algoritmos superaram os demais, ao passo que o CART foi superado por 
todos. Porém, nenhum dos três (Cubist, RETIS e M5 Model) conseguiu ser o melhor. Já nos experimentos realizados com o conjunto de dados housing, os algoritmos M5 Model, RT e M5 Regression apresentaram os melhores valores para as medidas MAD e MSE, ao passo que o Cubist e RETIS obtiveram os piores valores. No teste de hipóteses, o M5 Model superou todos os demais algoritmos, porém, sem o grau de confiança de $95 \%$.

Compreensibilidade: essa medida avalia o quāo o regressor é compreensivel para o usuário. Neste trabalho, a compreensibilidade foi definida de acordo com o número de condições da regra e do número de atributos na equação linear, para os algoritmos que realizam suas prediçōes dessa maneira - Cubist. M5 Model e RETIS. Nos experimentos realizados com o conjunto de dados abalone, devido ao grande número de regras gerado pelos algoritmos RT e M5 Regression, foram avaliados apenas a compreensibilidade dos algoritmos Cubist, M5 Model e RETIS. Com o conjunto de dados abalone, as regras mais compreensiveis dos algoritmos que utilizam equações lincares foram as regras \#1, \#2 e \#5 geradas pelo RETIS e a regra \#7 gerada pelo Cubist. Já no segundo ciclo de experimentos realizado com o conjunto de dados housing, a regra que se mostrou mais compreensivel foi a regra \#2 gerada pelo RETIS, seguida pela regra \#6 do Cubist. Já com relaçāo aos algoritmos que predizem por meio de uma constante, as duas últimas regras geradas tanto pelo algoritmo RT quanto pelo M5 Regression se mostraram as mais compreensíveis. Vale ressaltar que com o tratamento scmântico o número de condiçōes das regras reduziu na maioria dos casos.

Interessabilidade: essa medida avalia o quanto do conhecimento extraído é interessante ou inesperado. Neste trabalho, para avaliar a interessabilidade utilizou-se a medida novidade (Nov) calculada por meio da tabela de contingência. A medida novidade, apresentada $\mathrm{cm}$ (Lavrac, Flach, \& Zupan, 1999), objetiva identificar o quanto uma regra é interessante, inovadora ou não usual. Assim sendo, no primeiro ciclo de experimentos, verificou-se que as regras que apresentaram os valores mais significativos para essa medida foram as regras \#3 e \#1 geradas pelo CART e a regra \#4 gerada pelo RETIS. No segundo ciclo de experimentos realizado com o conjunto de dados housing, as regras que obtiveram os valores mais altos para a medida novidade foi a regra $\$ 5$ gerada pelo RETIS, a regra \#17 gcrada pelo R'T e a regra \# 11 gerada pelo M5 Regression.

Quanto à avaliaçāo das tabelas de contingência calculadas, pode-se dizer que os resultados mais coerentes foram obtidos com o conjunto de dados 
abalone. Uma das explicações pode ser o fato desse conjunto apresentar um número de exemplos bem superior ao conjunto de dados housing (4177 contra 506). Além disso, é bastante útil estudar novas formas de se avaliar o conhecimento extraído de problemas de regressão, uma vez que não existem muitas medidas disponiveis para avaliar o conhecimento de problemas desse tipo devido ao atributo-meta contínuo.

\subsection{Considerações Finais}

Neste capítulo foram descritos dois ciclos de experimentos realizados para validar o ambiente DIPER implementado neste trabalho. Esses experimentos visavam exemplificar as funcionalidades das classes do DIPER, descritas no capítulo anterior. O primeiro ciclo de experimentos foi realizado com o conjunto de dados abalone e o segundo com o conjunto de dados housing. ambos retirados do repositório de dados da UCI. Em cada ciclo de experimentos foram descritas as etapas de conversão dos regressores para o formato padrāo, tratamento semântico das regras, cálculo das medidas de precisāo e compreensibiliade, teste de hipóteses, construção das tabelas de contingência utilizando a estratégia de pseudo-classes e das medidas derivadas, bem como uma avaliação dos resultados obtidos. 


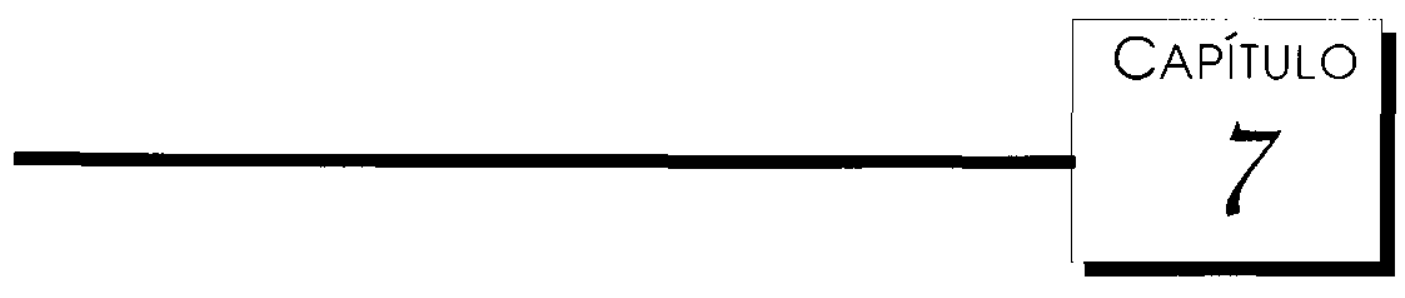

\section{Conclusões e Trabalhos Futuros}

$\mathcal{A}$

grande quantidade de dados que pode ser armazenada nos dias de hoje a um custo relativamente baixo, a necessidade das empresas de extrair conhecimento a partir de suas bases de dados para conhecer melhor seus clientes, a popularização da Internet, entre outros fatores, impulsionaram o processo de mineração de dados, responsável por identificar padrōes ou modelos embutidos em grandes conjuntos de dados. O processo de mineração de dados possui duas grandes atividades: a predição e a descrição. A predição, por sua vez, apresenta dois tipos de problemas, que são a classificação e a regressāo. A regressão tem como objetivo encontrar uma relação entre um conjunto de atributos de entrada e um atributo-meta que seja contínuo. No entanto, a maioria das pesquisas realizadas nas áreas de aprendizado de máquina e mineração de dados são voltadas para os problemas de classificação, que são mais encontrados na vida real do que os problemas de regressão. Porém, como muitos problemas são de regressão, è importante também estudar métodos para a exploraçāo de tarefas desse tipo.

Por outro lado, observa-se que a extraçâo dos padrões em mineraçāo de dados não é a etapa final desse processo. A etapa de pós-processamento visa avaliar esses padrōes segundo alguns aspectos, como precisão, compreensibilidade e interessabilidade. Visando auxiliar na construção de um modelo de regressão simbólico, e posteriormente, na sua avaliaçāo, foi proposto neste trabalho o ambiente computacional DIPER. Esse ambiente, que oferece uma série de métodos a serem utilizados na etapa de pós-processamento do processo de mineração de dados, é composto por uma biblioteca de classes e foi implementado de acordo com as especificaçōes do Discover, um projeto que está sendo desenvolvido em nosso laboratório de pesquisa (LABIC) com o objetivo de fornecer um ambiente integrado para apoiar as etapas do processo de descoberta do conhecimento, oferecendo funcionalidades voltadas para aprendizado de máquina, mineração de dados e de textos.

Algumas das funcionalidades que o ambiente DIPER disponibiliza são: 
- converter os regressores gerados pelos algoritmos de regressāo estudados neste trabalho (Cubist, RT, CART, RETIS, M5 Model e M5 Regression) para um formato padrāo de regras de regressāo definido para o DiscoveR (Pugliesi, Dosualdo, \& Rezende, 2003);

- aplicar um tratamento semāntico ao conjunto de regras de regressāo no formato padrão, melhorando assim a compreensibilidade das regras, além de aumentar o desempenho de programas que utilizam essas regras como entrada:

- calcular medidas de precisāo baseadas na diferença entre o valor predito e o valor real do atributo-meta;

- calcular medidas para avaliar a compreensibilidade de regras de regressāo;

- construir uma tabela de contingència para regras de regressão, permitindo assim, calcular uma série de medidas que são derivadas dessa tabela;

- realizar um teste de hipóteses para comparar os regressores induzidos pelos diferentes algoritmos de regressão sobre um mesmo conjunto de dados.

Para exemplificar as funcionalidades que o ambiente DIPER implementado neste trabalho disponibiliza foram realizados dois ciclos de experimentos utilizando conjuntos de dados retirados do repositónio de dados da UCI. O primeiro ciclo de experimentos foi realizado com o conjunto de dados abalone, utilizado para predizer a idade de um abalone (um tipo de molusco) e o outro com o conjunto de dados housing, utilizado para predizer o valor de um imóvel na cidade de Boston. Em cada ciclo de experimentos foram descritas as etapas de conversão dos regressores para o formato padrāo, tratamento semântico das regras, cálculo das medidas de precisāo e compreensibiliade, teste de hipóteses, construçāo das tabelas de contingência e das medidas de rivadas, além de ter sido apresentada uma avaliação dos resultados obtidos.

Alêm da apresentação e exemplificação do ambiente DiPER, foi feito neste trabalho um estudo sobre alguns dos principais métodos de regressão. Foram também apresentados os sistemas e algoritmos de regressão utilizados, mostrando os arquivos de entrada e o formato dos regressores por eles gerados.

Uma das contribuições deste trabalho está relacionada com sua integraçāo ao projeto Discover. Essa integração possibilita auxiliar na preparação dos dados para a construção de um regressor simbólico e na avaliação desse regressor. Este trabalho vem adicionar novas funcionalidades ao DISCOVER, uma vez que existem outros projetos que tratam de problemas de classificaçāo, 
regras de associação e agrupamentos. Outra contribuiçāo diz respcito ao mecanismo descrito neste trabalho que permite a construção de uma tabela de contingência para regras de regressāo utilizando a estratégia de pseudoclasses, permitindo dessa maneira, calcular as medidas dela derivadas. Como citado anteriormente, è muito importante estudar novas formas para avaliar o conhecimento extraido de problemas de regressão por dois motivos: primeiramente, pelo fato da maioria das pesquisas serem voltadas para os problemas de classificação; e segundo, pela própria dificuldade de se avaliar o conhecimento em regressão por causa do atributo-meta assumir valores continuos.

A seguir são apresentadas algumas propostas para trabalhos futuros que podem complementar o trabalho aqui desenvolvido:

- adiçāo de novos sistemas e algoritmos de regressão utilizando o formato padrāo de regras de regressāo definido. Dessa maneira, é possivel utilizar todas as classes implementadas neste trabalho para auxiliar na etapa de pós-processamento, uma vez que essas classes recebem como entrada um conjunto de regras no formato padrão e conjuntos de exemplos no formato padrão de exemplos definido para o Discover;

- incorporação de novas medidas ao ambiente DIPER, fornecendo assim, uma maior variedade de maneiras de se avaliar os regressores simbólicos;

- realização de experimentos utilizando outros conjuntos de dados para melhor validar o ambiente DIPER. 


\section{Referências Bibliográficas}

$\Lambda$ pte, C. \& S. Weiss (1997, November). Data Mining with Decision Trees and Decision Rules. Future Generation Computer Systems 13(2-3), 197-210. Disponivel em: http://citeseer.nj.nec.com/apte97data.html. Acesso em 20/03/2003. 15

Atkeson, C. G., A. W. Moore, \& S. Schaal (1997). Locally Weighted Learning. Artificial Intelligence Review 11(1-5), 11-73. Disponivel em http:// citeseer.nj.nec.com/atkeson96locally.html. Acesso em 20/03/2003. 21

Baranauskas, J. A. (2001). Extração Automática de Conhecimento por Múltiplos Indutores. Tese de Doutorado, Instituto de Ciências Matemáticas e de Computação - USP São Carlos. 15, 34, 35, 37

Baranauskas, J. A. \& M. C. Monard (2003). Combining symbolic classifiers from multiple inducers. Knowledge Based Systems 16(3), 129-136. Elsevier Science. 34

Batista, G. E. A. P. A. (2001). Definiçāo da Sintaxe Padrão de Dados do Sistema Discover. Disponivel em: http://www.icmc.sc.usp.br/ gbatista/ Discover/SintaxePadraoFinal .htm. Acesso em 20/03/2003. 4, 39

Batista, G. E. A. P. A. (2003). Pré-processamento de Dados em Aprendizado de Máquina Supervisionado. Tese de Doutorado, Instituto de Ciências Matemáticas e de Computação - USP São Carlos. 34, 35, 40

Batista, G. E. A. P. A. \& M. C. Monard (2003). Descriçāo da arquitetura e do projeto do ambiente computacional Discover Learning Environment - DLE. Relatório Técnico do ICMC - Número 187. Disponivel em: ftp://ftp.icmc. sc.usp.br/pub/BIBLIOTECA/rel_tec/RT_187.pdf. 34

Bernardini, F. C. (2002). Combinação de Classificadores para Melhorar o Poder Preditivo e Descritivo de Ensembles. Dissertação de Mestrado, Instituto de Cièncias Matemáticas e de Computação - USP São Carlos. 35

Blake, C. \& C. Merz (1998). UCI repository of machine learning databases. Disponivel em: http://www.ics.uci.edu/ mlearn/MLRepository.html. Acesso em 20/03/2003. 70, 82 
Braga, A. P., A. C. P. L. F. Carvalho, \& T. B. Ludermir (2000). Redes Neurais Artificiais: Teoria e Aplicaçōes. Rio de Janeiro, Brasil: LTC Press. 25

Braga, A. P., A. C. P. L. F. Carvalho, \& T. B. Ludermir (2003). Sistemas Inteligentes: Fundamentos e Aplicaçōes (1 ed.)., Chapter Redes Neurais Artificiais, pp. 141-168. In Rezende (2003). 25

Breiman, L., J. H. Friedman, C. J. Stone, \& R. A. Olshen (1984). Classification and Regression Trees. Chapman \& Hall / CRC. 35

Cabena, P., P. Hadjinian, R. Stadler, J. Verhees, \& A. Zanasi (1997). Discovering Data Mining From Concept To Implementation. Upper Saddle River, New Jersey 07458: Prentice Hall PTR, Prentice-Hall, Inc., A Simon \& Schuster Company. 9,12

Cheng, S. (1998). Statistical approaches to predictive modeling in large databases. Dissertaçāo de Mestrado. Simon Fraser University, British Columbia, Canada. 51

Clark, P. \& T. Niblett (1989). The CN2 Induction Algorithm. Machine Learning 3(4), 261-283. Disponivel em http://citeseer.nj.nec.com/ clark89cn. html. Acesso em 20/03/2003. 58

Dong, G. \& J. Li (1998). Interestingness of discovered association rules in terms of neighborhood-base unexpectedness. Lecture Notes in Artificial Intelligence 1394, 72-86. 15

Fayyad, U. M., G. Piatetsky-Shapiro, \& P. Smyth (1996). The KDD process for extracting useful knowledge from volumes of data. Communications of the ACM 39(11), 27-34. 8

Fayyad, U. M., G. Piatetsky-Shapiro, P. Smyth, \& R. Uthurusamy (1996). Advances in Knowledge Discovery and Data Mining. AAAI Press. 2, 7

Freitas, A. A. (1998). A multi-critcria approach for the evaluation of rule interestingness. In Proceedings of the International Conference on Data Miring. Rio de Janeiro, Brasil, pp. 7-20. WIT Press. Disponivel em: http: //www.ppgia.pucpr.br/〜alex/pub_papers.dir/dmrio98.ps. 15

Friedman, J. H. (1991). Multivariate Adaptive Regression Splines. Annals of Statistics 19(1), 1-141. 28

Geromini, M. R. (2002). Projeto e desenvolvimento da interface gráfica do sistema DISCOVER. Monografia de Qualificação de Mestrado. Instituto de Ciências Matemáticas e de Computação - USP São Carlos. 34 
Gomes, A. K. (2002). Análise do Conhecimento Extraido de Classificadores Simbólicos Utilizando Medidas de Avaliação e de Interessabilidade. Dissertação de Mestrado, Instituto de Ciências Matemáticas e de Computação - USP São Carlos. 35

Gonçalves, L. S. M. (2002). Técnicas para Extraçāo de Conhecimento de Textos. Dissertação de Mestrado, Instituto de Ciências Matemáticas c de Computação - USP São Carlos. 35

Hall, M. A. \& L. A. Smith (1998). Practical feature subset selection for Machine Learning. In Proceedings of the Australian Computer Science Conference, pp. 181-191. Springer. 10

Hastie, T., R. Tibshirani, \& J. Friedman (2001). The Elements of Statistical Learning - Data Mining, Inference and Prediction. New York: Springer-Verlag. 24,28

Haykin, S. (1999). Neural Networks: A Comprehensive Foundation (2 ed.). New Jersey: Prentice-Hall. 28

Horst, P. S. (1999). Avaliaçāo do Conhecimento Adquirido por Algoritmos de Aprendizado de Máquina Utilizando Exemplos. Dissertaçāo de Mestrado, Instituto de Ciências Matemáticas e de Computação - USP São Carlos. 14

Imamura, C. Y. (2001). Pré-processamento para Extração de Conhecimento de Bases Textuais. Dissertação de Mestrado, Instituto de Ciências Matemáticas e de Computaçāo - USP São Carlos. 35

Information Discovery (2003). Rules are Much More than Decision Trees. Disponivel em: http://www.datamining.com/trees.htm. Acesso em 20/03/2003. 52

Inmon, W. H. (1997). Como Construir o Data Warehouse (2 ed.). Rio de Janeiro: Editora Campus. 2

Joachims, T. (1999). Making large-scale SVM learning practical. In B. Schölkopf, C. Burges, \& A. Smola (Eds.), Advances in Kernel Methods - Support Vector Learning, Cambridge, MA: MIT Press. 28

Karalic, A. (1995). RETIS - a Machine Learning System. Disponivel em http://www-ai.ijs.si/AramKaralic/retis/index.html. Acesso em $07 / 10 / 2001.35$

Lavrac, N., P. Flach, \& B. Zupan (1999, June). Rule Evaluation Measures: $\Lambda$ Unifying View. In S. Džeroski \& P. Flach (Eds.), Ninth International Workshop 
on Inductive Logic Programming (ILP'99), Volume 1634 of Lecture Notes in Artificial Intelligence. Springer-Verlag. Disponivel em http://1ink. springer. de/link/service/series/0558/papers/1634/16340174.pdf. 54, 93

Lee, H. D. (2000). Seleção e Construção de Features Relevantes para o Aprendizado de Máquina. Dissertação de Mestrado, Instituto de Ciências Matemáticas e de Computação - USP São Carlos. 35

Martins, C. A. (2001). Interpretação de Clusters cm Aprendizado de Máquina. Monografia do Exame de Qualificação de Doutorado, Instituto de Ciências Matemáticas c de Computaçāo - USP São Carlos. 34, 35

Melanda, E. A. (2002). Pós-processamento de Conhecimento de Regras de Associação. Monografia do Exame de Qualificaçāo de Doutorado, Instituto de Cièncias Matemáticas e de Computação - USP Sāo Carlos. 34, 35

Merz, C. J. (1998). Classification and Regression by Combining Models. Tese de Doutorado, University of California, Irvine. Disponivel em: http://www. ics.uci.edu:80/ ${ }^{\sim}$ cmerz/thesis.ps. 51

Milaré, C. R. (2003). Extração de conhecimento de rede neurais artificiais utilizando sistemas de aprendizado simbólico e algoritmos genéticos. Tese de Doutorado, Instituto de Ciências Matemáticas e de Computação - USP São Carlos. 35

Mitchell, T. M. (1997). Machine Learning. McGraw-I Iill Series in Computcr Science. 11, 13

Nagai, W. A. (2000). Avaliação do Conhecimento Extraído de Problemas de Regressão. Dissertação de Mestrado. Instituto de Ciências Matemáticas e de Computaçāo - USP São Carlos. 20

Nash, W. J., T. L. Sellers, S. R. Talbot, A. J. Cawthorn, \& W. B. Ford (1994). The Population Biology of Abalone in Tasmania. I. Blacklip Abalone from the North Coast and Islands of Bass Strait. Technical Report 48, Sea Fisheries Division. 71

Paula, M. F. (2003). Ambiente para exploração de regras. Dissertação de Mestrado, Instituto de Ciências Matemáticas e de Computação - USP São Carlos. 35

Pazzani, M., S. Mani, \& W. Shankle (1997). Combining instance-based and model-based learning. In Proceedings of the Nineteenth Annual Conference of the Cognitive Science Society, pp. 596-60 l. Lawrence Erlbaum. 15 
Pazzani, M. J. (2000). Knowledge discovery from data? IEEE Intelligent Systems $15(2), 10-13.15$

Peppers and Rogers Group do Brasil (2000). CRM Series Marketing 1 to 1.1

Piatetsky-Shapiro, G. \& C. J. Matheus (1994). The interestingness of deviations. In Proceedings of KDD, pp. 25-36. Disponivel em http://citeseer. nj.nec.com/piatetsky-shapirog4interestingness.html. Acesso em 20/03/2003. 15

Pila, A. D. (2001). Seleção de Atributos Relevantes para Aprendizado de Máquina utilizando a Abordagem de Rough Sets. Dissertação de Mestrado, Instituto de Ciências Matemáticas e de Computação - USP São Carlos. 35

Prati, R. C. (2003). O framework de integração do sistema DISCOVER. Dissertação de Mestrado, Instituto de Ciências Matemáticas e de Computaçāo - USP São Carlos. 33

Prati, R. C., J. A. Baranauskas, \& M. C. Monard (2001a). Extração de Informaçōes Padronizadas para a Avaliação de Regras Induzidas por Algoritmos de Aprendizado de Máquina Simbólico. Relatório Técnico do ICMC - Número 145. Disponivel em: ftp://ftp.icmc.sc.usp.br/pub/ BIBLIOTECA/rel_tec/RT_145.ps.zip. 4

Prati, R. C., J. A. Baranauskas, \& M. C. Monard (2001b). Uma Proposta de Unificação da Linguagem de Representação de Conceitos de Algoritmos de Aprendizado de Máquina Simbólicos. Relatório Técnico do ICMC - Número 137. Disponivel em: ftp://ftp.icmc.sc.usp.br/pub/BIBLIOTECA/rel_ tec/RT_137.ps.zip. 4, 34, 37

Pugliesi, J. B. (2001). O Pós-Processamento em Extraçāo de Conhecimento de Bases de Dados. Monografia do Exame de Qualificação de Doutorado, Instituto de Ciências Matemáticas e de Computaçāo - USP São Carlos. 34, 35

Pugliesi, J. B., D. G. Dosualdo, \& S. O. Rezende (2003). Sintaxe Padrāo para Representar Regras de Regressão no Discover. Relatório Técnico do ICMC. Ėm preparaçāo. 4, 47, 67, 96

Pugliesi, J. B. \& S. O. Rezende (2003). Medidas de Erro para Regras de Regressão. ENLA - Encontro Nacional de Inteligência Artificial. Artigo submetido. 60

Guinlan. J. R. (1992). Learning with Continuous Classes. In Proceedings Australian Joint Conference on Artificial Intelligence, pp. 343-348. World Scientific. 36 
Quinlan. J. R. (1993a). C4.5: Programs for Machine Learning. Morgan Kaufmann. 58

Quinlan, J. R. (1993b). Combining instance-based and model-based learning. In Proceedings on the Tenth International Conference of Machine Learning, University of Massachusetts, Amherst, pp. 236-243. Morgan Kaufmann. 82

Rezende, S. O. (2003). Sistemas Inteligentes: Fundamentos e Aplicaçōes (1 ed.). Barueri, SP: Manole. 100, 104

Rezende, S. O., J. B. Pugliesi, E. A. Melanda, \& M. F. Paula (2003). Sistemas Inteligentes: Fundamentos e Aplicaçōes (1 ed.)., Chapter Mineraçāo de Dados, pp. 307-335. In Rezende (2003). 8, 15

Rulequest-Research (2001). An Overview of Cubist. Disponivel em: http: //www.rulequest.com/cubist-unix.html. Acesso em 20/03/2003. 36, 39

Rüping, S. (2000). mySVM - Manual. Disponivel em http://www-ai. cs.uni-dortmund.de/SOFTWARE/MYSVM/mysvm-manual.pdf. Acesso em 20/03/2003. 29

Russell, S. \& P. Norvig (1995). Artificial Intelligence: A Modern Approach. Prentice Hall. 13, 14

SNNS Simulator (1995). SNNS - User Manual, Version 4.1. Report 6 . Disponível em: ftp://ftp.informatik.uni-stuttgart.de/pub/sNNS/ SNNS4.1-Manual.zip. Acesso em 20/03/2003. 26

The Abalone dataset (2003). The Abalone dataset. Disponivel em: http: //www.cs.toronto.edu/ delve/data/abalone/abaloneDetail.html. Acesso em 20/03/2003. 71

The R Development Core (2002). The R Project for Statistical Computing. Disponivel em: http://www.r-project.org. Acesso em 20/03/2003. 28

Till, D. (1996). Teach Yourself Perl 5 in 21 Days. Sams Publishing. 33

Torgo, L. (1995). Data Fitting with Rule-based Regression. In J. Z. . P. Brazdil (Ed.), Proceedings of the Workshop on Artificial Intelligence Techniques (AIT'95), Brno, Czech Republic. Disponivel em http://www.ncc.up.pt/ Itorgo/Papers/DFRBR/DFRBR.html. 51

Torgo, L. (1997). Functional Models for Regression Tree Leaves. In D. Fisher (Ed.). Proceedings of the International Conference on Machine Learning (ICML97). Morgan Kaufmann. 25 
Torgo, L. (1999). Inductive Learning of Tree-Based Regression Models. Tese de Doutorado, Faculdade de Ciências da Universidade do Porto. Disponivel em: http://www.ncc.up.pt/ Itorgo/PhD/. 13, 18, 24, 26

Torgo, L. (2001). RT 4.1 User's Manual. Disponivel em: http://www.ncc.up . pt/ Itorgo/RT/rt manual.pdf. Acesso em 25/07/2001. 35

Uysal, I. \& H. A. Güvenir (1999). An Overview of Regression Techniques for Knowledge Discovery. The Knowledge Engineering Review 14(4), 319-340. $2,16,18,21,27$

Vapnik, V. N. (1998). Statistical Learning Theory. Chichester, GB: Wiley. 28

Venables, W. N. \& D. M. Smith (2002). Notes on R: A Programming Environment for Data Analysis and Graphics, Version 1.4.1. Disponivel em: http://cran.r-project.org/doc/manuals/R-intro.pdf Acesso em 20/03/2003. 28

Wang, Y. \& I. H. Witten (1997). Inducing Models Trees for Continuous Classes. In Proceedings of the Poster Papers of the European Conference on Machine Learning. Department of Computer Science, University of Waikato, New Zeland. 36

Weiss, S. M. \& N. Indurkhya (1995). Rule-based Machine Learning Mcthods for Functional Prediction. Journal of Artificial Intelligence Research 3, 383403. Disponivel em: http://www.cs.cmu.edu/afs/cs/project/jair/ pub/volume3/weiss95a.ps. Acesso em 20/03/2003. 2, 5, 17, 18, 24, 56 , 57,58

Weiss, S. M. \& N. Indurkhya (1998). Data Mining, a Practical Guide. San Francisco, California: Morgan Kaufmann Publishers, Inc. 2, 10, 12

Witten, I. H. \& E. Frank (1999). Data Mining: Practical Machine Learning Tools and Techniques with Java Implementations. San Francisco, California: Morgan Kaufmann. 36 